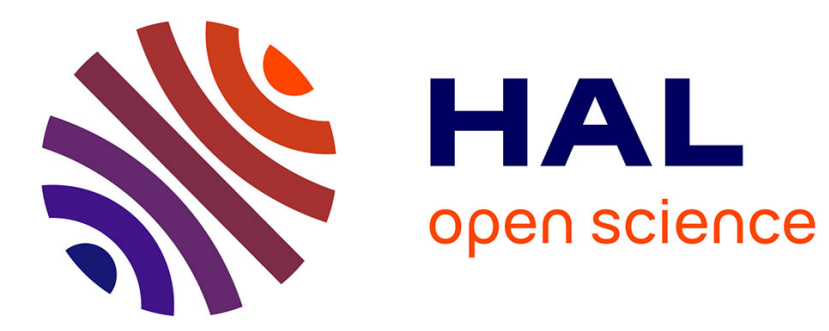

\title{
Gesture Projection and Cosuppositions
}

Philippe Schlenker

\section{- To cite this version:}

Philippe Schlenker. Gesture Projection and Cosuppositions. Linguistics and Philosophy, 2017, 41 (3), pp.295-365. 10.1007/s10988-017-9225-8 . hal-03051984

\section{HAL Id: hal-03051984 https://hal.science/hal-03051984}

Submitted on 10 Dec 2020

HAL is a multi-disciplinary open access archive for the deposit and dissemination of scientific research documents, whether they are published or not. The documents may come from teaching and research institutions in France or abroad, or from public or private research centers.
L'archive ouverte pluridisciplinaire HAL, est destinée au dépôt et à la diffusion de documents scientifiques de niveau recherche, publiés ou non, émanant des établissements d'enseignement et de recherche français ou étrangers, des laboratoires publics ou privés. 


\title{
Gesture Projection and Cosuppositions*
}

\author{
Philippe Schlenker** \\ Minor corrections, November 9, 2017. \\ To appear in Linguistics \& Philosophy
}

\begin{abstract}
In dynamic theories of presupposition, a trigger $p p^{\prime}$ (e.g. it stopped raining) with presupposition $p$ (it rained) and at-issue component $p^{\prime}$ (it doesn't now rain) comes with a requirement that $p$ should be entailed by the local context of $p p^{\prime}$. We argue that some co-speech gestures should be analyzed within a presuppositional framework, but with a twist: an expression $p$ co-occurring with a co-speech gesture $G$ with content $g$ comes with the requirement that the local context of $p$ should guarantee that $p$ entails $g$; we call such assertion-dependent presuppositions 'cosuppositions'. We show that this analysis can be combined with earlier theories of local contexts (e.g. Heim 1983, Schlenker 2009) to account for complex patterns of gesture projection in quantified and in attitudinal contexts, and we compare our account to two potential alternatives: one based on supervaluations, and one that treats co-speech gestures as supplements (Ebert and Ebert 2014). We argue that the latter is correct, but for 'post-speech' gestures (= gestures that come after the expressions they modify), rather than for co-speech gestures.
\end{abstract}

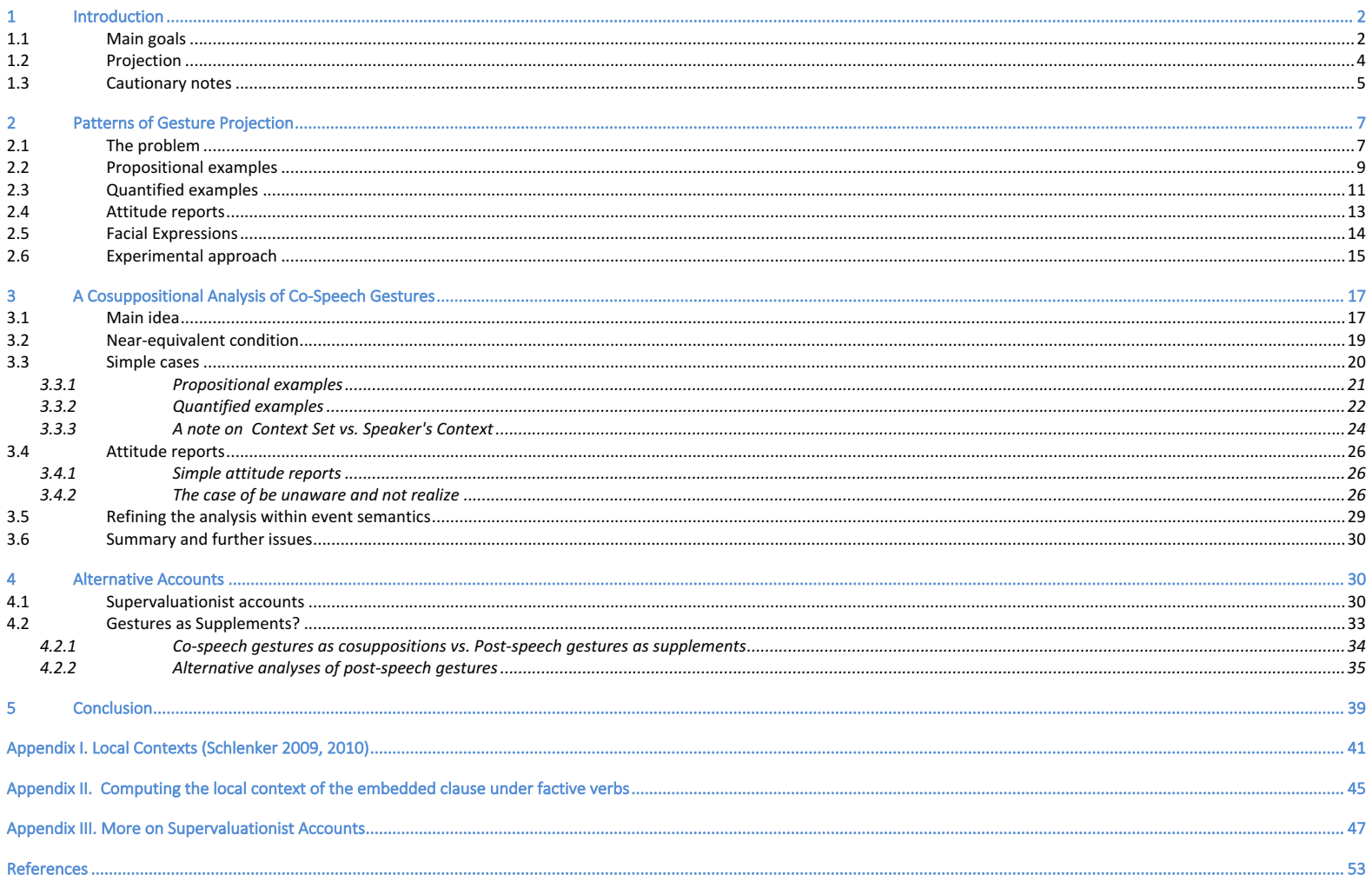

*I wish to thank the following colleagues for discussion and objections: Amir Anvari, Diane Brentari, Emmanuel Chemla, Miloje Despić, Cornelia Ebert, Karen Emmorey, Masha Esipova, Susan Goldin-Meadow, Chris Kennedy, Manfred Krifka, Manuel Križ, Jeremy Kuhn, Salvador Mascarenhas, Rob Pasternak, Benjamin Spector, Lyn Tieu, audiences at New York University, University of Chicago, MIT, and ZAS Berlin, as well as very constructive anonymous referees for Linguistics \& Philosophy. Special thanks to Rob Pasternak and to Emmanuel Chemla for discussion of most aspects of this project, to Manfred Krifka for detailed written suggestions, to Masha Esipova for pointing out passages that needed to be clarified, and to Jeremy Kuhn, Rob Pasternak and Lyn Tieu for discussion of specific examples, as well as for theoretical exchanges. This work started out as a reaction to Ebert and Ebert 2014, and Cornelia Ebert's seminal ideas and helpful comments are gratefully acknowledged.

The research leading to these results received funding from the European Research Council under the European Union's Seventh Framework Programme (FP/2004-2013) / ERC Grant Agreement N³24115-FRONTSEM (PI: Schlenker). Research was conducted at Institut d'Etudes Cognitives (ENS), which is supported by grants ANR10-IDEX-0001-02 PSL* and ANR-10-LABX-0087 IEC.

** Institut Jean-Nicod - CNRS, UMR 8129, ENS/EHESS - PSL Research University F-75005 Paris, France. Department of Linguistics, New York University, New York. 


\section{Introduction}

\subsection{Main goals}

Co-speech gestures provide a way to enrich the meaning of spoken language expressions. A simple example is provided in (1). Without a co-speech gesture, the sentence is neutral as to the kind of help that was provided. With the upward movement of the palms co-occurring with help, one naturally infers that John helped his son by lifting him in some way.

John UP_ $\$$ helped his son.

Notation: here and throughout, a co-speech gesture is notated in capital letters before the expression it co-occurs with. This expression is boldfaced for clarity, with square brackets if it contains several words. Whenever convenient, we illustrate the gesture with a picture following the capitalized gloss. ${ }^{1}$

Important research has been conducted in psychology and in linguistics on the typology of gestures (see for instance Kendon 2004, McNeill 2005 and Giorgolo 2010 for discussion). Here we will be primarily concerned with iconic co-speech gestures, i.e. gestures that occur with spoken words and enrich their meaning by depicting an aspect of the denoted situations. ${ }^{2}$ It should be emphasized that we will not seek to explain how a gesture such as $U P$ in (1) comes to have the content that it does; rather, we will just ask how this content interacts with the logical structure of a sentence. For although the example in (1) is very simple, gestures may appear in the scope of a variety of logical operators, hence a question: how are the enrichments of expressions modified by co-speech gestures inherited by complex sentences? This is the 'projection problem' for co-speech gestures; ${ }^{3}$ to our knowledge, it was initially studied in pioneering work by Ebert and Ebert 2014, who took the line that the semantic contribution of co-speech gestures should be likened to that of appositive relative clauses - hence

\footnotetext{
${ }^{1}$ Two notes might be useful at the outset. First, the capitalized gloss should not suggest that the 'lexical' contribution of these gestures is conventional: a given gesture might give rise to slightly different interpretations across individuals (as we explain in Section 1.3, this won't matter for our study because we seek to explain how gestural inferences interact with logical operators ('gesture projection'), rather than how they arise in the first place). Second, for greater clarity one might want to notate co-speech gestures above the modified expressions, borrowing notational conventions used in sign language research for non-manual markers. But this notation doubles the space occupied by examples, and makes it hard to cite examples in the main text; for these reasons, we do not adopt it here.

${ }^{2}$ McNeill 2005 (chapter 2) distinguishes between four types of gestures: iconic, metaphoric, deictic and beat, defined as follows.

(i) "Iconic: such gestures present images of concrete entities and/or actions. They are gestures in which the form of the gesture and/or its manner of execution embodies picturable aspects of semantic content."

(ii) "Metaphoric: Gestures can also present images of the abstract."

(iii) "Deictic: Although the prototypical deictic gesture is the hand with an extended index finger, almost any extensible body part or held object can be used for pointing."

(iv) "Beats: Levy and I called gestures 'beats' when they took the form of the hand beating time."

Some authors, such as Giorgolo 2010 (pp. 4-5), have a subcategory of 'emblems', which 'are "typically culture specific gestures, associated with a fixed meaning" - for instance the 'thumb up' gesture used in Western culture. We will not make use of emblems per se, but it will be useful to keep in mind that some gestures have a general, non-iconic interpretation; and as we discuss in fn. 7, the iconic component of gestures may be interpreted more or less literally depending on the gesture.

${ }^{3}$ This expression should be understood by analogy with the 'projection problem for presuppositions', which consists in determining how the presuppositions of complex sentences are inherited from the at-issue and presuppositional contributions of their component parts (strictly speaking, we are investigating the projection of gestural inferences, but we use 'gesture projection' for brevity).
} 
what we call a 'supplemental analysis', since the contribution of appositives is standardly called a 'supplement' (Potts 2005).

In this piece, we argue instead that a broad class of co-speech gestures should be analyzed within a presuppositional framework, but with a twist. In standard theories, a presupposition trigger $p p^{\prime}$ (e.g. it stopped raining) with presupposition $p$ (it rained) and at-issue component $p^{\prime}$ (it doesn't now rain) comes with a requirement that $p$ should be entailed by the local context of $p p^{\prime}$. By contrast, an expression $p$ co-occurring with a co-speech gesture $G$ with content $g$ comes with the requirement that the local context of $p$ should guarantee that $p$ entails $g$. In other words, the co-speech gesture triggers an assertion-dependent presupposition, something we call a 'cosupposition'. ${ }^{4}$ Importantly, no modification of presupposition theory is needed to handle such cases, since nothing prevents a trigger $\underline{p} p^{\prime}$ from having a presupposition $p$ with the content $\left(p^{\prime} \Rightarrow q\right)$, which is thus conditionalized on the atissue component $p^{\prime}$.

We show that this 'cosuppositional' analysis can be combined with standard analyses of presupposition projection to account for complex patterns of gesture projection in quantified contexts and in attitude reports (in some cases in which standard analyses of presupposition projection are insufficiently predictive, we will appeal to the theory of local contexts of Schlenker 2009 to derive precise predictions). We compare our account to two potential alternatives: a theory based on supervaluations, which we take to be interesting but probably flawed; and Ebert and Ebert's (2014) supplemental analysis. We argue that the latter is likely correct, but for 'post-speech' gestures (= gestures that come after the expressions they modify), rather than for co-speech gestures. Thus the timing of a gestural enrichment can significantly alter its semantic status.

The main intuition we pursue can be described rather simply by inserting the example in (1) in various environments, as in (2) (we notate under the examples the relevant inferences we take them to trigger, preceded by $=>$; in some cases, we will use the symbol $\neq>$ if a certain inference fails to arise).

(2) a. John UP_ $\$$ helped his son.

$=>$ John helped his son by lifting him

b. John didn't UP_ help his son.

=> if John had helped his son, he would have done so by lifting him

c. Did John UP_ help his son?

$=>$ if John helped his son, he did so by lifting him

As noted, (2)a triggers the inference that John helped his son by lifting him. Now in (2)b we infer that John didn't help his son, but that if he had, lifting would have been involved. As for the question in (2)c, it leaves open whether John helped his son, but it suggests that if he did, it was by lifting him.

The intuition we develop is that the context should guarantee that the co-speech gesture merely illustrates the expression it modifies, and thus that relative to that context the expression entails the content of the co-speech gesture. In unembedded cases, one can posit that the relevant inference must follow from the context of the conversation. But in embedded cases a more sophisticated notion is needed, that of a local context. To see why it is needed, consider the example in (3).

(3) If little Johnny takes part in the competition, will his mother UP_ help him?

$=>$ if little Johnny takes part in the competition, if his mother helps him, lifting will be involved

The requirement that the content of the gesture follow from the meaning of help relative to the global context would give rise to an overly strong inference, namely that in general, helping is understood to mean 'helping by lifting'. The inference which is in fact derived is narrower: besides the fact that it

\footnotetext{
${ }^{4}$ The terminology is intended to suggest that a cosupposition triggered in a local context $\mathrm{c}^{\prime}$ is computed in tandem with ('co') an at-issue component in c' (by contrast, a standard presupposition triggered in c' is computed before ('pre') any at-issue component in $\mathrm{c}^{\prime}$ ).
} 
only applies to Johnny and his mother, it is relative to the hypothesis that Johnny will take part in a competition; and we thus infer that this competition involves some kind of upward movement.

In modern theoretical parlance, the entailment need not hold with respect to the global context of the sentence, but only with respect to the local context obtained by 'updating' the global one with the antecedent of the conditional. The notion of a 'local context' is standardly used to motivate dynamic approaches to presupposition projection in the tradition of Heim 1983. Informally, the local context of an expression recapitulates the semantic content already contributed by expressions that precede it, combined with the context of the conversation. In most cases, we will take for granted the value of the relevant local context, as it can be established on the basis of traditional presuppositional data, and derived using standard tools of dynamic semantics. When things are less clear, we will base our discussion on the reconstruction of local contexts offered in Schlenker 2009, as it has the advantage of giving a recipe to compute the local context of an expression in any sentence once the bivalent (classical) behavior of the latter has been specified..$^{5}$

\subsection{Projection}

In agreement with Ebert and Ebert 2014, we will claim that co-speech gestures make meaning contributions that are not typically at-issue (or 'assertive', as one also says), and thus give rise to projection phenomena. Unlike Ebert and Ebert 2014, we will take the correct point of comparison for co-speech enrichments to be given by presupposition triggers rather than by appositive relative clauses. We should thus say a word about the typology of these inferences, which are illustrated in (4)-(6).

(4) At-issue entailment

a. John ensured that he had competent students.

$=>$ John had competent students

b. John didn't ensure that he had competent students.

\#> John had competent students

c. None of my colleagues ensured that he had competent students.

\#> some/all of my colleagues had competent students

(5) Presupposition

a. John knew that he had competent students.

$=>$ John had competent students

b. John didn't know that he had competent students.

$=>$ John had competent students

c. None of my colleages knew that he had competent students.

$=>$ each of my colleagues had competent students

(6) Supplement

a. John had students, who (by the way) were competent.

b. \#John didn't have students, who (by the way) were competent

c. \#None of my colleagues had students, who (by the way) were competent.

- In (4), the property $\lambda x . x$ ensured that $x$ had competent students has the at-issue entailment $\lambda x . x$ had competent students, hence the positive inference we obtain in (4)a, which disappears in the negative environments in (4)b and (4)c.

- By contrast, in (5), the property $\lambda x . x$ knew that $x$ had competent students triggers a presupposition $\lambda x . x$ had competent students. A hallmark of presuppositions is that they 'project' out of the scope of negation, as seen in (5)b, and yield universal positive inferences when they are triggered in the scope of none-type quantifiers, as seen in (5)c (see Chemla 2009 for experimental data). More generally,

\footnotetext{
${ }^{5}$ In simple cases, nothing is lost in this way because Schlenker 2009 shows that, modulo some technical assumptions, standard results of dynamic semantics are derived by this procedure. But the algorithm developed in Schlenker 2009 will allow us to derive predictions for some non-standard cases - notably, embedding under factive expressions such as be unaware that, where we will need to compute the local context of the embedded clause.
} 
presuppositions have a characteristic projection behavior that sets them apart from other inferences, although there are debates about how unified the class of presupposition triggers really is (Tonhauser et al. 2013), and why presuppositions display the projection behavior they do (see for instance Beaver and Geurts 2011 and Schlenker to appear a for surveys). In addition, presuppositions are often taken to have a particular epistemic status: they must follow from what the speaker and addressee take for granted, i.e. from the 'Context Set'. (In the accounts of Heim 1983 and Schlenker 2009, it makes no difference whether a presupposition is also part of the at-issue component of an expression, as rules of presupposition projection would make this component redundant. ${ }^{6}$ This is also the view we will take in this piece, although there are theories in which this is not the case, e.g. Sudo 2012, 2014.)

- Finally, in (6)a, the appositive relative clause triggers the inference that John had competent students. But the appositive is degraded in the negative environments in (6)b-c. Why this is so is debated. One standard view (due to Potts 2005) is that the meanings of appositive relative clauses, called 'supplements', cannot interact scopally with logical operators. Since in our examples the appositive clause modifies a narrow scope indefinite, this yields deviance. An alternative view is that, in some cases at least, appositive relative clauses attach to the matrix level, and that the relative pronoun who has in this case the semantics of (E-type) they - with the result that the appositive is deviant for the same reason as the second clauses are in the discourses in (7) (see for instance Schlenker 2010b, 2013, which analyzes supplements within a generalization of presupposition theory).

(7) a. John didn't have students $\mathrm{s}_{\mathrm{i}}$. \#They $_{\mathrm{i}}$ were competent.

b. None of my colleagues had students $\mathrm{s}_{\mathrm{i}}$. \#They $\mathrm{i}_{\mathrm{i}}$ were competent.

These properties will matter below. We will argue that co-speech gestures trigger a variety of presuppositions, while post-speech gestures (which come after the expressions they modify) display the behavior of appositive relative clauses.

\subsection{Cautionary notes}

Some cautionary remarks should be made at the outset.

- First, we are primarily concerned with patterns of gesture projection, defined as the way in which the gestural enrichments of elementary expressions are inherited by complex sentences. We are not concerned with how a particular gesture, such as $U P$ in (1), comes to be interpreted as it is. Some gestures have a general, emblematic meaning; others have a highly iconic meaning. Our only concern is how the gestural enrichment projects. ${ }^{7}$

${ }^{6}$ In the theories developed in Schlenker 2008a, 2009, a presupposition 'starts out' as part of the at-issue component but imposes strong conditions on the context by mechanisms that guarantee that its contribution should be contextually trivial.

${ }^{7}$ The example in (i), suggested by an anonymous referee, involves a gesture whose iconic component need not be interpreted precisely or literally.

\section{a. John OPEN-HANDLE [opened the window].}

b. Will John OPEN-HANDLE [open the window]?

Here $O P E N-H A N D L E$ refers to an iconic gesture in which the agent grasps an imaginary handle and pulls it. As the referee observes, (i) can be uttered in a situation in which the window under discussion slides to the side or must be pushed, or in a situation in which the way the window opens is not common knowledge. We take such a gesture to have a relatively general meaning, to the effect that a door-like part is involved, as is suggested by (ii)a: without the gesture, we cannot exclude the possibility that the object refers to a box, or to a book, but with the gesture these possibilities are excluded, although more precise information is not conveyed. Our concern is not to explain how this inference arises in (ii)a, but to understand why it is preserved in the question in (ii)b, or in the conditional in (ii)c. 
Another question we will only be tangentially addressing pertains to the epistemic status of gestural enrichments. As noted, presuppositions are usually taken to follow from the Context Set, and thus to be uninformative. Arguably, gestural enrichments are often informative. But by now there is a sizable literature on informative presuppositions, and hence the informative nature of co-speech gestures need not get in the way of a presuppositional account (see for instance Stalnaker 2002, von Fintel 2008, Schlenker 2012; we revisit this question in Section 3.3.3).

- Second, presuppositions notoriously give rise to patterns of local accommodation, whereby a presupposition essentially gets incorporated into the at-issue component. This happens for instance in the sentence John doesn't know that he is going to be hired-because he won't be!: the factive inference triggered by know is in this case evaluated within the scope of negation (if it projected, a contradiction would ensue). In this respect, some presupposition triggers are thought to be weaker than others, in the sense that they more readily allow for local accommodation. For instance, stop is typically thought to be weak (as is realize), which explains why the discourse in (8) does not lead to the inference that the interlocutor used to smoke (see also Beaver 2010).

(8) I notice that you keep chewing on your pencil. Have you recently stopped smoking? (Geurts 1994, cited in Simons 2001)

As we will see, we will have to posit at several junctures that co-speech gestures are usually weak triggers, and can easily give rise to local accommodation, especially under contrastive focus. ${ }^{8}$ While we will primarily discuss cases in which co-speech gestures have a non-at-issue contribution, it should be kept in mind that modulo local accommodation some at-issue uses can be obtained as well (Esipova 2016a, b). ${ }^{9}$ We will often compare gestural cosuppositions to the weak presuppositional inferences triggered by the verb realize (see e.g. Stalnaker 1974).

- Third, and relatedly, we will use standard linguistic methodology in basing our generalizations on introspective judgments, both our own and those of other linguists we have consulted. But there are obvious limitations to this method, especially when judgments are subtle - which is sometimes the case with gestures. Experimental means should thus prove crucial to investigate patterns of gesture projection. Still, we are convinced that they will prove particularly useful after one has explored the initial space of possible theories - which is a primary goal in the present study. Initial experimental results are discussed in Tieu et al. 2017, to appear and the clearest ones are briefly summarized in Section 2.6.

- Fourth, as briefly mentioned above, the timing of co-speech gestures greatly matters. There is a rich literature analyzing where co-speech gestures naturally occur, in particular in connection with intonation (see for instance Loehr 2004, Ebert et al. 2011). ${ }^{10}$ Here we will only be concerned with two types of cases, which are sharply distinct in terms of realization (so that confusion between them is unlikely): co-speech gestures, which co-occur with syntactically well-defined constituents; and post-speech gestures, which follow the expressions they modify, and are sharply separated from them

c. If John OPEN-HANDLE [open the damn thing], I'll be relieved.

\footnotetext{
${ }^{8}$ We owe this observation to Rob Pasternak (p.c.).

${ }^{9}$ Esipova 2016a, b argues that even strong triggers can give rise to local accommodation if this is necessary to make focus felicitous.

${ }^{10}$ Some terminology is useful to introduce the findings. In Loehr's (2004) terminology, following Kendon 1972 , 1980 , 'the smallest unit of motion is the stroke of the gesture', which is the 'short, dynamic peak of the movement'. Together with an optional 'preparatory phase' and an optional 'retraction phase', it forms a 'gestural phrase'. Now Loehr 2004 makes two relevant claims about timing. First, 'apexes of strokes align with pitch accents' (p. 111). Second, 'g-phrases [= gestural phrase] align with intermediate phrases' (p. 114), where the 'intermediate phrase' is a hierarchical level below the intonational phrase (Beckman and Pierrehumbert 1986). For their part, Ebert et al. 2011 find 'a clear, but shifted alignment for the onsets of gesture phrases and (new information) foci'. They conclude that 'gestures are a means of marking information structure next to intonational and syntactic means, i.e. speech-accompanying gestures can indicate focus domains'.
} 
by a pause. We come back to this distinction in Section 4.2.1, and use the contrast between co- and post-speech gestures as an argument against Ebert and Ebert's analysis of the former.

- Fifth, if our ideas are on the right track, they should in the end be combined with those of Lascarides and Stone 2009, who developed a framework in which gestures can be integrated into Logical Forms by way of explicit anaphoric and narrative relations. But since their emphasis was not on the projection problem per se (as they did not consider the interaction of co-speech gestures with logical operators $^{11}$ ), we will leave the integration of these two frameworks for future research.

- Finally, since the study of gesture projection is only in its infancy, we should be careful not to overstate the generality of our findings. We believe we have found one broad class of co-speech gestures that behave in a presuppositional fashion; but further investigations (in particular ones that connect to corpus work conducted by other researchers) will certainly uncover further projective behaviors among co-speech gestures.

\section{Patterns of Gesture Projection}

\subsection{The problem}

To introduce the projection problem for co-speech gestures, we start with the unembedded examples in (9).

(9)

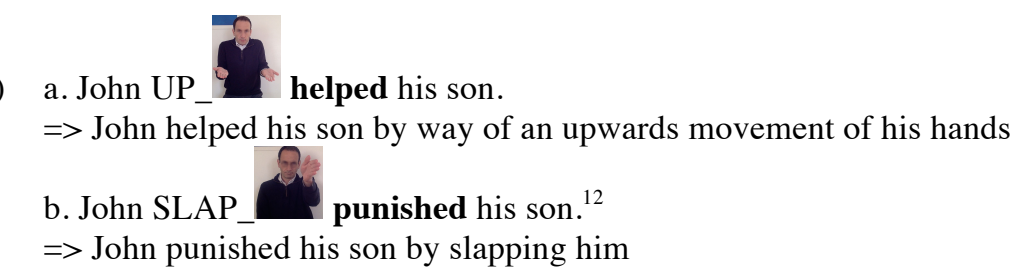

In (9)a, the gesture contributes the inference that the helping event involved some lifting; and in (9)b, that the punishment involved some slapping - or possibly, more broadly, that it was physical (the difference won't matter, as long as we assess the same inference in elementary clauses and in complex sentences).

Each example could easily be modified so as to involve minimally different co-speech gestures. For instance, $U P$ could be replaced with a forward motion, and SLAP could be replaced with a punching motion. The associated inferences would be modified accordingly (e.g. John helped his son by pushing him, John punished his son by punching him). ${ }^{13}$

Now let us embed each co-speech gesture under a none-type quantifier, using as at-issue controls some sentences in which the co-speech is replaced with the modifier like this, accompanied with the appropriate gesture. (We take the semantics of the control sentence to be unsurprising: this is a deictic expression whose denotation must be provided by the context, the gesture serves to make a certain manner of action salient in the context, and like this is an at-issue modifier.)

\footnotetext{
11 Lascarides and Stone 2009 do discuss the interaction between gestures and expressions that introduce discourse referents, in particular dynamic existential quantifiers. Their formal framework also contains standard logical connectives, but the examples they discuss do not involve embedding under any of the operators discussed in this piece; as a result, the issue of the at-issue, presuppositional or supplemental status of co-speech enrichments does not arise in their article.

${ }^{12}$ With apologies to the readers, some of our examples refer to objectionable situations. (This sometimes makes projection facts particularly striking. For instance, the negation John didn't SLAP punish his son still suggests something highly objectionable about John (and possibly the speaker), namely that he takes punishment to be physical).

${ }^{13}$ Some gestures are of course cultural. For instance, replacing SLAP with an ear pulling gesture is readily understood in France, and can be taken to be emblematic or metaphorical, so that one need not literally understand the punishment to have involved some ear pulling. By contrast, an American audience may not readily understand this gesture.
} 
(10) a. None of these 10 guys UP_ helped his son.

=> for each of these 10 guys, if he had helped his son, this would have involved some lifiting

b. None of these 10 guys helped his son like UP_ this.

$=>$ for each of these 10 guys, if he helped his son, it was not by lifting him

(11) a. None of these 10 guys SLAP_ punished his son.

$=>$ for each of these 10 guys, if he had punished his son, this would have involved some slapping.

b. None of these 10 guys punished his son like SLAP_this.

$=>$ for each of these 10 guys, if he punished his son, it was not by slapping him

In (10)a and (11)a, we obtain a universal positive inference, of the form: for each of the relevant individuals $\mathrm{x}$, if $\mathrm{x}$ had satisfied the $V P$, this would have involved an action that satisfied the content of the gesture. This universal positive inference is reminiscent of the behavior of presuppositions under none-type quantifiers, as we saw in (5)c, but with a twist: the presupposition is conditionalized on the at-issue component of the modified expression. Specifically, (10)a and (11)a do not yield the inference that some or all of the relevant guys lifted or slapped their sons. But they do seem to yield the inference that, in each relevant case, if a guy $x$ had helped/punished his son, $\mathrm{x}$ 's action would have involved lifting/slapping: the presupposition involves a conditional of the form: if $x$ had satisfied VP, where VP is the modified Verb Phrase.

By contrast, the control examples in (10)b and (11)b display an unsurprising behavior (on the assumption that like this is an at-issue modifier): given the meaning of none, we understand that none of the relevant guys helped his son by lifting him, or punished him by slapping him. Hence if a guy helped/punished his son, his action did not involve lifting/slapping. In other words, this is the opposite from the inferences triggered by the target sentences. ${ }^{14}$ It is also notable that, unlike the supplements in (6)c, the co-speech gestures seem to be acceptable in the scope of none-type quantifiers, which will provide an argument against a supplemental treatment (as we will see, post-speech gestures display a very different behavior and can be analyzed in supplemental terms).

In simple cases, related inferences can be obtained with co-speech gestures modifying NPs, as in (12). However these involve empirical and theoretical difficulties, and thus unless we specifically need them we will focus on co-speech gestures that co-occur with a verbal (or sometimes propositional) element. ${ }^{15}$

(12) a. None of these 10 philosophers found LARGE_L [a bottle he liked].

$=>$ for each of these 10 philosophers, if he had found a bottle he liked, it would have been a large one

b. None of these 10 philososphers found a bottle like LARGE_L this that he liked.

=> for each of these 10 philosophers, if he found a bottle he liked, it was not a large one

We now turn to propositional, quantificational and attitudinal examples to strengthen the parallel with presuppositions.

\footnotetext{
${ }^{14}$ Here and throughout, the at-issue controls with like this modifiers may trigger some implicatures, which we disregard for simplicity. Specifically, it is very plausible (in particular in view of the theory of alternatives outlined in Katzir 2007) that (10)b evokes a more informative alternative of the form: None of these 10 guys helped his son. The implicature that this alternative is false leads to the inference that at least one of the 10 guys helped his son.

${ }^{15}$ An anonymous referee finds the inference in (12)a to be less clear than those in (10)a and (11)a. If the contrast is real, this might be because gestural modification affects NPs and VPs differently - something the present analysis is not in a position to explain. Alternatively, inferences might be weakened in (12)a because the cosupposition is triggered within the restrictor of an existential quantifier, a position from which presupposition projection is thought to be weak (see Chemla 2009 for experimental data pertaining to French).
} 


\subsection{Propositional examples}

While inferences in unembedded clauses are clear, as in (13), they are not particularly helpful to distinguish the presuppositional component from the at-issue component of a construction, as can be seen by the fact that the same inferences are derived in the at-issue controls in (14).

(13) a. John will UP_ help his son.

=> John will help his son by lifting him

b. John will SLAP_ punish his son.

$=>$ John will punish his son by slapping him

c. John will realize that his son is losing.

$=>$ John's son is/will be losing

(14) a. John will help his son like UP_ this.

$=>$ John will help his son by lifting him

b. John will punish his son SLAP_ this.

=> John will punish his son by slapping him

c. John will correctly believe that his son is losing.

=> John's son is/will be losing

Thus in order to test the specifically presuppositional component of a construction, we must appeal to systematic presupposition tests that tease apart at-issue from presuppositional contributions (keeping in mind that in most theories a presupposition might also contribute to the at-issue component, although in standard cases this effect wouldn't be felt because the presuppositional contribution is stronger).

In questions and under negation, our co-speech gestures trigger conditional inferences, as is illustrated in (15)-(16), where we have included as a control a (weak) presupposition trigger, the verb realize. Of course realize triggers a simple factive presupposition, whereas co-speech gestures trigger conditionalized ones - but this is precisely the difference we wish to argue for. We also include controls with like this; unless otherwise noted, they clearly fail to trigger the relevant inferences.

(15) a. John won't (i) UP_ help his son. (ii) help his son like UP_ this.

(i) => If John helped his son, he would do so by lifting him

b. John won't (i) SLAP_ punish his son. (ii) punish his son like SLAP_ this.

(i) => If John punished his son, he would do so by slapping him

c. John won't realize that his son is losing.

$=>$ John's son is losing

(16) a. Will John (i) UP_ help his son? (ii) help his son like UP_ this?

(i) => If John helps his son, he will do so by lifting him

b. Will John SLAP_ punish his son? (ii) punish his son like SLAP_ this?

(i) => If John punishes his son, he will do so by slapping him

c. Will John realize that his son is losing?

(i) => John's son is losing

To study gesture projection in upward-monotonic environments (e.g. in the consequent of a conditional), it is sometimes useful to embed some of the examples in questions, as in (17), so as to 
distinguish the presuppositional component (which is preserved or 'projects' out of questions) from the at-issue component (which doesn't project).

(17) a. If little Johnny takes part in the competition, will (i) his mother UP_ help him? (ii) his mother help him like UP_t this?

(i) => if little Johnny takes part in the competition, if his mother helps him, lifting will be involved

b. If little Johnny cheats on the exam, will (i) his mother SLAP_ punish him? (ii) his mother punish

him like SLAP_ this?

(i) $=>$ if little Johnny cheats on the exam, if his mother punishes him, slapping will be involved

c. If little Johnny cheats on the exam, will his mother realize that he committed an extremely serious offense?

=> if little Johnny cheats on the exam, he will have committed an extremely serious offense

As mentioned at the outset, examples such as (17)a-b are important to disprove a simpler theory, one on which it is relative to the global (rather than local) context that the modified expression must entail the content of the co-speech gesture. This would seem to be too strong for these examples, which do not yield the general inference that if Johnny's mother helps/punishes him, lifting/slapping will be involved, but rather the narrower inference that this should hold when the antecedent clause is satisfied.

The same point can be made more forcefully by including a discourse that makes reference to a variety of situations that satisfy the relevant predicate. Thus in (18), the first occurrence of help is used to indicate (by way of a presupposition) that Johnny's mother helps him in all sorts of circumstances. Only the second occurrence of help is modified by the gesture UP, and it does not trigger an inference that all helping events involve lifting, but only that if Johnny takes part in the competition, any help his mother will provide will involve lifting. ${ }^{16}$ It will thus prove essential to compute the entailment between help and the content of $U P$ relative to the local context of help rather than with respect to the global context of the conversation - a result that will be obtained by the analysis developed in Section 3.

(18) Since Johnny's mother helps him no matter what, if he takes part in the competition, will she (i) UP

help him? (ii) help him like UP_ this?

(i) $=>$ if Johnny takes part in the competition, if his mother helps him, lifting will be involved

(i) $\neq>$ Johnny's mother always helps him by lifting him

Turning to the antecedent of conditionals (a non-upward-monotonic environment - which obviates the need for the question test), we seem to get the same inferences as under negation and in questions, possibly in weakened form: the cosupposition projects.

(19) a. If Johnny takes part in the competition and his mother (i) UP_ helps him, (ii) helps him like UP

this, people will talk about it.

(i) => if Johnny takes part in the competition, if his mother helps him, lifting will be involved

${ }^{16}$ By contrast, some native speakers tell us that in the following examples the gestural enrichment is preferably read as being at-issue. From the present perspective, these are cases of local accommodation, which do not make it possible to test the relevant cosuppositional inferences.

(i) a. John and I don't have quite the same drinking habits. If John comes to our workshop, will he bring LARGE [a bottle of beer]?

b. John and his wife don't quite agree on how to discipline their children. If John shows up in a minute, will he SLAP punish his son? 
b. If Johnny cheats on the exam and his mother (i) SLAP_ punishes him, (ii) punishes him like

SLAP_this, people will talk about it.

(i) => if Johnny cheats on the exam, if his mother punishes him, slapping will be involved

c. If Johnny cheats on the exam and his mother realizes that he committed an extremely serious offense, she will take appropriate measures.

=> if Johnny cheats on the exam, he will have committed an extremely serious offense

Finally, under existential modals, we are not certain of the facts, but believe that a weak conditional inference is triggered about the actual world -something that should be further investigated (see Tieu et al. 2017, to appear for relevant data involving embedding under might, a point to which we briefly return in Section 2.6). It might also be that with weak presupposition triggers such as realize the facts have the same unclear status. ${ }^{17}$

(20) a. Johnny's mother might (i) UP_ help him. (ii) help him like UP_ $\$$ this.

$=>$ ? if Johnny's mother helps him, lifting will be involved

b. Johnny's mother might (i) SLAP_ punish him. (ii) punish him like this SLAP_ this.

$=>$ ? if Johnny's mother punishes him, slapping will be involved

c. Johnny's mother might realize that he cheated on the exam.

$=>$ ? Johnny cheated on the exam

\subsection{Quantified examples}

We turn to quantified examples, and as before we place them in questions when this is needed to distinguish between presupposition and at-issue contribution (we henceforth omit pictures from the transcription of the gestures, unless these have not been exemplified before). We start with cases involving a quantificational adverb, as this makes for particularly minimal pairs with the propositional examples discussed earlier. As before, we include in each paradigm a point of comparison involving the weak presupposition trigger realize.

(21) a. On Mondays, did John always (i) UP help his son? (ii) help his son like UP this?

(i) => on Mondays, when John helped his son, he did so by lifting him

b. On Mondays, did John always (i) SLAP punish his son? (ii) punish his son like SLAP this?

(i) => on Mondays, when John punished his son, he did so by slapping him

c. On Mondays, did John always realize that his son needed help?

(i) => on Mondays, John's son needed help

Similar generalizations hold for nominal quantifiers:

(22) a. Did each of these 10 guys (i) UP help his son? (ii) help his son like UP this?

(i) $=>$ for each of these 10 guys, if he helped his son, he did so by lifting him

b. Did each of these 10 guys (i) SLAP punish his son? (ii) punish his son like SLAP this?

(i) => for each of these 10 guys, if he punished his son, he did so by slapping him

c. Did each of these 10 guys realize that his son needed help?

(i) $=>$ for each of these 10 guys, his son needed help.

Under negative quantifiers such as never and none, we obtain universal conditional presuppositions, as was already shown for nominal quantifiers in (10)a-(11)a, which we repeat with a presuppositional control in (23).

\footnotetext{
${ }^{17}$ We do not include questions in the paradigm because might is an existential modal, and thus any inference due to the at-issue component of the embedded clause would be weaker than the purported presupposition. For instance, in (20)a an at-issue contribution of $U P$ in the scope of might would only yield the modal inference that Johnny's mother might help by lifting him, which still does not imply that if Johnny's mother helps him, lifting will be involved.
} 
(23) a. On Mondays, John never (i) UP helped his son. (ii) helped his son like UP this.

(i) => on Mondays, John never helped his son, but if he had done so, it would have been by lifting him

b. On Mondays, John never (i) SLAP punished his son. (ii) punished his son like SLAP this.

(i) $=>$ on Mondays, John never punished his son, but if he had done so, it would have been by slapping

him

c. On Mondays, John never realized that his son needed help.

$=>$ ? on Mondays, John's son needed help ${ }^{18}$

(24) a. None of these 10 guys (i) UP helped his son. (ii) helped his son like UP this.

(i) => none of these 10 guys helped his son; but for each of them, if he had helped his son, it would have been by lifting him

b. None of these 10 guys (i) SLAP punished his son. (ii) punished his son like SLAP this.

$=>$ none of these 10 guys punished his son; but for each of them, if he had punished his son, it would have been by slapping him

c. None of these 10 guys realized that his son needed help.

$=>$ for each for each of these 10 guys, his son needed help

Embedding under exactly $n$ numerals is more difficult to assess, and as we will see the theoretical situation is complicated as well. We have tried to separate inferences that are clear from ones that are not, adding a question mark or two to the symbol $=>$ to indicate our degree of uncertainty. Here the controls with like this do give rise to some inferences of interest, hence (ii) may appear before the $=>$ sign. We note that in all cases involving modified numerals, the strong conditional inferences noted for embedding under none-type quantifiers are highly unclear, which will be taken up in the theoretical discussion below.

(25) a. On exactly 1 of the last 4 competitions, John (i) UP helped his son. (ii) helped his son like UP this.

(i), (ii) $=>$ on exactly one of the last 4 competitions, John helped his son by lifting him

(i) $=>$ ? on none other did John help his son

b. After exactly 1 of the last 4 competitions, John (i) SLAP punished his son (ii) punished his son like SLAP this.

(i), (ii) => after exactly 1 of the last 4 competitions, John punished his son by slapping him

(i) $=>$ ? after none other did John punish his son

c. On exactly 1 of the last 4 competitions, John realized that his son needed help.

$=>$ on exactly 1 of the last 4 competitions, John came to correctly believe that his son needed help

$=>$ ?? on none other did John come to believe that his son needed help

(26) a. Exactly 1 of these 10 guys (i) UP helped his son. (ii) helped his son like UP this.

(i), (ii) => exactly 1 of these 10 guys helped his son by lifting him

(i) $=>$ ? none other helped his son

b. Exactly 1 of these 10 guys (i) SLAP punished his son. (ii) helped his son like SLAP this.

(i), (ii) => exactly 1 of these 10 guys punished his son by slapping him

(i) $=>$ ? none other punished his son

c. Exactly 1 of these 10 guys realized that his son needed help

$=>$ exactly 1 of these 10 guys came to correctly believe that his son needed help

$=>$ ?? each of these 10 guy's son needed help

We note for future reference that in each case the clearest inference is obtained by taking the purported presupposition to contribute to the at-issue meaning, and therefore this inference is also triggered by the at-issue controls (the difficult question is to determine whether other inferences, due to projection, are also found in the co-speech case). This is transparent in the case of (25)c and (26)c, since John came to correctly believe that $p$ is the conjunction of the at-issue component of John realized that $p$ and of its factive presupposition $p$. In (25)a-b and (26)a-b, John helped his son by lifting him is in fact obtained from the at-issue component John helped his son and the purported cosupposition if John helped his son, lifting was involved; and similarly for John punished his son by slapping him.

The same distinctions must be drawn for the non-monotonic quantifier between 3 and 5, which gives rise to some clear and some unclear inferences.

\footnotetext{
${ }^{18}$ To our ear, the inference is a bit weaker than in other examples (it might become stronger if realized is replaced with was aware).
} 
(27) a. Between 3 and 5 of these 10 guys (i) UP helped their son. (ii) helped their son like UP this.

(i), (ii) $=>$ between 3 and 5 of these 10 guys helped their son by lifting him

(i) $=>$ ? none other helped their son

b. Between 3 and 5 of these 10 guys (i) SLAP punished their son. (ii) punished their son like SLAP this.

(i), (ii) $=>$ between 3 and 5 of these 10 guys punished their son by slapping him

$=>$ ? none other punished their son

c. Between 3 and 5 of these 10 guys realized that their son needed help.

$=>$ between 3 and 5 of these 10 guys came to correctly believe that their son needed help

$=>$ ?? for each of these 10 guys, their son needed help

\subsection{Attitude reports}

We turn to gesture projection in attitude reports. In possible worlds semantics, $x$ believes that $F$ is analyzed in terms of universal quantification over worlds compatible with what $\mathrm{x}$ believes, and thus we expect to find the same patterns of projection as under universal quantifiers. But some aspects of the discussion are more complicated due to additional inferences that can also arise with standard presupposition triggers under believe. Let us start with the paradigm in (28).

(28) a. Does Samantha believe that John (i) UP helped his son? (ii) helped his son like UP this?

(i) =>? Samantha believes that if John helped his son, lifting was involved

(i) $=>$ ?? if John helped his son, lifting was involved

b. Does Samantha believe that John (i) SLAP punished his son? (ii) punished his son like SLAP this?

(i) $=>$ ? Samantha believes that if John punished his son, slapping was involved

(i) =>?? if John punished his son, slapping was involved

c. Does Samantha believe that John realized that his son needed help?

$=>$ Samantha believes that John's son needed help

$=>$ ? John's son needed help

The presuppositional control in (28)c yields an expected presuppositional inference, to the effect that the worlds compatible with what Samantha believes satisfy the presupposition of the embedded clause - hence: she thinks that John's son needed help. But researchers noted that when such a sentence is uttered out of the blue, we often derive an inference to the effect that John's son did in fact need help this is a version of what is called the 'Proviso Problem' in the literature (it is a problem because dynamic theories fail to predict this inference). ${ }^{19}$ Thus in this case the presupposition of the clause embedded under believes is to some extent inherited by the matrix sentence (we may call it a 'matrix presupposition'). There is a debate in the literature to determine how this matrix presupposition should be obtained: for proponents of DRT, it should be immediately derivable by presupposition projection mechanisms (e.g. Geurts 1999); for dynamic theories (e.g. Heim 1983) and for the analyses of Schlenker 2008a, 2009, additional mechanisms of pragmatic enrichment are needed to derive the inference. But regardless of how they should be derived, the facts seem to be relatively well established.

Turning to the gestural examples in (28)a-b(i), the data are not entirely clear; pending further investigation, it would seem that to some extent the co-speech gestures give rise to conditional inferences relativized to Samantha's belief states - which the at-issue controls in (ii) certainly do not trigger. But in addition we might well obtain a matrix presupposition as well. ${ }^{20}$

19 The problem is more general, and arises in other modal constructions. For simplicity, we tried to discuss conditional examples that did not have this feature (in (17)). But it is easy to modify them in such a way that the presupposition is inherited by the entire sentence:

(i) a. If little Johnny encounters difficulties, will his mother UP help him?

$=>$ if little Johnny's mother helps him, lifting will be involved

b. If little Johnny comes home, will his mother SLAP punish him?

$=>$ if little Johnny's mother punishes him, slapping will be involved

c. If little Johnny comes home, will his mother realize that he committed an extremely serious offense?

$=>$ little Johnny committed an extremely serious offense

${ }^{20}$ An anonymous referee is of the opinion that the assertive version of a sentence such as (28)b cannot be continued as in (i), indicating that the cosupposition is inherited by the matrix sentence. 
Be that as it may, competing theories of presupposition agree that when the preceding discourse justifies the attitudinal presupposition but contradicts the relevant matrix presupposition, the discourse is still acceptable and the presupposition is not inherited by the matrix clause, as can be seen in (29)c. Importantly for our purposes, this observation extends to gestural cosuppositions, as shown in (29)a,b.

(29) a. Samantha is convinced, incorrectly, that John's son was trying to climb up, and she also believes that John UP helped him.

\#> if John helped his son, lifting was involved

b. Samantha wrongly thinks that John is violent, and she believes that he just SLAP punished his son.

\#> if John punished his son, slapping was involved

c. Samantha wrongly thinks that John's son had difficulties, but she feels reassured: she also believes that

John realized that his son needed help.

\#> John's son needed help

We should also mention striking patterns of projection under be unaware. The construction $x$ is unaware that $F$ is particularly interesting because it has a negative component $-x$ doesn't believe that $F$ - and also a positive one, which is presupposed - namely that $F$ is in fact the case. ${ }^{21}$ Strikingly, the co-speech inference makes itself felt in the positive but not (or not clearly) in the negative component of the meaning, as is illustrated in (30) (the at-issue modifier makes itself felt in both components, as one would expect). As we will see below, the cosuppositional analysis comes close to explaining these facts, albeit not perfectly.

(30) a. Samantha is unaware that John (i) UP helped his son. (ii) helped his son like UP this.

(i) [but not (ii)] $\Rightarrow$ Samantha doesn't believe that John helped his son

(i), (ii) $=>$ John helped his son by lifting him

b. Samantha is unaware that John (i) SLAP punished his son. (ii) punished his son like SLAP this.

(i) [but not (ii)] $\Rightarrow>$ Samantha doesn't believe that John punished his son

(i), (ii) => John punished his son by slapping him

Similar data can be obtained with $x$ doesn't realize that $F$, as can be seen in (31).

(31) a. Samantha doesn't realize that John (i) UP helped his son. (ii) helped his son like UP this.

(i) [but not (ii)] $\Rightarrow$ Samantha doesn't believe that John helped his son

(i), (ii) $=>$ John helped his son by lifting him

b. Samantha doesn't realize that John (i) SLAP punished his son. (ii) punished his son like SLAP this.

$=>$ Samantha doesn't believe that John punished his son

$=>$ John punished his son by slapping him

\section{$2.5 \quad$ Facial Expressions}

We believe that some of the same generalizations hold for some co-speech facial expressions. The advantage of facial expressions is that they seem rather natural over long stretches over which it would be unnatural to produce a single co-speech gesture. In simple cases, we replicate the inferences obtained with co-speech gestures. Here :-( stands for an unhappy or disgusted face, which we illustrate in (32)a. Importantly, the disgust might be attributed to the speaker or to Sam in (32)a; but what matters for present purposes is that whatever inference is obtained in the simple case is inherited by the complex sentences in the paradigm.

(32) Propositional examples

a. Sam went :-(_

(i) Samantha believe that John SLAP punished his son. However, I know that he just did not get ice cream for dessert.

${ }^{21}$ See Spector and Sudo, to appear, for other theoretical uses of this construction (specifically, for the analysis of the interaction between implicatures and presuppositions). 
=> for Sam to go skiing with Sam's parents would be disgusting (from Sam's / from the speaker's standpoint)

b. Sam won't go :-( [skiing with his parents].

=> for Sam to go skiing with Sam's parents would be disgusting (from Sam's / from the speaker's standpoint)

c. Did Sam go :-( [skiing with his parents]?

$\Rightarrow$ for Sam to go skiing with Sam's parents would be disgusting (from Sam's / from the speaker's standpoint)

d. If Sam goes :-( [skiing with his parents], I'll hear about it.

=> for Sam to go skiing with Sam's parents would be disgusting (from Sam's / from the speaker's standpoint)

We can also obtain examples in which the disgusted facial expression appears in the consequent of a conditional, and the disgust can be relativized to the content of the antecedent, as shown in (33). ${ }^{22}$

(33) Sam loves skiing, but if the snow is as terrible as it is today, he won't go :-( skiing tomorrow $\Rightarrow>$ if the snow is as terrible as it is today, skiing will be disgusting tomorrow (from Sam's / from the speaker's standpoint)

In more complex examples, we can see the effect of a facial modifier co-occurring with an expression that contains a bound variable. The same generalizations hold as in our earlier examples involving manual gestures. ${ }^{23}$ (Data pertaining to facial expressions in attitude reports are complex; we leave an investigation for another occasion.)

\section{(34) Quantificational examples}

a. Each of my friends goes :-( [skiing with his parents].

$=>$ for each of my friends, to go skiing with his/her parents would be disgusting (from the friend's / from the speaker's standpoint)

b. Does each of your friends go :-( [skiing with his parents]?

$\Rightarrow$ for each of my friends, to go skiing with his/her parents would be disgusting (from the friend's / from the speaker's standpoint)

c. None of my friends goes :-( [skiing with his parents]

=> for each of my friends, to go skiing with his/her parents would be disgusting (from the friend's / from the speaker's standpoint)

\subsection{Experimental approach}

Our discussion so far has been entirely based on introspective judgments, some of which might be unclear. But Tieu et al. 2017, to appear investigate the projection of co-speech gestures with experimental means. Their clearest results pertain to an inferential task (Tieu et al. 2017), performed in two separate experiments illustrated in (35) and (36) on the example of the quantifier none, with the types of inferential questions in (37).

\section{(35) Experiment 1: Target Gestures}

None of these three girls will

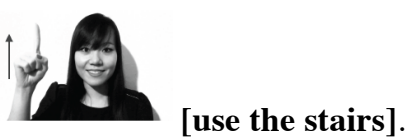

(36) Experiment 2: At-issue controls

None of these three girls will use the stairs in

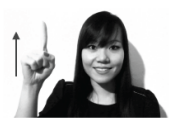

[this direction].

(37) Inferential questions (for both experiments)

a. Existential inference

\footnotetext{
${ }^{22}$ For reasons discussed above in connection with the 'Proviso Problem', some care is needed to construct examples in which a conditional rather than unconditional inference is obtained; see fn. 19 .

${ }^{23}$ See Schlenker 2016, to appear c for initial data that suggest that similar inferences can be replicated with some non-grammatical (disgusted) facial expressions in ASL.
} 
To what degree does this video suggest the inference below?

For at least one of these three girls, if she were to use the stairs, she would go up the stairs.

b. Universal inference

To what degree does this video suggest the inference below?

For each of these three girls, if she were to use the stairs, she would go up the stairs.

The expected cosuppositional inferences were tested in a variety of environments involving might, not, each, none and exactly one. Quantitative results are summarized in the graphs in (38); the results of the target experiment, involving co-speech gestures, are contrasted with those of the at-issue environmentsused in the control experiment. Quantified cases were tested both for universal inferences as in (37)b, and for existential inferences as in (37)a, in part because the data are not entirely clear, and in part because there is a debate between proponents of 'existential projection' vs. 'universal projection' in the presupposition literature (e.g. Beaver 2001, Chemla 2009).

(38) Endorsement rates for different linguistic environments (Tieu et al. 2017)

Endorsement of target inferences $(n=125)$

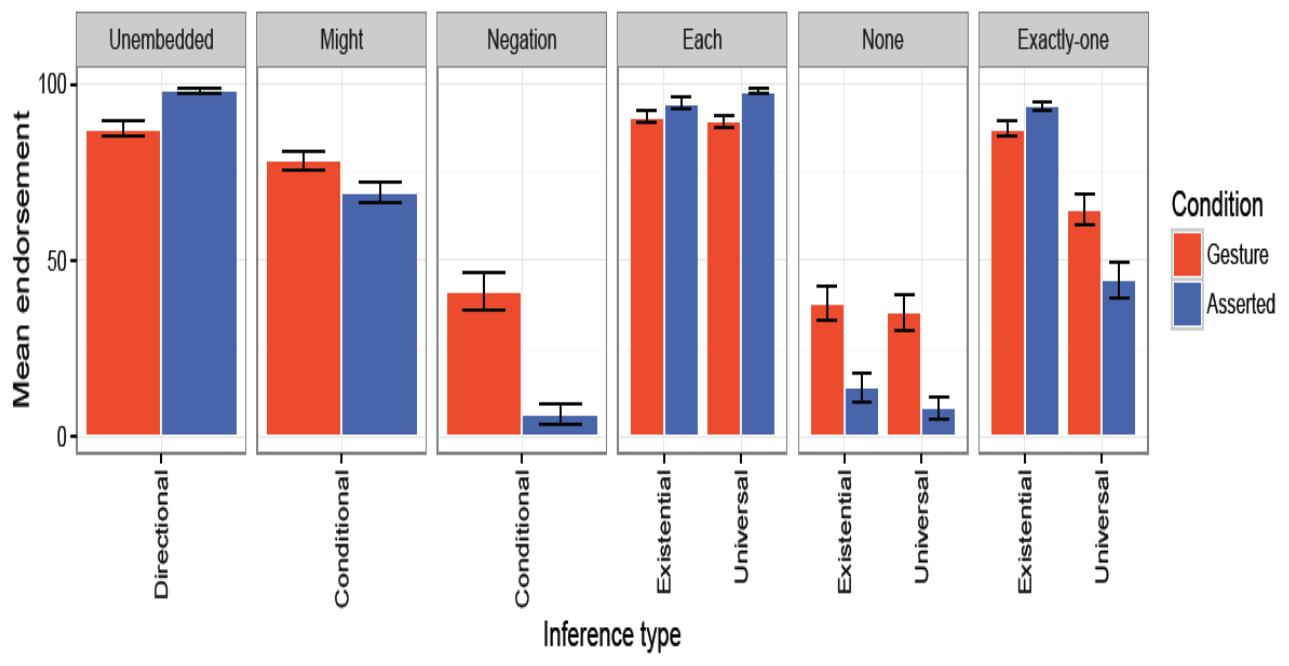

Without getting into too much detail, several points are worth noting

(i) First, in this experimental paradigm it was to some extent possible to just ignore the co-speech gestures, as shown by the fact that an unembedded sentence such as The girl will UP [use the stairs] gave rise to slightly weaker directional inferences than the at-issue control The girl will use the stairs in UP this direction. This need not be too surprising, however: in the control, the deictic this lacks a denotation if the gesture is ignored, whereas the co-speech gesture can be ignored in the target sentence without affecting its grammaticality.

(ii) Second, there are clear and significant differences between target gestural sentences and at-issue controls, and they go in the direction of the cosupposition theory. Still, cosuppositional inferences are often far less strong than expected. This might justify treating gestural triggers as very weak triggers, which easily give rise to local accommodation - a point we already highlighted in Section 1.3.

(iii) Third, in these inferential data there is some evidence of universal projection under none and under exactly one: despite the relative weakness of this projection behavior, it is significantly different from what is obtained with at-issue controls.

(iv) Fourth, the apparent availability of local accommodation turns out to be important in the detailed debate between the cosuppositional and the supplemental theory of co-speech gestures, as relevant controls with appositives do not seem to give rise to at-issue readings in the cases at hand. Tieu et al. 2017, to appear argue that intermediate rates of endorsement for the cosuppositional inferences (e.g. under Might, Negation and None in (38)) are evidence of local accommodation, and that the existence of this mechanism offers an important argument against supplemental analyses - a point we do not further develop in this piece. 


\section{A Cosuppositional Analysis of Co-Speech Gestures}

\subsection{Main idea}

Let us turn to the analysis. The main intuition is straightforward: we take a co-speech gesture to come with a requirement that its content should follow from the contextual meaning of the constituent it cooccurs with. In order to account for the interaction of gestural enrichments with the compositional semantics of the sentences they interact with, we take the relevant notion of 'contextual meaning' to be: meaning relative to the local context of the expression. For most of our discussion, we will rely on standard results of dynamic semantics, which offers an articulated account of local contexts and dynamic updates. But because dynamic semantics is intrinsically lexicalist (in the sense that the update behavior of connectives and operators is stipulated on a case-by-case basis), it sometimes fails to make predictions for cases that are of interest here. In such cases, we will follow the framework of Schlenker 2009, which in simple cases almost entirely agrees with the results of dynamic semantics, but provides a general recipe to compute local contexts once the bivalent semantics and syntax of a sentence have been specified.

Our analysis can be stated in presuppositional terms, as in (39): a co-speech gesture triggers a presupposition that its content is entailed by that of the expression it modifies. We provide a definition for cosuppositions that affect expressions whose type 'ends in $t$ ', but in practice we will restrict attention to the propositional and the predicative case (as is also the case in Schlenker 2008a, 2009).

(39) Cosuppositions triggered by co-speech gestures

Let $G$ be a co-speech gesture co-occurring with an expression $d^{\prime}$ whose type 'ends in $\mathrm{t}^{124}$, and let $g$ be the content of $G$. Then $G$ triggers a presupposition $d^{\prime} \Rightarrow g$, where $\Rightarrow$ is generalized entailment (among expressions whose type 'ends in t'). ${ }^{25}$

To put things differently, a co-speech gesture triggers a presupposition of a particular sort, namely one that is conditionalized on the at-issue content of the expression it modifies, as specified in (40). ${ }^{24}$ See for instance Rooth and Partee 1982. The definition of types 'that end in $\mathrm{t}^{\prime}$ (= 'conjoinable types') can be
given as in (i):

a. $t$ is a conjoinable type

$\mathrm{b}$. If $\mathrm{b}$ is a conjoinable type, then for any type $\mathrm{a},<\mathrm{a}, \mathrm{b}>$ is a conjoinable type.

${ }^{25}$ As in Rooth and Partee 1982, propositional operators are 'lifted' to apply to non-propositional arguments whose type 'ends in t', thanks to the recursive rule in (i), defined here for a binary functor *:

a. If $\mathrm{d}$ and $\mathrm{d}$ ' are two arguments of propositional type, $\mathrm{d}^{*} \mathrm{~d}$ ' has its 'normal' value.

$b$. If $d$ and $d^{\prime}$ are two arguments of a conjoinable type $<a, b>, d^{*} d^{\prime}=\lambda x_{a} \cdot d(x)^{*} d^{\prime}(x)$.

Thus if $d^{\prime}$ and $g$ are two arguments of a predicative type $\langle\mathrm{s},<\mathrm{e}, \mathrm{t}>>$, material implication can be lifted to yield the result in (ii), where we the semantic value of an expression is boldfaced:

(ii) $\left(\mathbf{d}^{\prime} \Rightarrow \mathbf{g}\right)=\lambda \mathrm{w}_{\mathrm{s}} \cdot \mathbf{d}^{\prime}(\mathrm{w}) \Rightarrow \mathbf{g}(\mathrm{w})=\lambda \mathrm{w}_{\mathrm{s}} \cdot \lambda \mathrm{x}_{\mathrm{e}} \cdot \mathbf{d}^{\prime}(\mathrm{w})(\mathrm{x}) \Rightarrow \mathbf{g}(\mathrm{w})(\mathrm{x})$

If a cosupposition $d^{\prime} \Rightarrow g$ modifying $d^{\prime}$ were locally accommodated , we would need to go one step further and conjoin the value in (ii) to d', yielding (iii):

(iii) $\mathbf{d}^{\prime} \&\left(\mathbf{d}^{\prime} \Rightarrow \mathbf{g}\right)=\lambda \mathrm{w}_{\mathrm{s}} \mathbf{d}^{\prime}(\mathrm{w}) \&\left(\mathbf{d}^{\prime} \Rightarrow \mathbf{g}\right)(\mathrm{w})=\lambda \mathrm{w}_{\mathrm{s}} \cdot \lambda \mathrm{x}_{\mathrm{e}} \cdot \mathbf{d}^{\prime}(\mathrm{w})(\mathrm{x}) \&\left(\mathbf{d}^{\prime} \Rightarrow \mathbf{g}\right)(\mathrm{w})(\mathrm{x})=\lambda \mathrm{w}_{\mathrm{s}} \cdot \lambda \mathrm{x}_{\mathrm{e}} \cdot \mathbf{d}^{\prime}(\mathrm{w})(\mathrm{x})$ $\left.\&\left(\mathbf{d}^{\prime}(\mathrm{w})(\mathrm{x}) \Rightarrow \mathbf{g}(\mathrm{w})(\mathrm{x})\right)=\lambda \mathrm{w}_{\mathrm{s}} \cdot \lambda \mathrm{x}_{\mathrm{e}} \cdot \mathbf{d}^{\prime}(\mathrm{w})(\mathrm{x}) \& \mathbf{g}(\mathrm{w})(\mathrm{x})\right)$

This point matters in our discussion of Local Accommodation in (45)b. (We are grateful to M. Esipova for urging us to clarify this point, as an earlier formulation was misleading.) 
(40) Cosuppositions as conditionalized presuppositions

An expression $E$ triggers a cosupposition if $E$ triggers a presupposition of the form $a \Rightarrow e$, where $a$ is the at-issue content of an expression that $E$ modifies.

It should be kept in mind that cosuppositions are presuppositions of a particular sort, and thus that we can rely on the theory of presupposition to make predictions about cosuppositions. In general, the presupposition triggered by an expression must be entailed by the 'local context' of that expression (this insight is incorporated in the dynamic update rules posited by Heim 1983; and it plays a direct role in the theory developed in Schlenker 2009). The general case is stated in (41)a, and the special case of cosuppositions in (41)b, with the notation in (41)c.

(41) Presupposition Satisfaction (dynamic approach)

Let $E$ be an expression with an at-issue component $a$ and a presupposition $\pi$ occurring in a sentence ...E ... uttered relative to a Context Set $\mathrm{C}$.

\section{a. General case of presuppositions}

Then $E$ is licensed in ...E... relative to $\mathrm{C}$ only in case the local context of $E$ given $\mathrm{C}$ entails $\pi$.

\section{b. Special case of cosuppositions}

Suppose that $\pi$ is of the form $a \Rightarrow e$. Then $E$ is licensed in ...E... relative to C only in case its local context entails $a \Rightarrow e$.

c. Notation: in simple cases, local contexts may be of propositional or predicative type. If lc is a local context and $F$ is a formula of the appropriate type, we write $1 \mathrm{l} \vDash \mathrm{F}$ in case lc entails $F$ by generalized entailment. $^{26}$

Let us immediately illustrate the main intuition with a particularly simple example, involving the $U P$-gesture co-occurring with the consequent of a conditional (in formulas, we write the gesture in capital letters, right before the expression it modifies - without boldfacing the latter).

(42) a. If little Johnny takes part in the competition, his mother will UP help him.

$$
\text { b. if } \mathrm{t}, \mathrm{Uh}
$$

We analyze this sentence as having the Logical Form in (42)b, where $t$ stands for little Johnny takes part in the competition, $h$ for his mother will help him, and $U$ for the gesture. When we come to quantified examples, we will take the content of the gestures to impose a predicative presupposition, of the same type of the modified VP. This approach will extend to non-quantified cases, but to see how the system works it is convenient to pretend that the co-speech gesture is propositional in nature, with the rough content $g=$ lifting was involved.

We now apply the satisfaction condition in (41) to (42)b.

- First, we need to compute the local context of $U h$ in if $t$, $U h$ given C; we call this local context lc(Uh) ${ }^{27}$ Standard dynamic analyses as well as the reconstruction of local contexts of Schlenker 2009 take lc(t) to correspond to the set of worlds in C that also satisfy $t$, as is written in (43).

(43) Local context of $\boldsymbol{U}$ in (42)b given a Context Set C

$\operatorname{lc}(\mathrm{Uh})=\lambda \mathrm{w}_{\mathrm{s}} \mathrm{w}$ is in $\mathrm{C}$ and $\mathrm{w}$ satisfies $t$

- Second, the licensing condition in (41)b specifies that relative to $\mathrm{lc}(\mathrm{h}), h$ should entail the content $g$ of $G$, i.e. lifting was involved. We obtain the result in (44).

(44) Licensing condition on $G$ in (42)b given a Context Set C

a. $\operatorname{lc}(\mathrm{Uh})$ as computed in (43) should guarantee that $\operatorname{lc}(\mathrm{Uh}) \vDash \mathrm{h} \Rightarrow \mathrm{u}$, where $u$ is the content of $U$.

b. $\left[\lambda \mathrm{w}_{\mathrm{s}} \mathrm{w}\right.$ is in C and w satisfies $\left.t\right] \models[\mathrm{h}=>\mathrm{u}]$

\footnotetext{
${ }^{26}$ More precisely, we can define the relevant notion of generalized entailment (between a set-theoretic object and a formula) as follows:

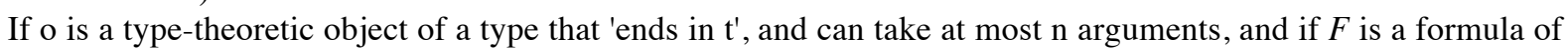
the same type, with meaning $\mathbf{F}$, then $\mathrm{o} F F$ just in case for all objects $\mathrm{x}_{1}, \ldots, \mathrm{x}_{\mathrm{n}}$ of appropriate types, if $\mathrm{o}\left(\mathrm{x}_{1}\right) \ldots($ $\left.\mathrm{x}_{\mathrm{n}}\right)=1$, then $\mathbf{F}\left(\mathrm{x}_{1}\right) \ldots\left(\mathrm{x}_{\mathrm{n}}\right)=1$. (When $\mathrm{o}$ and $F$ are of type $\mathrm{t}$, the standard notion of entailment applies.)

${ }^{27}$ Since the local context of an expression is computed without regard for the content of that expression, the local context of $U h$ in if $t, U h$ is the same as the local context of $h$ in if $t, h$.
} 
and thus we get the result that every world $\mathrm{w}$ in C that satisfies $t$ should satisfy $h=>u$.

In words: every world in $\mathrm{C}$ in which little Johnny takes part in the competition is one in which any help provided by his mother would involve lifting

This seems appropriate.

Finally, we must make provisions for local accommodation of the presupposition (Heim 1983). The condition is standard; one version is defined in (45)a for the general case, and applied in (45)b to the case of cosuppositions.

\section{(45) Local Accommodation}

a. General case

A presupposition which is 'locally accommodated' is treated as part of the at-issue component of the expression it belongs to.

\section{b. Application to cosuppositions}

A cosuppositional expression with at-issue component $a$ and presupposition $a \Rightarrow g$ acquires an at-issue component $(a \&(a \Rightarrow g))$, i.e. $a \& g$, after local accommodation (see the end of fn. 25). (The same result is obtained for the 'official' condition in (46)a and for the near-equivalent condition in (46)b below: it is immediate in the latter case that $a \& g$ gets locally accommodated to $a \& g$.)

In the case of gestural enrichments, the effect of local accommodation will simply be to turn the gestural enrichment into part of the at-issue component. A systematic comparison between the accommodation properties of co-speech gestures and of standard presupposition triggers is beyond the scope of this study, but as noted we conjecture that co-speech gestures are often weak triggers, which easily give rise to local accommodation (this was the reason we compared cosuppositions to the presuppositions triggered by the weak trigger realize).$^{28}$

\subsection{Near-equivalent condition}

Having illustrated the licensing condition in $(41) \mathrm{b}$, it is worth noting that within standard dynamic semantics it is equivalent to a treatment of the co-speech gesture as a separate and purely presuppositional conjunct following the expression it modifies. The reason is that in a sentence of the form ... $[e \& g] \ldots$, where the second embedded conjunct $g$ is purely presuppositional, standard rules of presupposition projection require that, relative to its local context, $e$ should materially entail $g-$ which is precisely the result we obtain for a sentences $\ldots \underline{e=>g} e^{*} \ldots$, where $\underline{e=>g} e^{*}$ has an atissue component $e^{*}$ and a presupposition $e=>g$. As a result, $\ldots e=>g e^{*} \ldots$ and $\ldots(e \& g) \ldots$ trigger the same presupposition, as is stated in (46)a (if $e^{*}=e$, the result of the dynamic update is also the same).

${ }^{28}$ An anonymous referee objects that co-speech inferences, unlike presuppositions, can sometimes be cancelled.

(i) Our house has SQUARE [5 windows]. Well, in fact they are round.

Clearly, local accommodation won't help here. We believe that this example should be analyzed in terms of correction, as suggested by the expression 'in fact', rather than in terms of cancellation. First, the pattern is not general; to our ear (and eye), it is hard to make sense of (ii):

(ii) John SLAP punished his son. ?But it wasn't a physical punishment.

(i) could be a simple case of correction, of the kind exemplified in (iii) - where one term is more common than another and tends to be used with a broader meaning, although this need not be technically correct:

(iii) I used a drone to spy on my neighbor today. Well actually it was a quadcopter. The names are so interchangeable and yet they aren't exactly the same. (retrieved online on 08/04/2016 at https://scriggler.com/SharePost/Story?cash=4b667c0a6bbbd0b6286a803789971059\#sthash.n4ZDGzSd.dpuf)

The case in (i) might also be related to a remark (originating with the same referee) we made in fn. 7: some gestures need not be interpreted strictly iconically, or may be ambiguous between a strict iconic reading and a broader one. The gesture SQUARE in (i) might be taken to represent windows in general, although on a strict iconic reading it is not appropriate, which might justify the correction in the second sentence. 
(46) Presuppositional equivalence of ... $\underline{e=>g} e^{*} \ldots$ and $\ldots(e \& g) \ldots$

Let $\underline{e=>g} e^{*}$ be a propositional expression with a presupposition with content $e=>g$ and an at-issue component with content $e^{*}$, and let $(e \& g)$ be the conjunction of an expression with content $e$ and of an expression with a presuppositional content $g$ and a trivial at-issue component.

a. A Heimian dynamic semantics guarantees that for any Context Set $\mathrm{C}, \mathrm{C}\left[\mathrm{e}=\mathrm{g} \mathrm{e} \mathrm{e}^{*}\right]$ is defined if and only if $\mathrm{C}[\mathrm{e} \& \mathrm{~g}]$ is. Furthermore, if $e^{*}=e, \mathrm{C}[\mathrm{e}=>\mathrm{g} \mathrm{e} *]=\mathrm{C}[\mathrm{e} \& \mathrm{~g}]$. It immediately follows that if $\ldots \underline{\boldsymbol{e}=>}$ $\boldsymbol{g} \boldsymbol{e}^{*} \ldots$ and $\ldots \boldsymbol{e} \& \boldsymbol{g} \ldots$ are identical sentences except for the boldfaced material, they trigger the same presuppositions.

Argument: A Heimian dynamic semantics has the following rules (where c may range over sequenceworld pairs, for instance):

(i) atomic case: $\mathrm{C}\left[\mathrm{pp}^{\prime}\right]=\#$ iff $\mathrm{C}=\#$ or for some $\mathrm{c}$ in $\mathrm{C}, p$ isn't true of $\mathrm{c}$. If $\neq \#, \mathrm{C}\left[\mathrm{pp} p^{\prime}\right]=\left\{\mathrm{c} \in \mathrm{C}\right.$ : $\mathrm{p}^{\prime}$ is true of c\}.

(ii) conjunctions: $\mathrm{C}[\mathrm{F} \& \mathrm{G}]=\mathrm{C}[\mathrm{F}][\mathrm{G}]$

From (i), $C\left[e=>g e^{*}\right]=\#$ iff $\mathbf{C}=\#$ or for some $\mathbf{c}$ in $\mathbf{C}, \boldsymbol{e}$ is true of $\mathbf{c}$ and $\boldsymbol{g}$ is false of $\mathbf{c}$. If $\neq \#, \mathrm{C}[\underline{\mathrm{e}=>}$ $\left.\mathrm{g} \mathrm{e}^{*}\right]=\left\{\mathrm{c} \in \mathrm{C}: \mathrm{e}^{*}\right.$ is true of $\left.\mathrm{c}\right\}$.

From (ii) and (i), $\mathrm{C}[\mathrm{e} \& \mathrm{~g}]=\mathrm{C}[\mathrm{e}][\mathrm{g}]=\#$ iff $\mathrm{C}=\#$ or for some $\mathrm{c}$ in $\mathrm{C}[\mathrm{e}], g$ isn't true of $\mathrm{c}$, iff $\mathrm{C}=\#$ or for some $\mathrm{c}$ in $\{\mathrm{c} \in \mathrm{C}$ : e is true of $\mathrm{c}\}, g$ isn't true of $\mathrm{c}$, iff $\mathbf{C}=$ \# or for some $\mathbf{c}$ in $\mathbf{C}, \boldsymbol{e}$ is true of $\mathbf{c}$ and $\boldsymbol{g}$ is false of $\mathbf{c}$. If $\neq \#, \mathrm{C}[\mathrm{e} \& \mathrm{~g}]=\{\mathrm{c} \in \mathrm{C}$ : $\mathrm{e}$ is true of $\mathrm{c}\}$.

The two boldfaced conditions are identical, hence $\mathrm{C}[\mathrm{e}=>\mathrm{g} \mathrm{e} *]=\#$ iff $\mathrm{C}[\mathrm{e} \& \mathrm{~g}]=\#$. Furthermore, by inspecting the result of the updates, if $e=e^{*}, \mathrm{C}\left[\mathrm{e}=>\mathrm{g} \mathrm{e}^{*}\right]=\mathrm{C}[\mathrm{e} \& \mathrm{~g}]$.

b. Due to the equivalence of the propositional fragment of Schlenker 2009 and of (a version of) Heim's dynamic semantics, it also follows that within that propositional fragment $\ldots e=>g \boldsymbol{e}^{*} \ldots$ and $\ldots \boldsymbol{e} \& \boldsymbol{g} \ldots$ trigger the same presuppositions.

The propositional fragment of Schlenker 2009 is equivalent to (a version of) Heim's propositional dynamic semantics, and thus the presuppositional equivalence of $\ldots e=>g e^{*} \ldots$ and $\ldots(e \& g) \ldots$ is derived as well in the system of Schlenker 2009, as stated in (46)b. As is explained in Appendix I, things are more complicated in the quantificational case: the fragment of Schlenker 2009 has neither variables nor complex predicates, hence it makes no prediction when, say, $(e \& g)$ contains bound variables or is predicative. But the general mechanism used to compute local contexts

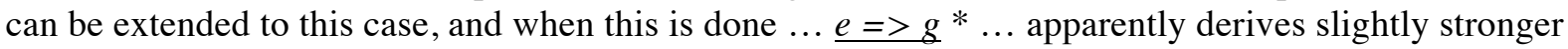
presuppositions than ... $(e \& g) \ldots$.

\subsection{Simple cases}

We turn to a treatment of a few sample cases. For simplicity, we pretend that the target co-speech gestures have a propositional contribution. In fact, the co-speech gestures we considered (with the exception of some facial expressions) made a predicative contribution, but nothing hinges on this simplification: in all standard systems including dynamic semantics, when a predicative presupposition trigger is applied to one or several referential expressions, the effect is the same as if a (properly adapted) propositional presupposition trigger had been applied. ${ }^{29}$

${ }^{29}$ For instance, in trivalent systems, stop smoking evaluated in a world $\mathrm{w}$ and at a time $\mathrm{t}$ (with respect to a context $\mathrm{c}$ and an assignment function $\mathrm{s}$ ) denotes the partial property in (i) (using the notation of Heim and Kratzer 1998, where the lambda-term $\lambda x: F . G$ yields a failure on x unless $\mathrm{F}$ is true of x; in this piece, we write this failure as \#).

(i) $\quad[$ stop-smoking $]]^{c, s, t, w}=\lambda x$. $x$ smoked before $t$ in $w$. $x$ smoked before $t$ but doesn't smoke at $t$ in $w$

As a result, John stops smoking evaluated in a world $\mathrm{w}$ and at a time thas the truth and failure conditions in (ii):

(ii) [[John stop-smoking $]]^{\mathrm{c}, \mathrm{s,t}, \mathrm{w}}$ is defined only if John smoked before t in w; if so, [[John stop-smoking $\left.]\right]^{\mathrm{c}, \mathrm{s}, \mathrm{t}, \mathrm{w}}=$ 1 iff John smoked before $t$ but doesn't smoke at $t$ in $w$ 
As before, co-speech gestures appear in capital letters, e.g. $U$ (for $U P$ ); and their content appears in normal letters, e.g. $u$. We write the global Context Set as C. We take presuppositions to provide constraints on the Context Set, while assertions provide information on (i.e. must be entailed by) the speaker's beliefs, which are more specific. In each case, line a. (a'., a".) includes an English sentence with co-speech gestures, and a simplified representation of its Logical Form; line b. states the licensing condition and the inferences that can be drawn from it. When needed, we write as $\mathbf{F}$ (in boldface) the semantic value of an expression $F$.

\subsubsection{Propositional examples}

We start with simple propositional examples. In (47), we consider cases in which the local context of the enriched expression is identical to the global context of the conversation. In case the sentence is a question, as in (47)a, we obtain the desired cosupposition: if Johnny's mother helped him, this involved some lifting, or with our notation (introduced in (41)c): $\mathrm{C} \vDash \mathrm{h}=>\mathrm{u}$. If instead of a question we have an assertion, as in (47)a, it interacts with the cosupposition to yield the inference that the content of the gesture was in fact instantiated - in our example, this is the inference that John in fact punished his son by slapping him.

(47) a. Johnny's mother UP helped him.

a'. Did Johnny's mother UP help him?

a". Uh (?)

b. Licensing condition:

$\mathrm{lc}(\mathrm{Uh}) \vDash \mathrm{h}=>\mathrm{u}$

hence

$\mathrm{C} \vDash \mathrm{h}=>\mathrm{u}$

and when $h$ is asserted, we thus infer: $h$ and $u$.

In (48), we obtain a further relativization to the antecedent of the conditional, as is desired as well. And in (49), the same cosupposition is obtained as in (47), simply because negation does not affect the computation of local contexts.

(48) a. If Johnny takes part in the competition, will his mother UP help him?

$\mathrm{a}$. if $\mathrm{t}, \mathrm{Uh}$ ?

b. Licensing condition:

$\mathrm{lc}(\mathrm{Uh}) \vDash \mathrm{h} \Rightarrow \mathrm{u}$

hence

$\mathrm{C} \vDash \mathrm{t}=>(\mathrm{h}=>\mathrm{u})$

hence an inference (which survives under questions) that

if Johnny takes part in the competition, then if his mother helps him, lifting will be involved.

(49) a. Johnny's mother didn't UP help him.

$a^{\prime}$. not Uh

b. Licensing condition:

$\operatorname{lc}(\mathrm{Uh}) \vDash \mathrm{h} \Rightarrow \mathrm{u}$

But in $\mathrm{a}^{\prime} . \operatorname{lc}(\mathrm{Uh})=\mathrm{C}$, the global context, hence

$\mathrm{C} \vDash \mathrm{h}=>\mathrm{u}$

In the end, we have two inferences:

relative to the Context Set, if Johnny's mother helps him, lifting will be involved;

relative to the (more specific) speaker's beliefs, Johnny's mother didn't help him.

This is the very result that would be obtained if John-stopped-smoking were treated as a propositional presupposition trigger, with the presupposition that John used to smoke and the at-issue component that John doesn't smoke. 


\subsubsection{Quantified examples}

Let us turn to quantified examples. Now it becomes essential that the gestures associate with the VP rather than with an entire clause, since the presuppositions must be predicative in nature. We assume for simplicity that the gesture associates with the entire VP even if it just co-occurs with the verb. ${ }^{30}$

\section{口 Basic results}

As desired, we derive a universal conditional presupposition in the case of embedding under none of these 10 guys. The key is that this quantifier gives rise to universal presuppositions - for instance, None of these 10 guys takes good care of his computer presupposes that each of these 10 guys has a computer, a result confirmed with experimental means in Chemla 2009. On a theoretical level, Heim 1983 incorporates this pattern of 'universal projection' in her analysis of all generalized quantifiers; and Schlenker 2009 shows that the local context of the Verb Phrase in such cases is the property of being one of these 10 guys relative to the Context Set - which derives the very same result (since the property of being one of these 10 guys must entail the relevant presupposition).

(50) a. None of these 10 guys UP helped his son.

a'. [No g] Uh

b. Licensing condition:

$\mathrm{lc}(\mathrm{Uh}) \mathrm{kh}=>\mathrm{u}$

Given standard results about the local contexts of the restrictor in quantified statements, this derives the

following result:

$\mathrm{C} \vDash[\forall \mathrm{x}: \mathrm{g}(\mathrm{x})](\mathrm{h}(\mathrm{x}) \Rightarrow \mathrm{u}(\mathrm{x}))$

In the end, we have two inferences:

relative to the Context Set, if any of the 10 guys helped his son, lifting was involved;

relative to the speaker's beliefs, none of these 10 guys helped his son.

In Heim's analysis (Heim 1983), all generalized quantifiers trigger universal presuppositions in their nuclear scope. This result is derived, modulo some technical assumptions, in the reconstruction of local contexts developed in Schlenker 2009 (see Appendix I of the present paper for a summary). This makes it possible to derive the desired inferences about the 'positive' part of the sentences in (51)-(52). The key is that in each case we derive a universal presupposition to the effect that for each of the relevant guys, if he punished his son, he did so by slapping him. This universal conditional presupposition then interacts with the at-issue component to yield the inference that the individuals that did in fact punish their son did so by slapping him.

${ }^{30}$ There are two reasons for this simplification.

- First, the equivalence between Heim's dynamic semantics (Heim 1983) and the reconstruction of local contexts in Schlenker 2009 holds for a fragment with 1-place predicates, hence it is expedient to treat VPs as atomic units.

- Second, in standard trivalent systems nothing hinges on this simplification as long as the object is referential, for the same reasons that were outlined in fn. 29. Specifically, in a trivalent system we can posit that the cospeech gesture triggers a presupposition on the value of a transitive verb as in (i) (of type $<\mathrm{e},<\mathrm{e}, \mathrm{t}>>$ ), which ends up constraining the value of a complex predicate as in (ii). But this yields the same effects as if we took the co-speech gestures to directly constrain the value of the VP, as in (iii). (For illustrative purposes, we simplify the derivation of the truth conditions by assuming that for every relevant individual $\mathrm{x}$, time $\mathrm{t}$ and world $\mathrm{w}, \mathrm{x}$ has exactly one son, $\operatorname{son}(\mathrm{x})$, at $\mathrm{t}$ in $\mathrm{w}$. We also illustrate the point within a static trivalent system; this should be extended to a dynamic trivalent system to fit the analysis developed in the text.)

(i) [[UP-help]] ${ }^{\mathrm{c}, \mathrm{t}, \mathrm{w}}=\lambda \mathrm{y} . \lambda \mathrm{x}$ : if $\mathrm{x}$ helps $\mathrm{y}$ at $\mathrm{t}$ in $\mathrm{w}$, lifting is involved . $\mathrm{x}$ helps $\mathrm{y}$ at $\mathrm{t}$ in $\mathrm{w}$ and lifting is involved

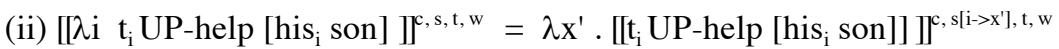

$=\lambda x^{\prime} .[[U P-h e l p]]^{c, s\left[i->x^{\prime}\right], t, w}\left(\operatorname{son}\left(x^{\prime}\right)\right)\left(x^{\prime}\right)=\lambda x^{\prime}$ : if $x^{\prime}$ helps $\operatorname{son}\left(x^{\prime}\right)$ at $t$ in $w$,

lifting is involved . $x^{\prime}$ helps son $\left(x^{\prime}\right)$ at $t$ in $w$ and lifting is involved

(iii) [[UP-help-his-son] $]^{c, s, t, w}=\lambda x$ : if $x$ helps $\operatorname{son}(x)$ at $t$ in $w$, lifting is involved $x$ helps $x^{\prime}$ s son at $t$ in $w$ and lifting is involved 
(51) a. Exactly one of these 10 guys UP helped his son.

$\mathrm{a}^{\prime}$. [=1 g] Uh

b. Licensing condition:

$\mathrm{lc}(\mathrm{Uh}) \vDash \mathrm{h}=>\mathrm{u}$

Given standard results about the local contexts of the restrictor in quantified statements, this derives the

following result:

$\mathrm{C} \vDash[\forall \mathrm{x}: \mathrm{g}(\mathrm{x})](\mathrm{h}(\mathrm{x}) \Rightarrow \mathrm{u}(\mathrm{x}))$

In the end, we have two inferences:

relative to the Context Set, if any of the 10 guys helped his son, lifting was involved;

relative to the speaker's beliefs, exactly one of the 10 guys helped his son; by the first inference, he did so

by lifting him, and the others didn't help their son (whether by lifting him or not).

It is worth noting that the predicted inferences are rather different from those obtained for Exactly one of these 10 guys helped his son by lifting him. Specifically, in our analysis, the sentence in (51) doesn't just yield the inference that exactly one guy helped his son by lifting him, but also that the other relevant guys didn't help their son (whether by lifting him or in some other way). The latter inference is not triggered by the at-issue control with the modifier by lifting him. Still, as we noted in (26)a, this inference ('no other guy helped his son, whether by lifting him or not') is not entirely clear. Furthermore, we derive this inference by way of a universal conditional presupposition to the effect that for each of these 10 guys, if he helped his son, lifting was involved. But as we noted in our empirical discussion in Section 2.3, this universal conditional inference is far less clear for modified indefinites than it is for none-type quantifiers. Still, as we briefly noted in Section 2.6, inferential data obtained by Tieu et al. 2017 suggest that there might indeed be some amount of universal projection of the cosupposition under exactly one.

If universal projection turns out not to be robust under exactly one, the difficulty might be related to an independent problem in the theory of presupposition: the experimental results of Chemla 2009 suggest that there are clear differences in terms of universal projection between none-type quantifiers (clear universal projection) and modified numerals (no clear universal projection). Thus there might be more similarity than we predict between the target sentence in (51)a and the at-issue control with the modifier by lifting him, but this need not show that the presuppositional analysis of co-speech gestures is incorrect: it might be that our theory of presupposition projection just makes overly strong predictions (an alternative way of weakening our predictions is discussed in Section 3.3.3).

For future reference, we also note that, on the assumption that presuppositions project universally in this case as well, we obtain related results for the quantifier between 3 and 5, as shown in (52). Again, one of the inferences predicted ('no other guy helped his son') might be too strong, but possibly for reasons having to do with inadequacies of the theory of presuppositions rather than with the cosuppositional analysis of co-speech gestures.

(52) a. Between 3 and 5 of these 10 guys UP helped their sons.

$\mathrm{a}^{\prime}$. [3 $\left.\leq \bullet \leq 5 \mathrm{~g}\right] \mathrm{Uh}$

b. Licensing condition:

$\mathrm{lc}(\mathrm{Uh}) \vDash \mathrm{h}=>\mathrm{u}$

Given standard results about the local contexts of the restrictor in quantified statements, this derives the following result:

$\mathrm{C} \vDash[\forall \mathrm{x}: \mathrm{g}(\mathrm{x})](\mathrm{h}(\mathrm{x})=>\mathrm{u}(\mathrm{x}))$

In the end, we have two inferences:

relative to the Context Set, if any of the 10 guys punished his son, he did so by slapping him;

relative to the speaker's beliefs, between 3 and 5 of these 10 guys punished their son; by the first inference, they did so by slapping him, and the others didn't help their son (whether by helping him or not).

\section{- Extension to NP-modifying co-speech gestures}

Before we consider attitude reports, we should say a word about some cases in which co-speech gestures modify quantified NPs. Consider again the example in (12)a, repeated in simplified form (without he bound variable he) in (53). 
(53) None of these 10 philosophers found LARGE_L_] [a bottle he liked].

$=>$ for each of these 10 philosophers, if he had found a bottle he liked, it would have been a large one

Our analysis allows co-speech gestures to trigger presuppositions on the value of a variety of elements whose type 'ends in $\mathrm{t}$ '. In this case it is simplest to take the co-speech gesture to modify the NP bottle he liked (rather than the entire DP with the determiner - the precise phonological difference would be hard to perceive since the determiner is so short). Without going into formal details, the present account could be extended to such cases as follows:

- with the gesture, the NP a bottle he liked triggers a presupposition, to the effect that if something satisfies that description, it is large;

- the subject quantifier gives rise to universal presupposition projection, whereby each individual $i$ who is of the 10 philosophers must satisfy the presupposition of $i$ found a LARGE [bottle he $\boldsymbol{~}_{\text {liked]. }}$ This propositional expression includes a presupposition trigger in the restrictor of an existential quantifier. In the theory of Heim 1983, this should give rise to universal projection as well, hence in the end the result that for every individual $i$ who is one of the 10 philosophers, if something is a bottle $i$ likes, it should be something large.

This seems arguably appropriate, although a more rigorous analysis should be given in the future. ${ }^{31}$

\subsubsection{A note on Context Set vs. Speaker's Context}

From the perspective of a theory with universal presupposition projection under quantifiers, there might be another way of solving the empirical problems we encountered with exactly one. In a nutshell, we could posit that gestural cosuppositions can be assessed relative to the speaker's beliefs (the 'Speaker's Context') rather than with respect to the Context Set of the conversation, with one proviso: the gestural cosupposition should not be assessed relative to the Speaker's Context if this makes the co-speech gesture vacuous, in the sense that the sentence with the co-speech gesture has the very same entailments as the sentence without it. This is stated in (54). ${ }^{32}$

(54) Gestural cosuppositions evaluated relative to the Speaker's Context (tentative)

a. A gestural cosupposition may be assessed with respect to the speaker's beliefs rather than with respect to the Context Set...

b. ... unless doing so would make the co-speech gesture vacuous, in the sense that the sentence with the cospeech gesture triggers the very same inferences as the sentence without it (if so, the gestural cosupposition must be evaluated with respect to the Context Set).

As we will now see, the proposed modification will keep the strong universal presupposition (with respect to the Context Set) for embedding under none-type quantifiers, while weakening the inferences triggered by some problematic examples.

- Let us first consider (50)a, and suppose we evaluate its various contributions relative to the Speaker's Context, which we write as $B$ (for 'belief state'). First, we obtain the universalized

\footnotetext{
${ }^{31}$ As mentioned in $\mathrm{fn} .15$, an anonymous referee finds the data less compelling for NP-modifying than for VPmodifying gestures. One difficulty raised by (53) is that the gesture modifies an NP which is the restrictor of an existential quantifier - a position from which universal projection is much weakened to begin with (Chemla 2009). As mentioned by M. Esipova (p.c.), another difficulty arises when the NP does not contain a bound variable, as in: None of these 10 philosophers brought LARGE [a bottle of beer]. Our analysis might in this case predict an overly strong presupposition, to the effect that bottles of beer in general (rather than bottles of beer brought by philosophers) are large. We leave this issue for future research, but not that assignment-sensitive domain restrictions would weaken the presupposition (as we would get a representation akin to: [None of these 10 philosophers $]_{i}$ brought LARGE [a ${ }^{D_{i}}$ bottle of beer], where $D_{i}$ is a domain restriction that depends on the value of variable $i$; see for instance Breheny 2003).

${ }^{32}$ Two remarks should be added. First, evaluation with respect to the Speaker's Context might come very close to an analysis in which Global Accommodation is automatic and without cost; but this would raise a question about the difference obtained between gestural embedding under none-type quantifiers vs. modified indefinites in cases in which Global Accommodation must be applied to the first case. Second, as pointed out by an anonymous referee, there are treatments of specific indefinites on which they too impose pragmatic conditions on the Speaker's Context; see for instance Saebø 2013.
} 
cosupposition (boldfaced) in (55)a, evaluated with respect to the Speaker's Context rather than with respect to the Context Set. Second, the at-issue component of the sentence also contributes information about the speaker's beliefs, hence the contribution in (55)b. (Note that due to the universal projection of the cosupposition, it would be redundant to add the cosupposition as part of the at-issue component.)

(55) Contribution of (50)a with evaluation relative to the Speaker's Context

a. Globally accommodated presupposition:

$\mathrm{B} \vDash[\forall \mathrm{x}: \mathrm{g}(\mathrm{x})](\mathbf{h}(\mathbf{x})=\mathbf{u}(\mathbf{x}))$

b. At-issue component:

$\mathrm{B} \vDash[\forall \mathrm{x}: \mathrm{g}(\mathrm{x})] \operatorname{not} \mathrm{h}(\mathrm{x})$

It is immediate that the conjunction of (55)a and (55)b is equivalent to (55)b, since it makes the boldfaced material in (55)a vacuously satisfied. But this is also the meaning we would obtain for the sentence without the co-speech gesture, hence (54)b mandates that we not evaluate the cosupposition relative to the Speaker's Context, but evaluate it instead with respect to the Context Set. We thus preserve the universal cosupposition of our initial theory, which seems to be a good thing.

- Predictions are different in the case of quantifiers that have a positive component, for instance those in (51) and (52): in such cases, the universal conditional presupposition yields inferences that the gesture-less sentence wouldn't. This is illustrated for (51) (involving exactly one) in (56).

(56) Contribution of (51)a with evaluation relative to the Speaker's Context

a. Globally accommodated presupposition: $\quad \mathrm{B} \vDash[\forall \mathrm{x} \mathrm{x}: \mathrm{g}(\mathrm{x})](\mathbf{h}(\mathbf{x})=>\mathbf{u}(\mathbf{x}))$

b. At-issue component:

$\mathrm{B} \vDash[=1 \mathrm{x}: \mathrm{g}(\mathrm{x})] \mathrm{h}(\mathrm{x})$

The conjunction of (56)a and (56)b can be seen to be equivalent to (57): the speaker believes that exactly one guy helped his son, and that every guy who did used lifting. In other words: the speaker believes that exactly one guy helped his son, and that he did so by lifting him. It is immediate that this is stronger than the meaning of the gesture-free sentence, so evaluation with respect to the Speaker's Context can be applied.

(57) Restatement of the conjunction of (56)a and (56)b

The speaker believes that exactly one guy helped his son, and that he did so by way of lifting.

Furthermore, due to evaluation with respect to the Speaker's Context, the Context Set does not have to satisfy the universal cosupposition any more - which might or might not be a good thing.

Related results are obtained for (52) (involving between 3 and 5), as shown in (58): we obtain the inference that the speaker believes that between 3 and 5 of the guys punished their son, and that all the guys who helped their son did so by way of lifting. In other words, the speaker believes that between 3 and 5 guys helped their son, and that they did so by way of lifting (as in (59)) - which is stronger than what the gesture-free sentence would deliver, hence global accommodation can be applied. Again, the Context Set does not have to satisfy the universal cosupposition any more.

(58) Contribution of (52)a with evaluation relative to the Speaker's Context

a. Globally accommodated presupposition: $\quad \mathrm{B} \vDash[\forall \mathrm{x} \mathrm{x}: \mathrm{g}(\mathrm{x})](\mathbf{h}(\mathbf{x}) \Rightarrow \mathbf{u}(\mathbf{x}))$

b. At-issue component:

$B \vDash[3 \leq \bullet \leq 5 x: g(x)] h(x)$

(59) Restatement of the conjunction of (58)a and (58)b

The speaker believes that between 3 and 5 guys helped their son, and that they did so by way of lifting.

It is worth pausing to reflect on the strategy explored here. Since the Speaker's Context is always more specific than the Context Set, it is easier for a cosupposition to be entailed by the former than by the latter. This is one reason why the inferences predicted for gestural embedding under modified indefinites are now weaker than for none-type quantifiers. In addition, part of these inferences will now be redundant with the at-issue component of the sentence, and hence harder to detect unless further projection tests are used. Importantly, when we embed the target sentences in questions, we should still see evidence for projection since the at-issue component won't be entailed any more; the judgments should be investigated.

This is of course a tentative proposal, whose empirical and theoretical ramifications should be explored in greater depth in future research. 


\section{$3.4 \quad$ Attitude reports}

\subsubsection{Simple attitude reports}

Let us turn to co-speech gestures that are embedded within belief reports. Since belief reports are standardly analyzed in terms of universal quantification over possible worlds, we obtain the same types of predictions as for co-speech gestures embedded under universal quantifiers. The simplest case involves embedding under believe, analyzed as in (60).

(60) a. Samantha believes that John UP helped his son.

$\mathrm{a}^{\prime} \cdot \mathrm{Bel}_{\mathrm{s}} \mathrm{Uh}$

b. Licensing condition:

$\mathrm{C} \vDash \mathrm{Bel}_{\mathrm{s}}(\mathrm{h}=>\mathrm{u})$

Heim 1983, 1992 and Schlenker 2009 derive the result that for a presupposition trigger $q q^{\prime}$ with presupposition $q, B e l_{s} q q^{\prime}$ presupposes $B_{e} l_{s} q$. In a'. the presupposition is of the form $h=>u$, hence the result. ${ }^{33}$

The at-issue component yields $\mathrm{Bel}_{s} h$, hence also an inference that $\mathrm{Bel}_{s} h$ : Samantha believes that John helped his son and that lifting was involved.

This seems adequate to derive the attitudinal inference we discussed in (28)a; the additional inference that might be obtained when the sentence is uttered out of the blue (to the effect that the speaker believes that the helping event involved lifting) would require a strengthening mechanism, but as we noted the same issue arises with standard presuppositions.

The data are more subtle and harder to assess in the negative example in (61). The predicted cosupposition is the same as in (60), but given the negative nature of the at-issue component, the overall inferences are of course different. Here we predict a presupposition that might be too strong, namely that Samantha believes that if John helped his son, lifting would have been involved. We leave this problem for future research.

(61) a. Samantha doesn't believe that John UP helped his son.

a'. not $\mathrm{Bel}_{\mathrm{s}} \mathrm{Uh}$

b. Licensing condition:

$\mathrm{C} \vDash \mathrm{Bel}_{\mathrm{s}}(\mathrm{h}=>\mathrm{u})$

The presuppositional result is the same as in (60), but the at-issue component is negative and thus we do not obtain the inference that Samantha believes that John helped his son and that lifting was involved.

\subsubsection{The case of be unaware and not realize}

Let us turn to the case of be unaware and not realize, which yield the interesting inferences we discussed in Section 2.4. While one is typically interested in the local context of the entire constituent

${ }^{33}$ More precisely, the condition we derive is that the local context of the embedded clause entails its cosupposition, as stated in (i):

(i) $\operatorname{lc}(\mathrm{Sp}) \vDash \mathrm{p}=>\mathrm{s}$

Schlenker 2009 shows that the value of the local context of the embedded clause in a formula $\operatorname{Bel}_{s} F$ is $1 \mathrm{l}(\mathrm{F})=$ $\lambda \mathrm{w}^{*} \lambda \mathrm{w}\left(\mathrm{w}^{*} \in \mathrm{C}\right.$ and $\left.\mathrm{w} \in \operatorname{Dox}_{\mathrm{s}}\left(\mathrm{w}^{*}\right)\right)$, where abstraction over $\mathrm{w}^{*}$ corresponds to the context parameter and abstraction over $\mathrm{w}$ corresponds to the world parameter, while $\operatorname{Dox}_{\mathrm{s}}\left(\mathrm{w}^{*}\right)$ is the set of worlds compatible with what individual $\mathrm{p}$ believes in world $\mathrm{w}^{*}$. As a result, we obtain the presupposition in (ii), which is also what Heim 1992 posits:

(ii) $\mathrm{C} \vDash \mathrm{Bel}_{\mathrm{s}} \mathrm{p}=>\mathrm{s}$

(As Daniel Rothschild (p.c.) notes, in simple cases the framework of Schlenker 2009 could have handled presupposition projection under believe without resorting to the device of double indexing, but throughout the present discussion we stick to the precise framework of Schlenker 2009.) 
[be unaware that $F$ ] or [realize that $F$ ] (as these are presupposition triggers), we need to compute the local context of the embedded clause $F$ in order to assess the effects of a gesture that co-occurs with it. Dynamic accounts do not provide a straightforward (or a predictive) way to compute the value of that local context, and thus it is expedient to make use of the reconstruction of local contexts developed in Schlenker 2009 (andpresented more concisely in Schlenker 2010a).

By way of motivation, let us explain what goes wrong if we simply assume that the gestural inference is conjoined with the embedded clause, so that John UP helped his son means $h$ \& $(h=>$ $u$ ): John helped his son, and if he helped him, lifting was involved. This is immediately equivalent to: $h \& u$, i.e. John helped his son and lifting was involved. Under be aware, be unaware, realize and not realize, this conjunction becomes presupposed, which is compatible with the observed presuppositional inferences (e.g. Samantha realizes that John UP helped his son does give rise to the inference that John did in fact help his son, and that lifting was involved). But under be unaware and not realize, the at-issue component derived for the entire sentence is now too weak: we infer that Samantha doesn't believe that John helped his son by lifting him, whereas the correct result is arguably that Samantha doesn't believe that John helped his son.

We will now show that this stronger result does follow from the mechanism of local context computation of Schlenker 2009 (although we might also obtain a result that is in some respects too strong). The key intuition can be summarized as follows. The local context of a clause John UP helped his son embedded under Samantha is unaware that is in essence the smallest set of worlds that one can restrict attention to when assessing the embedded clause. For this reason, the local context will turn out to include the worlds compatible with the agent's beliefs, but also the actual world - due to the factive component of these constructions. Since the local context should entail that if John helped his son, lifting was involved, this conditional will hold both in the actual world and in the worlds compatible with Samantha's beliefs. And since be unaware is factive, we will get the inference that in the actual world John helped his son, and that lifting was involved; but we will still preserve the at-issue inference that Samantha doesn't believe that John helped his son (together with a conditional inference - possibly too strong - that she believes any such help would have involved lifting).

Let us see this in greater detail. We start by assuming that the bivalent meaning of a formula Unaware_s $F$ (used as the Logical Form of $s$ is unaware that $F$ ) is in essence that (i) $F$ is true, and (ii) individual s doesn't believe that $F$; and that the bivalent meaning of a formula Aware_s $F$ is that (i) $F$ is true, and (ii) individual s believes that $F$. With these assumptions, it can be shown that the local context of the embedded clause is in essence the union of the actual world and of the worlds compatible with the agent's beliefs. As a result, the gestural cosupposition will impose conditions both on the actual world and on the worlds compatible with the agent's beliefs.

Specifically, modulo a technical assumption, the local context of $F$ in both constructions is the function that assigns to each world $\mathrm{w}^{*}$ the null set if $\mathrm{w}^{*}$ is not in the Context Set $\mathrm{C}$, and otherwise the set of worlds compatible with what individual $\mathrm{s}$ believes in $\mathrm{w}^{*}$ (as was the case for the local context of a clause embedded under believe), augmented with the world $\mathrm{w}^{*}$ itself (due to the factive entailment of be unaware $)$. In technical terms: $\mathrm{lc}(\mathrm{F})=\lambda \mathrm{w}^{*} \lambda \mathrm{w}\left(\mathrm{w}^{*} \in \mathrm{C}\right.$ and $\left(\mathrm{w} \in \operatorname{Dox}_{\mathrm{s}}\left(\mathrm{w}^{*}\right)\right.$ or $\mathrm{w}=$ $\left.\mathrm{w}^{*}\right)$ ). This result is stated in (62) and proven in Appendix II. But a word of explanation might be useful. In the framework of Schlenker 2009, one should think of the first world argument $w^{*}$ as the context parameter (but see the end of fn. 33). Thus if (Un)aware_s $F$ is evaluated within a context $\mathrm{c}$ of the context set $\mathrm{C}$, setting $\mathrm{w}^{*}=\mathrm{c}$, the local context of $F$ is $\operatorname{lc}(\mathrm{F})(\mathrm{c})=\lambda \mathrm{w} \cdot\left(\mathrm{w} \in \operatorname{Dox}_{\mathrm{s}}(\mathrm{c})\right.$ or $\left.\mathrm{w}=\mathrm{c}\right)$, which can be thought of as the set $\operatorname{Dox}_{s}(c) \cup\{c\}$. This, in turn, captures the intuition that when evaluating the embedded clause one can restrict attention to the worlds compatible with the agent's beliefs (given c), hence $\operatorname{Dox}_{\mathrm{s}}(\mathrm{c})$, augmented with itself, $\{\mathrm{c}\}$.

(62) Local context of $\boldsymbol{F}$ in (Un)aware_s $\boldsymbol{F}$

Assume that (Un)aware_s $F$ is equivalent to $F \&$ (not) Bel_s $F$.

In the framework of Schlenker 2009, modulo some technical assumptions stated in Appendix II, the local context of the embedded clause $F$ is:

$\operatorname{lc}(\mathrm{F})=\lambda \mathrm{w}^{*} \lambda \mathrm{w}\left(\mathrm{w}^{*} \in \mathrm{C}\right.$ and $\left(\mathrm{w} \in \operatorname{Dox}_{\mathrm{s}}\left(\mathrm{w}^{*}\right)\right.$ or $\left.\left.\mathrm{w}=\mathrm{w}^{*}\right)\right)$ 

in (63).

We can now consider the case of Samantha is aware that John UP helped his son, analyzed

(63) a. Samantha is aware that John UP helped his son.

a'. Aware $\mathrm{Uh}$

b. Licensing condition:

$\operatorname{lc}(\mathrm{Uh}) \vDash \mathrm{h}=>\mathrm{u}$

By (62), lc $(U h)=\lambda w^{*} \lambda w\left(w^{*} \in C\right.$ and $\left(w \in \operatorname{Dox}_{s}\left(w^{*}\right)\right.$ or $\left.\left.w=w^{*}\right)\right)$, where $\operatorname{Dox}_{\mathrm{s}}\left(w^{*}\right)$ is the set of worlds compatible with what individual $\mathrm{s}$ believes in world $\mathrm{w}^{*}$. As a result, we obtain the presupposition that

(i) $\mathrm{C} \models(\mathrm{h}=>\mathrm{u}) \& \operatorname{Bel}_{\mathrm{s}}(\mathrm{h}=>\mathrm{s})$

In addition, we can derive a factive presupposition triggered by aware (we do not provide the derivation here, as it is straightforward in dynamic semantics or in the reconstruction of local contexts of Schlenker 2009). Thus we also have:

(ii) $\mathrm{C} \vDash \mathrm{h} \&(\mathrm{~h}=>\mathrm{u})$, hence $\mathrm{C} \vDash \mathrm{h} \& \mathrm{u}$

Since Aware $_{s} U h$ is asserted, if the speaker is sincere we obtain the result in (iii), with $\mathrm{B}=$ the set of worlds compatible with the speaker's beliefs:

(iii) $\mathrm{B} \vDash \mathrm{Bel}_{\mathrm{s}}(\mathrm{h} \& \mathrm{u})$

The presuppositions are the same if aware is replaced with unaware, but we lose the inference in (63)(iii):

(64) a. Samantha is unaware that John UP helped his son.

a'. Unaware $\mathrm{sh}$

b. Since the local context of the embedded clause is the same under Unaware and under Aware, and since the factive presupposition is the same for both constructions, we obtain exactly the same presuppositions in the two cases, hence:

(i) $\mathrm{C} \vDash(\mathrm{h}=>\mathrm{u}) \& \mathrm{Bel}_{\mathrm{s}}(\mathrm{h}=>\mathrm{u})$

(ii) $\mathrm{C} \vDash \mathrm{h} \& \mathrm{u}$

The at-issue component gives us in the present case:

(iii) $\mathrm{B} \vDash \operatorname{not} \mathrm{Bel}_{\mathrm{s}}(\mathrm{h} \& \mathrm{u})$

and by (i) and (iii)

(iv) $\mathrm{B} \vDash$ not $\mathrm{Bel}_{\mathrm{s}} \mathrm{h}$

since for $\mathrm{w} \in \mathrm{B}$, if $\mathrm{w} \vDash \mathrm{Bel}_{\mathrm{s}} \mathrm{h}$, by (i) $\mathrm{w} \vDash \mathrm{Bel}_{\mathrm{s}}\left(\mathrm{h} \Rightarrow \mathrm{u}\right.$ ) [because $\mathrm{C} \vDash \mathrm{F}$ implies $\mathrm{B} \vDash \mathrm{F}$ ], hence $\mathrm{w} \vDash \mathrm{Bel}_{\mathrm{s}}(\mathrm{u} \&$ h), which contradicts (iii).

Importantly, it might seem that $\operatorname{Bel}_{s}(h=>u)$ in (i) is still too strong. This is directly related to the difficulty we already encountered in (61), and we also leave this problem for future research.

Since the local context of the embedded clause is the same under aware and unaware, we obtain the further result that Samantha is not aware that John UP helped his son in (65)a is predicted to behave like (64)a.

(65) a. Samantha is not aware that John UP helped his son.

a'. not Aware $\mathrm{Uh}$

b. Since the local context of the embedded clause is the same under Unaware and under Aware, and since the factive presupposition is the same for both constructions, we obtain exactly the same presuppositions in the two cases, hence:

(i) $\mathrm{C} \vDash(\mathrm{h}=>\mathrm{u}) \& \operatorname{Bel}_{\mathrm{s}}(\mathrm{h}=>\mathrm{u})$ 
(ii) $\mathrm{C} \vDash \mathrm{h} \& \mathrm{u}$

The at-issue component gives us in the present case:

(iii) $\mathrm{B} \vDash \operatorname{not}_{\mathrm{Bel}}(\mathrm{h} \& \mathrm{u})$

and by (i) and (iii)

(iv) $\mathrm{B} \vDash \operatorname{not}_{\mathrm{Bel}_{\mathrm{s}} \mathrm{h}}$

since if $\mathrm{B} \vDash \mathrm{Bel}_{\mathrm{s}} \mathrm{h}$, by (i) $\mathrm{B} \vDash \mathrm{Bel}_{\mathrm{s}}\left(\mathrm{h}=>\mathrm{u}\right.$ ) [because $\mathrm{C} \vDash \mathrm{F}$ implies $\mathrm{B} \vDash \mathrm{F}$ ], hence $\mathrm{B} \vDash \mathrm{Bel}_{\mathrm{s}}(\mathrm{h} \& \mathrm{u})$, a contradiction.

\subsection{Refining the analysis within event semantics}

As M. Krifka (p.c.) has noted, the inferences we predict are in some respect too weak. Consider again the sentences John UP helped his son or Did John UP help his son? We predict a presupposition to the effect that if John helped his son, lifting was involved - but our framework does not specify what kind of connection, if any, there should be between the help and the lifting. We clearly want something stronger, namely: if John helped his son, lifting was involved in the helping event in question. As Krifka points out, this more adequate inference can be obtained by integrating cosuppositions to an event semantics, one in which help holds true of events and individuals rather than just of individuals.

Without going into the full details of a proper event semantics (see for instance Rothstein 2004), we can follow Krifka's suggestion in positing the event-theoretic analysis in (66)a: help will compose with two individual arguments $\mathrm{y}$ (corresponding to the patient) and $\mathrm{x}$ (corresponding to the agent) to yield an event predicate true of helping events involving $\mathrm{x}$ and $\mathrm{y}$ as an agent and as a patient respectively. For concreteness, we adopt a trivalent framework in which UP help yields a failure unless the helping event (relative to certain arguments) entails a lifting motion, as is encoded in (66)b (using the notation of Heim and Kratzer 1998, where $\lambda x: F . G$ yields a failure on an argument $\mathrm{x}$ unless $\mathrm{F}$ is true of $\mathrm{x}){ }^{34}$

(66) a. Lexical entry of help (where help' is a meta-linguistic predicate true of helping events, and $u p^{\prime}$ is a metalinguistic predicate true of lifting events)

$[$ help $]=\lambda \mathrm{y} \lambda \mathrm{x} \lambda \mathrm{e}[$ help'(e) and agent $(\mathrm{e})=\mathrm{x}$ and patient $(\mathrm{e})=\mathrm{y}]$

b. Cosupposition triggered by $U P$ co-occurring with help

$\left[\left[U P\right.\right.$ help]] $=\lambda \mathrm{y} \lambda \mathrm{x} \lambda \mathrm{e}$ : $\left[\mathrm{help}^{\prime}(\mathrm{e})\right.$ and $\operatorname{agent}(\mathrm{e})=\mathrm{x}$ and patient $\left.(\mathrm{e})=\mathrm{y}\right] \Rightarrow \mathrm{up}^{\prime}(\mathrm{e})$. [help'(e) and agent $(\mathrm{e})=\mathrm{x}$ and patient $(\mathrm{e})=\mathrm{y}]$

c. [[John UP help his son]]

$=\left[\lambda \mathrm{y} \lambda \mathrm{x} \lambda \mathrm{e}\right.$ : $[\mathrm{help}(\mathrm{e})$ and agent $(\mathrm{e})=\mathrm{x}$ and patient $(\mathrm{e})=\mathrm{y}]=\mathrm{up}^{\prime}(\mathrm{e})$. help $(\mathrm{e})$ and agent $(\mathrm{e})=\mathrm{x}$ and

patient $(\mathrm{e})=\mathrm{y}]($ john's_son')(john')

$=\lambda \mathrm{e}:[$ help' $(\mathrm{e})$ and agent $(\mathrm{e})=$ john' and patient $(\mathrm{e})=$ john's_son'] $=>$ help' $(\mathrm{e})$. help'(e) and agent $(\mathrm{e})=$ john' and patient $(\mathrm{e})=$ john's_son'

For John UP help his son, we obtain in (66)c a predicate that is true of events in which John helped his son, with a cosupposition that such events are lifting events. To obtain final truth conditions, we need to 'feed' an event argument to this predicate. This can for instance be done by way of an existential quantifier over events with a domain restriction $D$, written as $\exists^{D}$ in (67).

(67) $\exists^{\mathrm{D}}$ John UP help his son

The final result depends on presupposition projection in existentially quantified structures - a controversial topic. Assuming (as in Heim 1983 and Schlenker 2009) that we obtain universal

\footnotetext{
${ }^{34}$ For notational simplicity, we do not repeat the presupposition as part of the at-issue component. As mentioned in fn. 6 and in the corresponding part of the main text, in standard theories this makes no difference, but there are exceptions.
} 
projection, and thus that every event that satisfies the restrictor $D$ must satisfy the presupposition of the predicate, we will obtain a presupposition to the effect that for every event e satisfying $\mathrm{D}$, if $e$ is an event in which John helps his son, $e$ is a lifting. This seems roughly adequate. Of course further refinements should be explored, but since we are interested in the projection properties of gestural cosuppositions rather than in the details of their lexical specifications, we will leave this issue for future research.

\subsection{Summary and further issues}

In this section, we have implemented the idea that the contextual meaning of an expression should entail the content of a co-speech gesture that modifies it. By taking the contextual meaning of an expression to be the meaning it has relative to its local context, we predicted a subtle interaction between co-speech gestures and logical operators. For a (non-presuppositional) predicate $p$ modified by a co-speech gesture $G$ in a sentence ...G $p \ldots$ uttered in a Context Set C, the key condition was that $\mathrm{lc}=\mathrm{p}=>\mathrm{g}$, where lc is the local context of $G p$ and $g$ is the content of the gesture $G$. This accounts for the analogies we described in Section 2 between presupposition projection and gesture projection. As a consequence, barring local accommodation, co-speech gestures strengthen the meaning of sentences because their contribution is cosuppositional, and hence presuppositional.

One issue we did not address is under what conditions local accommodation of a cosupposition is possible - but in fairness this is a complex question in the context of standard presuppositions as well. As mentioned by several colleagues, including an anonymous referee, examples such as (68)a, with contrastive focus, make such readings easy to obtain; we believe they extend to operators besides negation, as in (68)b, which makes it unlikely that mere meta-linguistic readings are at stake. Related remarks are made about the interaction of focus with presuppositions in Simons et al., to appear, and we refer the reader to Esipova 2016a, b for a comparative discussion of the role of focus in triggering local accommodation of standard presuppositions and of gestural cosuppositions $^{35}$.

(68) a. I did not bring LARGE [a bottle], I brought SMALL [a bottle].

b. If you bring SMALL [a bottle], I'll be disappointed, but if you bring LARGE [a bottle], I won't be.

\section{Alternative Accounts}

In this section, we consider two alternative accounts. One treats co-speech gestures as having a supervaluationist semantics; the intuition is that the Context Set should guarantee that the same semantic result is obtained whether the content of the co-speech gesture is taken into account or not. This makes interesting predictions, but ones which are in the end flawed. Still, they could be combined with our main account to yield a more sophisticated (but conceptually odd) theory. The second alternative follows Ebert and Ebert 2014 in treating co-speech gestures as making a 'supplemental' contribution, or in other words as having the same kind of contribution as appositive relative clauses. We argue that this analysis is incorrect for co-speech gestures, but that it works well for post-speech gestures, which come after the expressions they modify, and have their own time slot.

\subsection{Supervaluationist accounts}

As noted above, our initial cosuppositional analysis predicted some inferences that were arguably too strong. This might be the case in (51)a (Exactly one of these 10 guys UP helped his son), for which we initially predicted a universal conditional presupposition to the effect that for each of these 10 guys, if he helped his son, lifting was involved (but note that Tieu et al. 2017 do find an argument for a universal inference). The same potential problem arose in (64)a (Samantha is unaware that John UP helped his son), for which we initially predicted a presupposition that Samantha believes that either John didn't help his son, or he did so by lifting him. These difficulties motivate the exploration of a different theory, which goes like this: when we perceive a co-speech gesture, we interpret it as enriching the meaning of the sentence, but instead of doing so in a cosuppositional fashion, we simply

\footnotetext{
${ }^{35}$ Esipova's analysis is broadly compatible with the view that local accommodation is used as a 'last resort'.
} 
take the conjunction of the sentence without the co-speech gesture, and of the sentence with the cospeech gesture. The intuition behind this treatment is that the gesture, being somehow parasitic, should only enrich the gesture-free meaning of the sentence. The enrichment is not obtained in a presuppositional fashion, but by conjoining with the gesture-free meaning of the sentence the meaning it has if the gesture is taken to be part of its at-issue component.

The intuitive motivation for this analysis is to treat the meaning of the sentence as being in a sense indeterminate: one can take it to have its literal meaning without the accompanying gesture; or one can take it to have its meaning with the gesture (conjunctively) incorporated to its normal at-issue component. For instance, John UP helped his son is indeterminate between two meanings: one akin to John helped his son, and one to John helped his son by lifting him. On the supervaluationist treatment of indeterminacy/vagueness, a sentence is clearly true (or 'super true') only if each resolution of its meaning is true. This is a standard idea in the analysis of vagueness: for John is bald to be clearly true, the sentence should be true on all resolutions of the predicate bald, whose extension is vague because it is not clear how many hairs one may have while still counting as bald (if different resolutions yield different truth values, the sentence is neither true nor false). Importantly, in our discussion we do not assume that the utterance of a vague statement comes with a presupposition that it should have a clear value (true or false, rather than indeterminate); but of course if a statement is uttered by a cooperative speaker, we can assume that she believes it to be felicitous and true (we come back to this point at the end of this section) ${ }^{36}$ Now in the gestural case, the idea is that the sentence is clearly true only if two versions of the sentence are true: one without the gesture, and one in which the gesture makes an at-issue contribution, hence the conjunction of John helped his son and John helped his son by lifting him. In this simple case, this just yields the same meaning as the strongest of the two conjuncts, but in more complex logical environments the predictions are quite interesting.

As we will see, some are excellent, and some are initially flawed. But in any event it is worth briefly exploring this analysis in view of the resurgence of interest in (diverse versions of) supervaluationist approaches, which have been applied to (i) presuppositions (see van Fraassen 1969, George 2008, Fox 2008, Schlenker 2008b), (ii) semantic paradoxes (e.g. McGee 1991), (iii) vagueness (e.g. Keefe 2008), and (iv) and 'homogeneity' inferences triggered by plural definites and other constructions (Spector 2013, Križ 2015, 2016 ). ${ }^{37}$ It is thus of interest to explore whether cospeech gestures might offer a further domain of application for supervaluations. In addition, we will see that one might be able to combine the supervaluationist and the cosuppositional approaches to yield subtle and interesting predictions. Let us give an initial statement of a Basic Supervaluationist Account:

(69) Basic Supervaluationis Account

A sentence of the form ...Ge ... with a co-speech gesture $G$ with a content expressed by $g$ modifying an expression $e$ of the same (conjoinable) type is true (resp. false) just in case the two sentences ...e ... and $\ldots[e \& g] \ldots$ are both true (resp. false).

When the sentence has different truth values depending on whether the co-speech gesture is taken into account or disregarded, the sentence will be neither true nor false - hence a trivalent account of gesture projection. It is also clear that on this analysis a co-speech gesture is predicted to always strengthen the meaning of a sentence: if the enriched sentence is true, so is the bare sentence (this property is shared with our cosuppositional account, at least given standard assumptions about presupposition projection).

Let us see how this mechanism can be applied to the sentence Samantha is unaware that John UP helped his son. As shown in (70), the proposed analysis ends up yielding the strongest of the presuppositions of Unaware $h$ and Unaware $(h \& u)$, hence a presupposition that John helped his son by lifting him. It also yields the strongest of the two at-issue components, and hence (since the at-

\footnotetext{
${ }^{36}$ Thanks to Amir Anvari (p.c.) for helping us clarify this point.

37 In addition, supervaluationist ideas were explored in unpublished work by Fox and Spector on the interpretation of the covert exhaustivity operator that accounts for embedded implicatures (their idea was that when an exhaustivity operator is present, the sentence should be true whether one computes the effect of the operator or not).
} 
issue component is negative) an assertion that Samantha doesn't believe that John helped his son irrespective of whether this was by lifting him or by other means.

(70) a. Samantha is unaware that John UP helped his son.

a'. Unaware ${ }_{\mathrm{s}} \mathrm{Uh}$

b. (a') is true iff Unaware $_{s} h$ and Unaware $_{s}(h \& u)$ are both true,

iff it is presupposed that $h$, and (it is asserted that) s doesn't believe that $h$, and it is presupposed that (h \&

$\mathrm{u}$ ), and (it is asserted that) s doesn't believe that ( $\mathrm{h} \& \mathrm{u}$ )

iff it is presupposed that $h$ and $u$, and s doesn't believe that $h$. In other words, it is presupposed that John helped his son by lifting him, and (it is asserted that) Samantha doesn't believe that John helped his son.

Importantly, we do not derive in this way the questionable inference that Samantha believes that if John helped his son, lifting was involved (where the conditional is a material implication). Thus we have solved one of the problems encountered by the cosuppositional approach.

This initial success of the Basic Supervaluationist Account might extend to other nonmonotonic environments such as exactly one, as shown in (71).

(71) a. Exactly one of these 10 guys UP helped his son.

$\mathrm{a}^{\prime}$. [=1 g] Uh

b. (a') is true and felicitous iff $[=1 \mathrm{~g}] h$ and $[=1 \mathrm{~g}](h \& u)$ are both true and felicitous. It follows that

exactly one guy helped his son, and furthermore he did so by lifting him.

This result can be compared to the stronger inference we obtained in our presuppositional approach in (51). As will be recalled, we had derived two relevant inferences:

- relative to the Context Set, if any of the 10 guys helped his son, slapping was involved.

- relative to the (more specific) speaker's beliefs, exactly one of the 10 guys helped his son; by the first inference, lifting was involved.

The supervaluationist approach has the potential advantage of not generating a conditional presupposition about the 9 guys who didn't punish their sons. But of course this assessment changes if the cosupposition turns out to project universally, as might be suggested by experimental results summarized in Section 2.6.

Several supervaluationist treatments are discussed in greater detail in Appendix III. As we explain there, the Basic Supervaluationist Account suffers from two deficiencies.

(i) First, as stated above, it predicts no gestural inference at all in downward-monotonic environments (unless the gesture is embedded under a presupposition trigger, as was the case above with be unaware). The reason is that in such cases the sentence with the gestural enrichment is weaker than the sentence without it, and thus conjoining the two yields the same result as if there had been no gestural enrichment in the first place. For instance, for None of these 10 guys UP helped his son, we obtain in essence the conjunction of None of these 10 guys helped his son, and None of these 10 guys helped his son by lifting him - which is equivalent to the first conjunct.

In Appendix III, we consider a more complex Mixed Supervaluationist Account, which combines mechanisms of the Basic Supervaluationist Account and of our cosuppositional analysis, as stated in (72).

(72) Mixed Supervaluationist Account

A co-speech gesture

(a) is treated in terms of the Basic Supervaluationist Account in (69)...

(b) ... unless this fails to strengthen the meaning, in which case it is treated as a cosupposition (as outlined in Section 3).

The resulting theory combines many of the advantages of the supervaluationist and of the cosuppositional theory - but it is conceptually odd.

(ii) Still, there are further problems with both versions of the Supervaluationist Account. As we discuss in Appendix III, they predict odd inferences under expressions such as an odd number of, or between 3 and 5. Consider for instance the sentence Between 3 and 5 guys UP helped their son. In essence, the Basic Supervaluationist Account treats this as the conjunction of Between 3 and 5 guys helped their son, and Between 3 and 5 guys helped their son by lifting him. This turns out to be true in 
particular when exactly 5 guys helped their son, and exactly 3 guys helped their son by lifting him which seems to us to be a counterintuitive result. We believe the desired inference is closer to: Between 3 and 5 helped their son, and those that did lifted him. The latter inference is correctly obtained within the cosuppositional approach of Section 3.

We also discuss in Appendix III a stronger ('pointwise') supervaluationist account, which solves some of these problems (with an odd number) but not others (with between 3 and 5). It still has the drawback of predicting no gestural enrichment in downward-monotonic environments, and thus it too must be transformed into a 'mixed theory' that follows the cosuppositional approach in such cases. Further variants are discussed in Appendix III.

One final remark is in order. As Amir Anvari (p.c.) points out, stronger and possibly more adequate predictions are regained within a vagueness-inspired account if we assume that a presupposition (evaluated with respect to the Context Set) is triggered to the effect that the statement is clearly true or clearly false - or in other words that all its resolutions have the same value. This modifies the situation for downward-monotonic environments, in particular. As Anvari notes, None of these 10 guys UP helped his son will now trigger a presupposition that None of these 10 guys helped his son has the same value as None of these 10 guys helped his son by lifting him, which boils down to a requirement (evaluated with respect to the Context Set) that if at least one of these 10 guys helped his son, then at least one helped his son by lifting him. ${ }^{38}$ While this is weaker than the universal inference of our cosuppositional account (= for each, if he helped his son, he did so by lifting him), this is not a trivial requirement either: in this modified supervaluationist analysis, the gesture isn't vacuous in downward-monotonic environments. We leave an assessment of this account for future research. ${ }^{39}$

\subsection{Gestures as Supplements?}

Pioneering ideas on gesture projection originated in work by Ebert and Ebert (2014). They argued that co-speech gestures have the same kind of semantic contribution of appositive relative clauses - they are thus 'supplements'. We submit that this analysis of co-speech gestures is in error, but that postspeech gestures indeed contribute supplements. The contrast between these two provides an important argument against Ebert and Ebert's analysis.

Importantly, there should be a clear temporal distinction between the relevant co-speech gestures and post-speech gestures; the latter should only start after the end of the production of the spoken expressions they modify. As we mentioned in Section 1.3 (and especially in fn. 10), there is a

${ }^{38}$ Formally, the statement [No g] Uh triggers the presupposition in (i)a, which boils down to (i)b - but the leftto-right direction is trivial, hence we should perceive' the presupposition: [Some $g$ ] $h=>$ [Some $g$ ] $(h \& u$ ).

$$
\begin{aligned}
& \text { a. } \mathrm{Cl}=[\mathrm{Nog}](\mathrm{h} \& \mathrm{u}) \Leftrightarrow \Rightarrow[\mathrm{Nog}] \mathrm{h} \\
& \text { b. } \mathrm{Cl}=[\text { Some } \mathrm{g}](\mathrm{h} \& \mathrm{u})<=>[\text { Some } \mathrm{g}] \mathrm{h}
\end{aligned}
$$

${ }^{39}$ Two preliminary remarks should be made, however.

1. It is not clear that the predicted presupposition is strong enough. Consider the case of a pendulum ride in an amusement park, with two gondolas at opposite ends of a swinging arm. Suppose the pendulum is stuck with the arm in vertical position, with 5 passengers in each gondola. The cosuppositional analysis predicts that (i)a could be uttered felicitously, but that (i)b couldn't be, since it is not the case that all passengers will move up if they move (since passengers from the top gondola would move down). But the modified vagueness-inspired analysis predicts that both statements should be felicitous; in particular, it is guaranteed that if any passenger moves, then some passengers will move up (namely those from the bottom gondola), and this should suffice to make (i)b acceptable.

(i) a. None of the 5 passengers in the bottom gondola are UP moving.

b. None of the 10 passengers are UP moving.

2. In cases such as Between 3 and 5 guys UP helped their son, we still derive the somewhat counterintuitive result that the sentence could be true in case exactly 5 guys helped their son, and exactly 3 guys helped their son by lifting him. 
rich literature on the alignment between gestures and speech, particularly in connection with intonation. But for our purposes the distinction between co- and post-speech gestures does not require such a fine-grained distinction: a co-speech gesture does not have its own time slot and co-occurs with the entire expression it modifies, as encoded in our notation; by contrast, a post-speech gesture has its own time slot and starts after the expression it modifies.

\subsubsection{Co-speech gestures as cosuppositions vs. Post-speech gestures as supplements}

Schlenker 2015a provides initial arguments against a supplemental analysis by focusing on negative environments in which supplements are degraded. But to understand the full typology, we need to consider a broader range of examples, with positive and negative environments, co-speech and postspeech gestures, as well as appositive relative clauses. Here we focus on size-denoting gestures that modify NPs, as these make a comparison with appositives particularly easy. It seems rather clear that the distribution of indicative appositive relative clauses does not mirror that of co-speech gestures, but rather that of post-speech gestures. It is of course important to pronounce the appositives as is appropriate for non-restrictive relative clauses; the relevant reading can be brought out by adding by the way right after the relativizer. ${ }^{40}$ Overall, and with a possible exception in (78), the acceptability of post-speech gestures tracks that of appositive relative clauses. ${ }^{41}$ Since at this point we are interested in the distribution of these expressions rather than in the inferences they give rise to, we omit the latter from the present discussion.

(73) a. Some/No philosopher brought LARGE [a bottle of beer].

b. Some/\#No philosopher brought a bottle of beer, which (by the way) was LARGE this large.

c. Some/\#No philosopher brought a bottle of beer - LARGE.

(74) a. It's likely/It's unlikely that the previous speaker brought LARGE [a bottle of beer] to his talk.

b. It's likely/\#It's unlikely that the previous speaker brought a bottle of beer, which (by the way) was

LARGE this large. ${ }^{42}$

c. It's likely/\# It's unlikely that the previous speaker brought a bottle of beer - LARGE.

(75) a. One/None of these 10 guys UP helped his son.

b. One/\#None of these 10 guys helped his son, which (by the way) he did by lifting him.

c. One/\#None of these 10 guys helped his son - UP.

(76) a. It's likely/It's unlikely that John UP helped his son.

b. It's likely/\#It's unlikely that John helped his son, which (by the way) he did by lifting him.

c. It's likely/\#It's unlikely that John helped his son - UP.

(77) a. One/None of these 10 guys SLAP punished his son.

b. One/\#None of these 10 guys punished his son, which (by the way) he did by slapping him.

c. One/\#None of these 10 guys punished his son - SLAP.

(78) a. It's likely/It's unlikely that John SLAP punished his son.

b. It's likely/\#It's unlikely that John punished his son, which (by the way) he did by slapping him

c. It's likely/(?) It's unlikely that John punished his son - SLAP.

As mentioned in Schlenker 2015a, a supplemental approach could deal with(73)a-(74)a by taking the gestures to behave like the appositives in(73)b-(74)b, but with which would be replacing which is. On the assumption that the resulting sentence is more acceptable, one would still need to ask why such an option should be available. But the crucial problem is that this approach does not explain why such a strategy fails to be available in the case of post-speech gestures (we come back below to a potential explanation). A more natural account is afforded by positing that post-speech gestures are supplements and that they cannot involve a covert counterfactual mood.

\footnotetext{
40 Thanks to Miloje Despić for making this suggestion.

${ }^{41}$ See however Tieu et al. to appear for other examples in which appositives display a behavior that is closer to that of co-speech gestures.

${ }^{42}$ Note that here and in the other b-examples one might expect a slight pragmatic oddity with likely because this expression implicates that it is not established that the relevant event took place, whereas the which-clause presupposes its existence. But in any event the version of the sentence with unlikely seems far worse.
} 
We note for completeness that related contrasts can be obtained on the basis of facial expressions. (79)a is an example we already discussed to highlight the presuppositional effect of facial expressions co-occurring with a predicate under the quantifier no. In (79)b, the same facial expression is post-posed. We believe this yields several readings, which can be paraphrased with different supplements, depending on the size of the constituent that the post-speech gesture modifies.

(79) a. None of my friends goes :-( [skiing with his parents].

$\Rightarrow$ for each of my friends, skiing with his parents wouldn't be fun

b. None of my friends goes skiing with his parents - :-(.

c. None of my friends goes skiing with his parents,

(i) which is sad [i.e. it is sad that none of my friends goes skiing with his parents];

(ii) which is unpleasant [i.e. it is generally unpleasant to go skiing with one's parents].

\subsubsection{Alternative analyses of post-speech gestures}

At this point, our discussion shows that a distinction must be posited between co-speech and postspeech gestures, and that the latter can be analyzed within a supplemental account. But alternative theories could be explored. In particular, one could grant that post-speech gestures share with appositive relative clauses the property of containing an anaphoric element that must be resolved (in standard appositive relative clauses, this anaphoric element is the relative pronoun, which has been argued to display the semantics of an E-type element, e.g. in Del Gobbo 2003). But from this assumption it need not follow that post-speech gestures have the semantics of supplements. One could argue instead (i) that they make an at-issue contribution; or (ii) that they have a cosuppositional semantics. We discuss each theory in turn.

\section{- An at-issue semantics for post-speech gestures?}

First, could post-posed gestures have an at-issue semantics? $?^{43}$ If so, they should be able to take scope under operators. The deviance of the negative version of the c-examples in (73)-(77) already suggests that under the negative quantifier No NP this is impossible. But one could argue that the post-speech gesture is in this case attached 'too high' to be in the scope of the quantifier, possibly because it can only be conjoined with full-fledged clauses. This, however, would fail to account for the cases of embedding under unlikely. Similarly, to the extent that (80)a is interpretable, it seems to us that it differs sharply from the controls with at-issue modifiers in (80)b-c: the latter are interpreted in the scope of deny, but the post-speech gesture SLAP isn't.

(80) a. ?? I deny that John punished his son - SLAP.

b. I deny that John punished his son (and [that he] did so) like SLAP this.

c. I deny that John punished his son (and [that he] did so) by slapping him.

Similar remarks apply to (81)a: to the extent that it is acceptable, it seems to us to assume that punishment would involve slapping - unlike the at-issue controls in (81)b-c. It isn't entirely clear what an at-issue analysis of co-speech gestures should say about this case: even conjoining the postspeech gesture with the matrix clause might be problematic, because the matrix clause is interrogative while the post-speech gesture makes a positive contribution; so one might have to say that the postspeech gestures constitutes a separate clause in discourse.

(81) a.?(?) Do you think that John punished his son - SLAP?

b. Do you think that John punished his son (and [that he] did so) like SLAP this?

c. Do you think that John punished his son (and [that he] did so) by slapping him?

An at-issue semantics for post-speech gestures would need to posit that they somehow cannot take scope under operators. This could be done by positing that they are connected to their antecedent by an anaphoric device that strongly favors matrix resolution; why this should be so is currently unclear. In addition, it is not clear that this 'matrix only' requirement would account for the data in (82): it seems to us that a post-speech gesture in the antecedent of a conditional, as in (82)a, yields the same kinds of inferences as an appositive or parenthetical attached to the antecedent, as in (82)c,d

\footnotetext{
${ }^{43}$ Thanks to Cornelia Ebert (p.c.) and to an anonymous reviewer for suggesting that we discuss this possibility.
} 
(which sharply differ in their meaning from (82)b, which involves an at-issue modifier). By contrast, a post-speech gesture following the entire sentence, as in (82)e, does not seem to us to yield a very coherent reading - or possibly one on which the speaker's scream would be accompanied by a slapping. But if matrix attachment is the only possibility for post-speech gestures, it is hard to see how the contrast between (82)a and (82)e can be derived. ${ }^{44}$

(82) a. If John punishes his son - SLAP, I might scream.

$\Rightarrow>$ if John punishes his son, slapping will be involved

b. If John punishes his son by slapping him, I might scream.

$\neq>$ if John punishes his son, slapping will be involved

c. If John punishes his son, which will/would involve some slapping, I might scream.

$=>$ if John punishes his son, slapping will be involved

d. If John punishes his son (this would involve some slapping), I might scream.

$=>$ if John punishes his son, slapping will be involved

e. <??> If John punishes his son, I might scream - SLAP.

On the other hand, it is striking that the post-speech gestures in (73)-(77) have the same distribution as appositive relative clauses in the indicative mood. This led Schlenker 2015a to propose that post-speech gestures are supplements and thus display the same type of behavior as appositive relative clauses.

Still, it should be noted that full parentheticals also display a non-at-issue behavior, and hence a variant of the present theory could treat post-speech gestures as parentheticals. For instance, (73)b, repeated as (83)b, displays the same behavior as (83)a, which involves a clausal parenthetical in lieu of an appositive relative clause. The point generalizes across examples and thus at this point it cannot be excluded that post-speech gestures are parentheticals.

(83) a. Some/\#No philosopher brought a bottle of beer (it was LARGE this large).

b. Some/\#No philosopher brought a bottle of beer, which (by the way) was LARGE this large.

Although the data would need to be investigated much more thoroughly (and possibly with experimental means), we take them to suggest that post-posed gestures do not have an at-issue semantics. We leave it for future research to distinguish between an appositive and parenthetical treatment of post-speech gestures.

\section{- A cosuppositional semantics for post-speech gestures (Krifka, p.c.; Pasternak, p.c.)}

An alternative was suggested by Manfred Krifka (p.c.), and independently by Rob Pasternak (p.c.). Krifka's proposal is that post-speech gestures have a cosuppositional semantics, but come with an anaphoric element that must be resolved - hence the deviance of the negative version of the cexamples in (73)-(77). The behavior of (82)a can now be explained in terms of properties of presupposition projection. In this case, we can take the post-speech gesture SLAP to take a covert anaphoric argument denoting a property of events. We can take its denotation to be resolved in the same way as that of the pronoun this in $(82) \mathrm{d}$, which certainly makes reference to punishments satisfying the antecedent of the conditional. The cosupposition will then yield the inference that such events involve slapping, as is desired.

Without fully implementing the proposal, it could be made more concrete along the lines of

${ }^{44}$ The epistemic status of post-speech gestures should be investigated in future research. On an at-issue theory of post-speech gestures, one would expect that these can be targeted by negation in discourse, as in (i)a - which thus might not contrast in this respect with (i)b. On a non-at-issue theory, one might expect a contrast between (i)a and (i)b, as negation should have a harder time targeting the non-at-issue gesture in (i)a than the at-issue modifier in (i)b.

$$
\begin{aligned}
& \text { a. A: John punished his son - SLAP. B: No! } \\
& \text { b. A: John punished his son by slapping him. B: No! }
\end{aligned}
$$

The issue is complex, however, because Koev 2012 argued that clause-final appositives can have an at-issue status. Thus clause-medial post-speech gestures should be investigated to address the present point. 
(84) Cosuppositional analysis of post-speech gestures and facial expressions (informal statement)

a. A post-speech gesture or facial expression $G$ takes a null anaphoric expression, hence has the form:

G pro $_{i}$.

b. It yields a semantic failure unless, relative to the local context of $G$ pro $_{i}$, pro $_{i}$ has the appropriate type and entails the (bivalent) content of $G$ ('generalized entailment' must be used if these expressions are not of propositional type).

c. If it does not yield a failure as in b., $G$ pro $_{i}$ makes a trivial (tautologous) contribution: it has a purely cosuppositional meaning.

As an example, consider again the example in (34)c, repeated in (85).

(85) None of my friends goes skiing with his parents - :-(_)

There are at least two conceivable ways to resolve the anaphoric element pro $_{i}$ introduced by the postspeech gesture (on the assumption that the disgusted facial expression is of ambiguous type, and can thus modify a propositional or a predicative meaning).

- If $\mathrm{pro}_{i}$ is a proposition-denoting pronoun, it is natural to take it to be coindexed with the entire proposition that none of my friends goes skiing with his parents. This should yield a cosupposition to the effect that this fact is disgusting - hence it would be good for my friends to go skiing with their parents.

- If $\mathrm{pro}_{i}$ is a property-denoting pronoun, it is natural to take it to refer to the property of going skiing with one's parents. There is a technical issue involved at this point: one must determine (i) what the local context of the post-speech gesture is, and (ii) what it means for the property of going skiing with one's parents to entail disgust. We leave this issue open at this point, but it is plausible that the local context of the post-speech gesture is the initial context, updated with the propositional content of the main sentence. If so, we will get the result that the Context Set updated with the asserted sentence entails that skiing with one's parents in general should be disgusting (an alternative would be that it is only the case that for each of my friends $\mathrm{x}$, x's skiing with x's parents is disgusting; it isn't quite clear to us how this could be derived).

To the extent that (85) is ambiguous, the cosuppositional analysis of post-speech gestures could be maintained. But it encounters difficulties in several cases. In a nutshell, the problem is that post-speech gestures have a more restricted distribution than one might expect on a cosuppositional analysis.

(i) Our initial argument against Ebert and Ebert's (2014) supplement-based analysis of co-speech gestures was that these are less constrained than appositive relative clauses. But as we saw in Section 4.2.1, post-speech gestures are constrained in exactly this way. The cosuppositional analysis of postspeech gestures would have to posit that the antecedent of the covert pronoun is constrained to be propositional in nature. However this measure won't be enough for examples (74) and (76) above, where a full clause is embedded under it is unlikely/it is likely that, but can apparently not be targeted by the post-speech gesture. Thus one would need to posit a general preference for resolving the null pronoun to a matrix proposition. We leave such explorations for future research.

(ii) In order to compare this cosuppositional analysis of post-speech gestures with the supplemental analysis, we would need to be more precise about the semantics and pragmatics of supplements. Some analysts take them, following Potts 2005 , to be radically different from presupposition triggers in that supplements fail to interact scopally with logical operators. By contrast, Schlenker 2010c, 2013 takes supplements to give rise to bona fide projection phenomena reminiscent of presuppositions, but with one important proviso: syntactically, appositive relative clauses tend to attach high, with the result that it is only in the rare cases in which they are in the scope of logical operators that genuine supplement projection can be observed. Due to this potential similarity between supplement 
projection and presupposition projection, more research would be needed to compare the cosuppositional and the supplemental analysis of post-speech gestures. ${ }^{45}$

Still, it should be mentioned that one further property distinguishes presuppositions from supplements: as emphasized by Potts 2005, the latter but not the former come with a requirement that they should be non-trivial, as shown by $(86) .^{46}$

(86) Lance Armstrong survived cancer. \#When reporters interview Lance, a cancer survivor / who survived cancer, he often talks about the disease. (after Potts 2005)

In that respect, post-speech gestures appear to pattern with supplements rather than with presuppositions. Consider (87)a, which has a post-speech gesture following a modifier, namely like SLAP this, which already provides the same information. Our impression is that if the two gestures are realized identically, the result is rather sharply deviant.

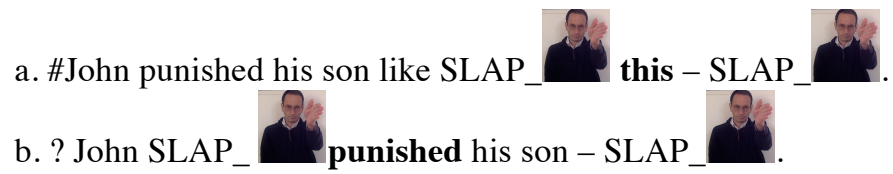

Facts are more subtle in (87)b, where the first occurrence of SLAP contributes cosuppositional rather than at-issue information. Our impression is that the post-speech gesture can be made acceptable if it is realized differently from the first gesture - in which case the first occurrence seems to us to make clear that the punishment was a slapping, whereas the post-speech gesture more concretely demonstrates how the slapping was realized. If so, we will of course have to refine our understanding of the precise contribution of co- and post-speech gestures (in order to understand why the postspeech gesture has a more precise demonstrative contribution), but our point will remain that postspeech gestures obey a version of Potts's non-triviality condition. This would go against a cosuppositional analysis of post-speech gestures, since cosuppositions are a species of presuppositions, and thus should not be subject to a non-triviality condition.

Still, this argument wouldn't be complete without an assessment of the non-triviality condition for $c o$-speech gestures. As it stands, our cosuppositional theory predicts that in this case violations of non-triviality could be acceptable. But judgments on (88)a do not bear this out, or at least not clearly: speakers we have consulted find the version with two occurrences of the same cospeech gesture redundant. The relevant point of comparison is $(88) \mathrm{b}$, which is predicted to be deviant because the appositive contributes no information; in this case the prediction seems to be correct. ${ }^{47}$

(88) Yesterday John bought (i) LARGE_L [a bottle of beer]. / (ii) a bottle of beer, which was LARGE_ this large. I thought he'd drink it over dinner last night. But this morning, he brought

a. (\#) LARGE_ [his bottle of beer] to the workshop!

b. (\#) his bottle of beer, which was LARGE_this large, to the workshop!

More detailed work would be needed to compare judgments on (88)a and on (88)b. But we should be open to the possibility that some non-redundancy condition should in the end be added to the analysis of gestural cosuppositions - which would at a minimum require a refinement of the present theory. ${ }^{48}$

\footnotetext{
${ }^{45}$ The availability of such 'low scope' readings with post-speech gestures remains to be investigated. A closer analysis of examples such as (82)a would be of direct relevance. In this connection, Pasternak (p.c.) suggests that this example might have a 'locally accommodated' reading, which could be explained if the post-posed gesture triggers a (weak) cosupposition. An alternative is that this is in fact a supplement with a low reading.

${ }^{46}$ An anonymous referee suggests that presupposition are a heterogeneous class and could thus differ along this dimension, with some having a non-triviality requirement; see fn. 48 for relevant remarks.

${ }^{47} \mathrm{~J}$. Kuhn (p.c.) notes that if one uses an insistent intonation that makes it clear that the repetition is intentional, the sentence becomes acceptable.

${ }^{48}$ An interesting point of comparison can be found in 'redundant' modifiers in the scope of a definite description, as in (i)a and (i)c:
} 


\section{Conclusion}

We have suggested that a very simple analysis can account for complex patterns of 'gesture projection'. There were two parts to our proposal. Our main hypothesis was that the content of a cospeech gesture should be entailed by the 'contextual meaning' of the expression it modifies - in effect, the intuition was that a co-speech gesture serves to illustrate (and thus to make more precise) the meaning of the expression if modifies. The second part consisted in a completely standard explication of 'contextual meaning' as the meaning that an expression has relative to its local context, as defined in dynamic semantics (Heim 1983) or in reconstructions of it (Schlenker 2009). Putting both parts together, we arrived at a cosuppositional analysis in which the content of a co-speech gesture is presupposed to follow from the content of the expression it modifies, and interacts with the logical structure of a sentence by way of local context computation. ${ }^{49}$ We saw that these cosuppositions are often easy to accommodate locally as well as globally, which of course raises the question why this should be so - a problem we leave for future research. In addition, it will be essential in the future to explain under what conditions local accommodation applies; a sophisticated theory is developed in Esipova 2016a, b.

We argued against a supervaluationist alternative to our analysis, although we do not claim to have exhausted the space of possible supervaluationist theories; and a supervaluationist analysis could be combined with our main theory to yield a sophisticated but conceptually odd account. On the other hand, we did not so much refute the supplemental analysis of Ebert and Ebert 2014 as displace it: we argued that it is not correct for co-speech gestures, but might well capture essential properties of postspeech gestures (as noted, there is also a 'parenthetical' variant of the supplemental analysis). If this typology is on the right track, one should of course ask how the same primitive objects - speechaccompanying gestures - can have a cosuppositional behavior in some cases and a supplemental (or parenthetical) behavior in others. Thus the analysis of gestures leads to new questions about some foundational issues in semantics - in particular about the connection between presuppositions and supplements. ${ }^{50}$
a. ??John's blond father has arrived
b. John's blond brother has arrived.
c. John's idiotic father has arrived. (Schlenker 2005)

Like co-speech gestures on the cosuppositional analysis, these redundant modifiers make a purely presuppositional contribution at the clausal level, and they can be removed without affecting the grammaticality of the relevant clause. They arguably come with a requirement that they should be non-trivial, or at least remind the addressee of relevant information (see Schlenker 2005, 2007a for further data, and for a mechanism that guarantees that the relevant presuppositions end up being informative; see also Leffel 2014 for a discussion of related examples). When this is not the case, as in (i)a, these modifiers are deviant. These facts could be used to argue on Gricean grounds that separable elements that make a purely presuppositional contribution should still be informative in some way (or else they would violate a maxim of brevity). But the issue is complex, since anaphoric presupposition triggers such as too and again would also seem to make a purely presuppositional contribution, and yet they do not come with a non-triviality requirement. Furthermore, a principled analysis will have to be embedded in a theory of alternatives and implicatures which takes into account presuppositions - not a trivial matter (but see Katzir 2007).

49 See Schlenker 2015 c for an alternative derivation of the formal behavior of cosuppositions within the 'Transparency Theory' developed in Schlenker 2008a. This alternative leads one to expect that non-gestural expressions could also trigger cosuppositions, a prediction that has yet to be appropriately tested.

${ }^{50}$ This dual behavior is surprising if presuppositions and supplements are entirely distinct semantic phenomena. On the other hand, it is less surprising if presuppositions and supplements have a common core, as argued in Schlenker 2010b, 2013. In that framework, presuppositions must be trivial or 'transparent' in their local context (as is also the case in dynamic semantics). Supplements should not be trivial (as emphasized by Potts 2005), but they should be 'translucent', in the sense that it should be easy to add to the context of the conversation uncontroversial assumptions that would make them trivial in their local context. The underlying intuition is that material that is 'syntactically parasitic' should also be 'semantically parasitic'. An appositive is syntactically parasitic on the rest of the sentence because it is attached into fully-formed syntactic constituents, and could be omitted without leading to ill-formedness. It is also semantically parasitic, in the sense that its informational 
Finally, the analysis of the semantics of co-speech gestures matters for a broader debate about the expressive power of spoken and sign language. Due to the presence of a rich iconic component at the logical core of sign language, some researchers have argued that the latter is in some respects more expressive than spoken language (e.g. Schlenker et al. 2013, Schlenker to appear c). Others have countered that both sign and spoken language have a gestural component, and that some instances of iconicity in sign language should really be compared to co-speech gestures in sign language (Davidson 2015; Goldin-Meadow and Brentari 2015). The present piece indirectly contributes to this debate by sharpening our understanding of the 'co-speech gesture' side of the comparison - and by suggesting that co-speech gestures often have a presuppositional/cosuppositional status. Importantly, although the iconic effects in sign language discussed in Schlenker et al. 2013 were presuppositional in nature, many others are at-issue (Schlenker 2016, to appear c).

Schlenker, 2016, to appear $\mathrm{b}$ tentatively proposes that there is a principled reason for this difference. Briefly, the idea is that an iconic enrichment of an expression that comes from a different sign (= external enrichment) always starts out as non-at-issue, whereas an iconic enrichment of an expression obtained by modulating that very expression (=internal enrichment) can have any status. Many iconic effects in sign language are internal, as it is easy to modulate signs in rich iconic ways; they may thus be at-issue. But by their very nature, co- and post-speech gestures always yield external enrichments, and thus one might expect that they are never at-issue. A systematic comparative investigation would be needed to confirm or refute this potential generalization.

In sum, we hope to have shown (following Ebert and Ebert's (2014) lead) that gesture projection offers a fertile ground for formal semantics and pragmatics, with a non-trivial interaction between gestural enrichments and logical operators, and an interesting role played by timing considerations. On a theoretical level, the cosuppositional analysis of co-speech gestures and the supplemental analysis of post-speech gestures further enriches the typology of 'projective content' (see Tonhauser et al. 2013) - and highlights the need for theoretical attempts to derive it on principled grounds. Besides its intrinsic interest for semantics and pragmatics, gesture projection also has an important role to play in the comparison between the expressive possibilities of spoken and sign languages. On an empirical level, the data we explored could fruitfully be investigated with experimental means in the future - especially in cases that are unclear or controversial. In addition, it is likely that the typology of projective behaviors we sketched in this piece will be refined and enriched in the future, especially when further types of gestural enrichments are taken into account.

contribution is less important than that of the rest of the sentence. Still, an appositive occupies a dedicated time slot, and for this reason it should not make an entirely trivial contribution, or else considerations of brevity should exclude it; this explains the non-triviality requirement on supplements.

These ideas could be extended to the analysis of gestural enrichments (see Schlenker 2016). Co-speech gestures are syntactically parasitic on the expressions they modify, since they come from a different modality and could thus be omitted without yielding ill-formedness. Furthermore, nothing in their timing requires that they should be non-trivial since they do not occupy a separate time slot. Post-speech gestures are also syntactically parasitic, but unlike co-speech gestures they have their own time slot and thus should obey a nontriviality requirement, just like appositives. (Of course the analysis would have to change somewhat if there is in the end some kind of non-triviality requirement on cosuppositions, as mentioned at the end of Section 4.2.2. In addition, as noted in fn. 48, anaphoric triggers such as too and again have their own time slot but do not come with a requirement of non-triviality, which complicates the picture.) 


\section{Appendix I. Local Contexts (Schlenker 2009, 2010)}

\section{Fragment}

The reconstruction of local contexts proposed in Schlenker 2009, 2010a is defined for a fragment that includes propositional connectives, unary predicates and generalized quantifiers. (We write $\mathbf{F}^{\mathrm{w}}$ for the semantic value of an expression $F$ evaluated at world w. We put between angle brackets $<>$ optional material.)

(89) Syntax



(90) Classical Semantics

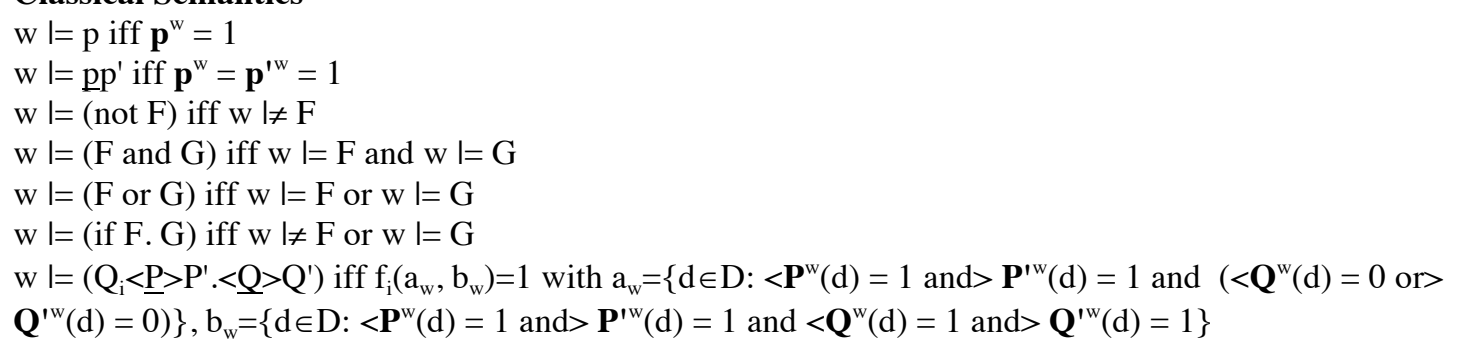

The following dynamic semantics corresponds to Heim's analysis (Heim 1983), except that (i) it applies to all generalized quantifiers, (ii) it does not include variables, (iii) it applies to disjunction, which Heim does not discuss (here we follow Beaver 2001).

(91) Dynamic Semantics

$\mathrm{C}[\mathrm{p}]=\left\{\mathrm{w} \in \mathrm{C}: \mathbf{p}^{\mathrm{w}}=1\right\}$

$\mathrm{C}\left[\mathrm{pp}^{\prime}\right]=\#$ iff for some $\mathrm{w} \in \mathrm{C}, \mathbf{p}^{\mathrm{w}}=0$; if $\neq \#, \mathrm{C}\left[\mathrm{pp}^{\prime}\right]=\left\{\mathrm{w} \in \mathrm{C}: \mathbf{p}^{\prime \mathrm{w}}=1\right\}$

$\mathrm{C}[(\operatorname{not} \mathrm{F})]=\#$ iff $\mathrm{C}[\mathrm{F}]=\# ;$ if $\neq \#, \mathrm{C}[(\operatorname{not} \mathrm{F})]=\mathrm{C}-\mathrm{C}[\mathrm{F}]$

$\mathrm{C}[(\mathrm{F}$ and $\mathrm{G})]=\#$ iff $\mathrm{C}[\mathrm{F}]=\#$ or $(\mathrm{C}[\mathrm{F}] \neq \#$ and $\mathrm{C}[\mathrm{F}][\mathrm{G}]=\#)$; if $\neq \#, \mathrm{C}[(\mathrm{F}$ and $\mathrm{G})]=\mathrm{C}[\mathrm{F}][\mathrm{G}]$

$\mathrm{C}[(\mathrm{F}$ or $\mathrm{G})]=\#$ iff $\mathrm{C}[\mathrm{F}]=\#$ or $(\mathrm{C}[\mathrm{F}] \neq \#$ and $\mathrm{C}[$ not $\mathrm{F}][\mathrm{G}]=\#) ;$ if $\neq \#, \mathrm{C}[(\mathrm{F}$ or $\mathrm{G})]=\mathrm{C}[\mathrm{F}] \cup \mathrm{C}[\operatorname{not} \mathrm{F}][\mathrm{G}]$

$\mathrm{C}[($ if $\mathrm{F} . \mathrm{G})]=\#$ iff $\mathrm{C}[\mathrm{F}]=\#$ or $(\mathrm{C}[\mathrm{F}] \neq \#$ and $\mathrm{C}[\mathrm{F}][\mathrm{G}]=\#)$; if $\neq \#, \mathrm{C}[($ if F.G $)]=\mathrm{C}-\mathrm{C}[\mathrm{F}][$ not $\mathrm{G}]$

$\mathrm{C}\left[\left(\mathrm{Q}_{\mathrm{i}}<\underline{\mathrm{P}}>\mathrm{P}^{\prime},<\underline{\mathrm{R}}>\mathrm{R}^{\prime}\right)\right]=\#$ iff $<$ for some $\mathrm{w} \in \mathrm{C}$, for some $\mathrm{d} \in \mathrm{D}, \mathbf{P}^{\mathrm{w}}(\mathrm{d})=0>$ or $<$ for some $\mathrm{w} \in \mathrm{C}$, for some $\mathrm{d} \in \mathrm{D},\left\langle\mathbf{P}^{\mathrm{w}}(\mathrm{d})=1\right.$ and $>\mathbf{P}^{\mathrm{w}}(\mathrm{d})=1$ and $\mathbf{R}^{\mathrm{w}}(\mathrm{d})=0>$. If $\neq \#, \mathrm{C}\left[\left(\mathrm{Q}_{\mathrm{i}}<\mathrm{P}>\mathrm{P}^{\prime} .<\mathrm{R}>\mathrm{R}^{\prime}\right]\right)=\left\{\mathrm{w} \in \mathrm{C}: \mathrm{f}_{\mathrm{i}}\left(\mathrm{a}^{\mathrm{w}}, \mathrm{b}^{\mathrm{w}}\right)=1\right\}$ with $\mathrm{a}^{\mathrm{w}}=\left\{\mathrm{d} \in \mathrm{D}: \mathbf{P}^{\mathrm{w}}(\mathrm{d})=1\right.$ and $\left.\mathbf{R}^{\mathrm{w}}(\mathrm{d})=0\right\}, \mathrm{b}^{\mathrm{w}}=\left\{\mathrm{d} \in \mathrm{D}: \mathbf{P}^{\prime \mathrm{w}}(\mathrm{d})=1\right.$ and $\left.\mathbf{R}^{\prime \mathrm{w}}(\mathrm{d})=1\right\}$

- Local contexts and presupposition satisfaction

Local contexts are then defined as follows for the fragment in (89) with the classical semantics in(90):

(92) Local Contexts

The local context of an expression $d$ of propositional or predicative type which occurs in a syntactic environment $a_{-} b$ in a context $\mathrm{C}$ is the strongest proposition or property $\mathrm{x}$ which guarantees that for any expression $d^{\prime}$ of the same type as $d$, for all strings $b^{\prime}$ for which $a d^{\prime} b^{\prime}$ is a well-formed sentence,

$C \models^{c^{\prime} \rightarrow x} \quad a\left(c^{\prime}\right.$ and $\left.d^{\prime}\right) b^{\prime} \Leftrightarrow a d^{\prime} b^{\prime}$

(If no strongest proposition or property x with the desired characteristics exists, the local context of $d$ does not exist ${ }^{52}$.

Presupposition satisfaction is then defined by reference to local contexts:

${ }^{51}$ This Appendix borrows from Schlenker 2009 and Schlenker 2010a (especially Section 2.4. of Schlenker 2009).

${ }^{52}$ See Schlenker 2009 for a discussion of the case in which local contexts do not exist. 
(93) Presupposition Satisfaction

An elementary presuppositional expression $E$ is acceptable in a sentence $S$ uttered in a context $\mathrm{C}$ just in case the presupposition of $E$ is entailed by the local context of $E$ (if it exists).

\section{- Relation to dynamic semantics}

Schlenker 2009 proves some general results about the relation between this reconstruction of local contexts and a Heimian dynamic semantics in which generalized quantifiers trigger universal presuppositions (see Schlenker 2009 Section 2.4. and Appendix A; these, in turn, build on technical results of Schlenker 2007b).

In the propositional case, we obtain full equivalence with the system outlined in Heim 1983, enriched with the asymmetric dynamic disjunction of Beaver 2001. Specifically, it can be shown that for any propositional formula $F$ and for any Context Set $\mathrm{C}$, the local contexts as we have defined them always exist. Furthermore, if we write as $\mathrm{C}[\mathrm{F}]$ the Heimian update of $\mathrm{C}$ with $F, \mathrm{C}[\mathrm{F}] \neq \#$ just in case for each presupposition trigger of the form $\underline{d} d^{\prime}$ that occurs in $F, d$ is entailed by its local context as reconstructed here (we write this as $\operatorname{Sat}(C, F) ; l c\left(C, \underline{d} d^{\prime}, a \_b\right)$ refers to the local context of $\underline{d} d^{\prime}$ 'in the sentence $a \underline{d} d^{\prime} b$, as obtained by (92)). This result is summarized in (94).

(94) Let $\mathrm{C} \subseteq \mathrm{W}$ be a context set and let $F$ be a propositional formula. Then:

(i) for all expressions $a, b, \underline{d} d^{\prime}$, if $\mathrm{F}=\mathrm{a} \underline{\mathrm{dd}} \mathrm{d}^{\prime} \mathrm{b}, \mathrm{lc}\left(\mathrm{C}, \underline{\mathrm{dd}} \mathbf{d}^{\prime}, \mathrm{a} \_\mathrm{b}\right) \neq \#$. Furthermore,

(ii) $\operatorname{Sat}(\mathrm{C}, \mathrm{F})$ iff $\mathrm{C}[\mathrm{F}] \neq \#$.

In the quantificational case, things are more complicated. In a nutshell, when all the relevant local contexts exist, (94) also holds for all generalized quantifiers that can be defined by way of the 'tree of numbers', but only when two technical conditions are met:

-Non-Triviality: quantificational clauses should not be 'trivial', i.e. replaceable with a tautology or a contradiction - as stated in (95).

(95) Non-Triviality

Let $\mathrm{C}$ be a Context Set and let $F$ be a formula. $<\mathrm{C}, \mathrm{F}>$ satisfies Non-Triviality just in case for any initial string of the form $\alpha A$, where $A$ is a quantificational clause (i.e. a formula of the form $\left(Q_{i} G . H\right)$ ), there is a sentence completion $\beta$ such that:

$\mathrm{C} \mid \neq \alpha \mathrm{A} \beta \Leftrightarrow \alpha \mathrm{T} \beta$

$\mathrm{C} \mid \neq \alpha \mathrm{A} \beta \Leftrightarrow \alpha \mathrm{F} \beta$

where $T$ is a tautology and $F$ is a contradiction.

-Constancy: the domain of individuals should be finite, and in addition restrictors should hold true of a constant number of individuals throughout the context set, as is stated in (96).

(96) Constancy

Let $\mathrm{C}$ be a Context Set and let $F$ be a formula. $<\mathrm{C}, \mathrm{F}>$ satisfies Constancy if each restrictor that appears in $F$ holds of the same number of individuals throughout the worlds of $\mathrm{C}$ (in other words, the size of its extension is constant throughout $\mathrm{C}$ ).

(In case local contexts fail to exist, a modified version of the approach of Schlenker 2009 guarantees full equivalence with Heim's result when Non-Triviality and Constancy are satisfied; see C.19 in Appendix C of Schlenker 2009.)

Note that an extension of the theory was countenanced to compute the local context of expressions embedded under attitude reports, as is discussed in Appendix II.

\section{- Two versions of cosuppositions}

In (46), we explained that (a) in a Heimian dynamic semantics ... [e $e>g] e \ldots$ and $\ldots[e \& g] \ldots$ generate the same presuppositions, and (b) the result extends to the propositional version of the system of Schlenker 2009 due to the presuppositional equivalence with a Heimian dynamic semantics (as in the main text, we use $\&$ to abbreviate and). In the quantificational case, the fragment in (89) does not make it possible to define expressions $[a \& \underline{e}]$ when $a$ or $e$ are predicative expressions or contain variables (since this fragment has no variables, and also has no complex predicates).

Still, one can ask what would happen if we extended the framework of Schlenker 2009 to this more complex case. Rather than doing things in two steps by computing a local context and checking that it satisfies a presupposition, we will use the near-equivalent formulation of the 'Transparency 
Theory' of Schlenker 2008a (the two formulations are equivalent within the fragment defined in Appendix I ${ }^{53}$ when local contexts exist; see Schlenker 2009, Appendix C, C. 21).

(97) Principle of Transparency (after Schlenker 2007b, 2008a)

A predicative or propositional presupposition trigger $\underline{d} d^{*}$ which occurs in a syntactic environment $a_{-} b$ is infelicitous unless for every $d^{\prime}$ ' of the same type as $d$, for every string $b^{\prime}$ for which $a d^{\prime} b^{\prime}$ is a wellformed sentence,

$C \vDash a\left(d \& d^{\prime}\right) b^{\prime} \Leftrightarrow a d^{\prime} b^{\prime}$

We show that in extensions of the fragment of Schlenker 2007b, 2008a, 2009 which countenance complex predicates, (i) if the sentence $a \underline{(e \Rightarrow g)} e^{*} b$ satisfies (97) (with non-presuppositional $a$ and $b)$, then this is also the case of the sentence $a(e \& g) b$, but (ii) in general the converse does not hold, even when Non-Trivality and Constancy are satisfied.

(i) Let us prove the first result.

(98) If $a(e \Rightarrow g) e^{*} b$ satisfies (97) (with non-presuppositional $a$ and $b$ ), then this is also the case of the sentence $a(e \& g) b$

Proof: By assumption, for each $c^{\prime}$ of the same type as $g$ (as well as $e$ and $e^{*}$ ), for each acceptable sentence completion $b^{\prime}$, the following holds:

(99) $\mathrm{Cl}=\mathrm{a}\left((\mathrm{e} \Rightarrow \mathrm{g}) \& \mathrm{c}^{\prime}\right) \mathrm{b}^{\prime} \Leftrightarrow \mathrm{a} \mathrm{c}^{\prime} \mathrm{b}^{\prime}$

Now for every $c^{\prime \prime}$ of the same type as $g$, take $c^{\prime}=\left(e \& c^{\prime \prime}\right)$ and derive from (98) that for each acceptable sentence completion $b$,

$\mathrm{Cl}=\mathrm{a}\left((\mathrm{e} \Rightarrow \mathrm{g}) \&\left(\mathrm{e} \& \mathrm{c}^{\prime \prime}\right)\right) \mathrm{b}^{\prime} \Leftrightarrow \mathrm{a}\left(\mathrm{e} \& \mathrm{c}^{\prime \prime}\right) \mathrm{b}^{\prime}$, hence

$\mathrm{Cl}=\mathrm{a}\left(\mathrm{e} \&\left(\mathrm{~g} \& \mathrm{c}^{\prime \prime}\right)\right) \mathrm{b}^{\prime} \Leftrightarrow \mathrm{a}\left(\mathrm{e} \& \mathrm{c}^{\prime \prime}\right) \mathrm{b}^{\prime}$

This shows that $a(e \& g) b$ satisfies (97).

(ii) Let us turn to the second result.

(100) In general, the converse of (98) does not hold, even under the hypotheses of Non-Triviality and Constancy: there are cases in which $a(e \& g) b$ satisfies (97) but $a(e \Rightarrow g) e^{*} b$ does not.

Counterexample: Consider the sentence $(Q T$. $(e \& g))$, where $Q$ is a generalized quantifier meaning at most $k$, with $\mathrm{k} \geq 1$, and $T$ is a tautological predicate (so that $Q T$ means at most $k$ objects). To simplify notations, boldfaced expressions refer to the semantic values of these expressions.

(101) Partial specification of a model
a. Worlds: $\left\{w, w^{\prime}\right\}$
b. Domain of objects: $\mathrm{D}$, with $\mathrm{k}+1 \leq|\mathrm{D}| \leq 2 \mathrm{k}$
b. $|\mathbf{e}(\mathrm{w})|=\mathrm{k}$
c. $\left|\mathbf{e}\left(\mathrm{w}^{\prime}\right)\right|=0$

(97) applied to $(Q T$. $(e \& g))$ is given in (102), which is trivially true: both sides of the equivalence are true because both complex predicates hold of at most k objects, thus satisfying $Q T$.

(102) For al $c^{\prime}$ of the same type as $e, \mathrm{C}=\left(\mathrm{Q}\right.$ T. (e \& ( $\left.\left.\left.\& \& \mathrm{c}^{\prime}\right)\right)\right) \Leftrightarrow\left(\mathrm{Q}\right.$ T. (e \& $\left.\left.\mathrm{c}^{\prime}\right)\right)$

But (97) applied to $\left(Q T\right.$. $\left.\left((e \Rightarrow g) e^{*}\right)\right)$ as in (103)a will fail to hold in case $c^{\prime}$ is a tautologous predicate and $g$ is, as before, a contradictory predicate. This is because (103)a can in this case be simplified to (103)b (making use of the fact that $g$ is contradictory and $c^{\prime}$ is tautological). The right-hand side of (103)b is false because $\mid \mathrm{DI} \geq \mathrm{k}+1$, but the left-hand side is true because there are (IDI - k) not-e objects, and $\mid \mathrm{Dl} \leq 2 \mathrm{k}$, whence $(\mid \mathrm{Dl}-\mathrm{k}) \leq \mathrm{k}$, with the result that (not e) satisfies $Q T$.

$\begin{aligned} \text { (103) a. } \mathrm{Cl} & =\left(\mathrm{Q} T .\left((\mathrm{e} \Rightarrow \mathrm{g}) \& \mathrm{c}^{\prime}\right)\right) \Leftrightarrow\left(\mathrm{Q} \mathrm{T} \cdot \mathrm{c}^{\prime}\right) \\ \text { b. } \mathrm{C} l & =(\mathrm{Q} \mathrm{T} .(\text { not e })) \Leftrightarrow(\mathrm{Q} \mathrm{T} . \mathrm{T})\end{aligned}$

\footnotetext{
${ }^{53}$ Note, however, that this fragment does not countenance complex predicates, although they do play a role in the present discussion.
} 
It can also be checked that this counterexample is still compatible with the conditions of NonTriviality and Constancy (defined in (95) and (96) above), under which Schlenker 2007b proved for his quantificational fragment a complete equivalence between the Transparency theory and Heim 1983. Our target formula is $\left(Q T\right.$. $\left.\left((\underline{e \Rightarrow g}) e^{*}\right)\right)$ (interpreted in a bivalent system), where we take $g$ to be a contradictory predicate (as before) and $e^{*}$ to be a tautologous predicate, with the result that $(Q T$. $\left.\left((e \Rightarrow g) e^{*}\right)\right)$ is equivalent to $(Q T$. (not e $\left.)\right)$. First, given that the domain of objects $\mathrm{D}$ is constant across worlds, it is immediate that the restrictor $T$ in $Q T$ satisfies Constancy as defined in (96). Second, with $e$ defined as in (101), $\left(Q T\right.$. (not e ) ) has different values in $\mathrm{w}$ and $\mathrm{w}^{\prime}$, which shows that Non-Trivality as defined in (95) is satisfied as well.

Importantly, this result does not extend to the quantifier No. In fact, Transparency predicts the same presuppositions for (No P. ( $e \& g))$ and for $\left(N o P\right.$. $\left.\left(\underline{(e \Rightarrow g)} e^{*}\right)\right)$, as shown in (104)

(104) Transparency predicts the same presuppositions for $\left(\right.$ No P . $\left.\left((e \Rightarrow g) e^{*}\right)\right)$ and $($ No P . $(e \& g))$

a. (98) shows that if (No P. $\left.\left((e \Rightarrow g) e^{*}\right)\right)$ and C satisfy (97), so do (No P . (e \& g)) and C.

b. To see the converse, suppose, for contradiction, that (No P . (e\&g)) and C satisfy (97) but (No P. $\left.\left((e \Rightarrow g) e^{*}\right)\right)$ and $\mathrm{C}$ don't. So we have:

(i) for all $c^{\prime}$ of the same type as $e, \mathrm{C}=\left(\right.$ No P. $\left.\left(\mathrm{e} \&\left(\mathrm{~g} \& \mathrm{c}^{\prime}\right)\right)\right) \Leftrightarrow($ No P. (e \& c'))

(ii) for some $c^{\prime}$ of the same type as $e$, for some $\mathrm{w}$ in $\mathrm{C}, \mathrm{w} \mid \neq($ No P. ((e $\left.\left.\Rightarrow \mathrm{g}) \& \mathrm{c}^{\prime}\right)\right) \Leftrightarrow$ (No P . $\left.\mathrm{c}^{\prime}\right)$, hence since the right-to-left direction of the equivalence is always true,

(iii) $\mathrm{w} l=\left(\right.$ No $\left.P .\left((\mathrm{e} \Rightarrow \mathrm{g}) \& \mathrm{c}^{\prime}\right)\right)$ but

(iv) $\mathrm{w} \mid \neq$ (No $\mathrm{P}$. c')

If in w no P-object satisfies $\left(e \& c^{\prime}\right)$, then for every P-object $\mathrm{d}$, either $c^{\prime}$ is false of $\mathrm{d}$, in which case $((e \Rightarrow g)$ $\left.\left.\& c^{\prime}\right)\right)$ is as well; or $c^{\prime}$ is true of $\mathrm{d}$, in which case $e$ is false of $\mathrm{d}$, and $\left.\left((e \Rightarrow g) \& c^{\prime}\right)\right)$ is true of $\mathrm{d}$. In other words, relative to P-objects $\left.\left((e \Rightarrow g) \& c^{\prime}\right)\right)$ and $c^{\prime}$ should have the very same extension, which contradicts (iii)-(iv). Hence we can negate the underlined hypothesis:

(v) $w \mid \neq$ (No P. (e \& c')).

But if in w some P-object satisfies $e$ and $g$ and $c^{\prime}$, (iii) would be refuted, hence

(vi) $\mathrm{w} \mathrm{l}=\left(\right.$ No P. $\left.\left(\mathrm{e} \&\left(\mathrm{~g} \& \mathrm{c}^{\prime}\right)\right)\right)$

(v) and (vi) show that (No P . ( $\& \& g)$ ) and C don't satisfy (97), contra hypothesis.

One last remark is in order. If the equivalence between Transparency and a Heimian system were extended, subject to Non-Triviality and Constancy, to a fragment with complex predicates or propositions with variables bound by quantifiers, then we would expect $a(e \Rightarrow g) e^{*} b$ and $a(e \& g) b$ to yield the same presuppositions, contrary to fact. Thus Non-Triviality and Constancy would seem to be insufficient to guarantee an equivalence between Transparency and a Heimian system. ${ }^{54}$

\footnotetext{
${ }^{54}$ It should be noted that our counterexample was based on a violation of a more subtle version of NonTriviality, since in $(Q T$. $(e \& g))$ the restrictor was trivial, and more importantly $g$ couldn't affect the truth conditions, which were already guaranteed to be satisfied in view of the beginning of the formula (since $e$ had such a small extension that $\left(e \& d^{\prime}\right)$ was guaranteed to satisfy the quantifier $Q T$ for any $\left.d^{\prime}\right)$. Thus one could ask whether strengthening Non-Triviality could yield a presuppositional equivalence between $a(e \Rightarrow g) e^{*} b$ and $a$ $(e \& g) b$.
} 


\section{Appendix II. Computing the local context of the embedded clause under factive verbs}

We assume the general framework of Schlenker 2009, Section 3.1.2 ('Adding Belief Reports'), and in particular the device of double indexing (hence the double abstraction over $w^{*}$ and over $w$ ), which was used to compute local contexts in intensional cases (but see the end of fn. 33). As before, we write $l c(F)$ to refer to the local context of an expression $F$, and we write $\mathbf{F}$ for the semantic value of an expression $F$.

Schlenker 2009 shows that for non-factive formulas such as Believe_s $F$, the value of the

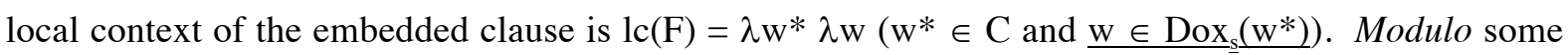
technical assumptions, we show that in the factive case the underlined formula must be replaced with the disjunction $\left(\mathrm{w} \in \operatorname{Dox}_{\mathrm{s}}\left(\mathrm{w}^{*}\right)\right.$ or $\left.\mathrm{w}=\mathrm{w}^{*}\right)$, which guarantees that an expression entailed by the local context must hold in the actual world.

Notation: If $\mathrm{w}^{*}$ is a world, we write $\mathrm{w}^{*} \mathrm{I}=\mathrm{F}$ just in case $\mathbf{F}\left(\mathrm{w}^{*}\right)\left(\mathrm{w}^{*}\right)=1$. If $\mathrm{C}$ is a set of worlds, we write $\mathrm{C} \vDash \mathrm{F}$ just in case for each world $\mathrm{w}^{*}$ in $\mathrm{C}, \mathrm{w}^{*} \vDash \mathrm{F}$.

\section{(105) Local context of $\boldsymbol{F}$ in (Un)aware_s $\boldsymbol{F}$}

Assume that $(U n)$ Aware_s $F$ is equivalent to $F \&(n o t) B e l \_s F$, where the $n o t$ in parentheses is present for Unaware and absent for Aware.

Claim: $\operatorname{lc}(\mathrm{F})=\lambda \mathrm{w}^{*} \lambda \mathrm{w}\left(\mathrm{w}^{*} \in \mathrm{C}\right.$ and $\left(\mathrm{w} \in \operatorname{Dox}_{\mathrm{s}}\left(\mathrm{w}^{*}\right)\right.$ or $\left.\left.\mathrm{w}=\mathrm{w}^{*}\right)\right)$

By definition, $\operatorname{lc}(\mathrm{F})$ is the most restrictive $\mathrm{c}^{\prime}$ of type $<\mathrm{s},<\mathrm{s}, \triangleright>>$ such that for all $\mathrm{d}^{\prime}$,

$\mathrm{C} \models(\mathrm{Un})$ Aware_s $\left(c^{\prime} \& \mathrm{~d}^{\prime}\right)<=>(\mathrm{Un})$ Aware_s d', or in other words,

(E) $\mathrm{C} \vDash\left[\left(\mathrm{c}^{\prime} \& \mathrm{~d}^{\prime}\right) \&\left(\right.\right.$ not) Bel_s $\left.\left(\mathrm{c}^{\prime} \& \mathrm{~d}^{\prime}\right)\right]<=>$ [d' \& (not) Bel_s d']

We need to show that (i) our value of $\operatorname{lc}(\mathrm{F})$ satisfies equivalence (E), and that (ii) no more restrictive value does.

(i) Clearly, equivalence (E) holds if $\mathrm{c}^{\prime}$ denotes $\mathrm{lc}(\mathrm{F})$ as defined above.

(ii) Now suppose (= Assumption) that for $\mathrm{w}^{*}$ and $\mathrm{w}$ that satisfy ( $\mathrm{w}^{*} \in \mathrm{C}$ and $\left(\mathrm{w} \in \operatorname{Dox}_{\mathrm{s}}\left(\mathrm{w}^{*}\right)\right.$ or $\mathrm{w}=$ $\left.\left.\mathrm{w}^{*}\right)\right), \mathbf{c}^{\prime}\left(\mathrm{w}^{*}\right)(\mathrm{w})=0$. We show that such a value for $c^{\prime}$ is overly restrictive, in the sense that it may fail to satisfy equivalence (E).

\section{Aware}

Take d' to be a tautology. In order to refute equivalence (E), we show that

a. $w^{*} \not \neq\left(c^{\prime} \& d^{\prime}\right) \&$ Bel_s(c' \& d')

but

b. w* $^{*}$ d' \& Bel_s d'

b. is immediate since $\mathrm{d}^{\prime}$ is a tautology.

a. follows by cases.

If $\mathbf{c}^{\prime}\left(\mathrm{w}^{*}\right)\left(\mathrm{w}^{*}\right)=0, \mathrm{w}^{*} \not \neq \mathrm{c}^{\prime}$ and the result is immediate.

If $\mathbf{c}^{\prime}\left(\mathrm{w}^{*}\right)\left(\mathrm{w}^{*}\right)=1$, then for some $\mathrm{w} \in \operatorname{Dox}_{\mathrm{s}}\left(\mathrm{w}^{*}\right), \mathbf{c}^{\prime}\left(\mathrm{w}^{*}\right)(\mathrm{w})=0$ (by the Assumption in (ii)), and thus $\mathrm{w}^{*} \not \neq$ Bel_s (c' \& d'), from which the result follows.

\section{Unaware}

Auxiliary assumption: for each $\mathrm{w}^{*} \in \mathrm{C}$, for some $\mathrm{w}_{\mathrm{s}} \neq \mathrm{w}^{*}, \operatorname{Dox}_{\mathrm{s}}\left(\mathrm{w}^{*}\right)\left(\mathrm{w}_{\mathrm{s}}\right)=1 .{ }^{55}$

${ }^{55}$ This auxiliary assumption is minimal, in the sense that if (i) below is satisfied, equivalence (E), taking the form in (ii), won't be refuted.

(i) for each $\mathrm{w}^{*} \in \mathrm{C}$, for each $\mathrm{w}_{\mathrm{s}}, \operatorname{Dox}_{\mathrm{s}}\left(\mathrm{w}^{*}\right)\left(\mathrm{w}_{\mathrm{s}}\right)=1 \Rightarrow \mathrm{w}_{\mathrm{s}}=\mathrm{w}^{*}$

(ii) $\mathrm{C} \vDash\left[\left(\mathrm{c}^{\prime} \& \mathrm{~d}^{\prime}\right) \&\right.$ not Bel_s (c' \& d')] $<=>$ [d' \& not Bel_s d'] 
Case 1. $\mathbf{c}^{\prime}\left(\mathrm{w}^{*}\right)\left(\mathrm{w}^{*}\right)=0$. Take $\mathrm{d}^{\prime}$ to be defined by $\mathbf{d}^{\prime}\left(\mathrm{w}^{*}\right)=\left\{\mathrm{w}^{*}\right\}$. Since $\mathrm{w}^{*} \not \not \mathrm{c}^{\prime}$, we also have that a. $w^{*} \not \equiv\left(c^{\prime} \& d^{\prime}\right) \&$ not Bel_s $\left(c^{\prime} \& d^{\prime}\right)$. However,

b. $\mathrm{w}^{*} \vDash \mathrm{d}^{\prime} \&$ not Bel_s d', since $\mathbf{d}^{\prime}\left(\mathrm{w}^{*}\right)=\left\{\mathrm{w}^{*}\right\}$ and $\operatorname{Dox}_{\mathrm{s}}\left(\mathrm{w}^{*}\right)\left(\mathrm{w}_{\mathrm{s}}\right)=1$, whence $\mathrm{w}^{*} \vDash \mathrm{d}^{\prime}$ and $\mathrm{w}^{*} \vDash$ not Bel_s d'.

Case 2. $\mathbf{c}^{\prime}\left(\mathrm{w}^{*}\right)\left(\mathrm{w}^{*}\right)=1$, hence (by the Assumption in (ii)) for some $\mathrm{w} \in \operatorname{Dox}_{\mathrm{s}}\left(\mathrm{w}^{*}\right), \mathbf{c}^{\prime}\left(\mathrm{w}^{*}\right)(\mathrm{w})=0$. Take $\mathrm{d}^{\prime}$ to be a tautology. Then:

a. $\mathrm{w}^{*} \vDash\left(\mathrm{c}^{\prime} \& \mathrm{~d}^{\prime}\right) \&$ not Bel_s$\left(\mathrm{c}^{\prime} \& \mathrm{~d}^{\prime}\right)$ because $\mathrm{c}^{\prime}\left(\mathrm{w}^{*}\right)\left(\mathrm{w}^{*}\right)=1$ and $\mathrm{d}^{\prime}$ is a tautology, whence $\mathrm{w}^{*} \vDash\left(\mathrm{c}^{\prime} \& \mathrm{~d}^{\prime}\right)$; and $\mathrm{w} \in \operatorname{Dox}_{\mathrm{s}}\left(\mathrm{w}^{*}\right)$ and $\mathbf{c}^{\prime}\left(\mathrm{w}^{*}\right)(\mathrm{w})=0$, whence $\mathrm{w}^{*}=$ not Bel_s $\left(\mathrm{c}^{\prime} \& \mathrm{~d}^{\prime}\right)$. However,

b. $w^{*} \not \models$ d' \& not Bel_s d' because d' is a tautology, whence $w^{*} \vDash B e l \_s$ d'.

Assuming (i), both sides of the equivalence in (ii) will be false throughout C. For assume, for contradiction, that for some $\mathrm{w}^{*} \in \mathrm{C}$, one of the two sides, of the form $F$ and not Bel_s $F$, satisfies $\mathrm{w}^{*} \vDash \mathrm{F}$ and not Bel_s F. This entails that $\mathrm{w}^{*} \not \neq \mathrm{Bel} \_\mathrm{s} \mathrm{F}$, hence by (i) $\mathbf{F}\left(\mathrm{w}^{*}\right)\left(\mathrm{w}^{*}\right)=0$ - but then $\mathrm{w}^{*} \not \neq \mathrm{F}$, contra hypothesis. 


\section{Appendix III. More on Supervaluationist Accounts}

This Appendix discusses in greater detail the supervaluationist accounts of co-speech gestures that were sketched in Section 4.1. As noted, we do not assume that the utterance of a vague statement comes with a presupposition that it should have a clear value (true or false, rather than indeterminate); but if a statement is uttered by a cooperative speaker, we can assume that she believes it to be felicitous and true (see the end of Section 4.1 for a brief discussion of the inferences obtained if we add to the supervaluationist account a presupposition that the statement uttered is clearly true or clearly false, as suggested by A. Anvari).

\section{$\square$ The cosuppositional approach predicts stronger inferences than the Basic Supervaluationist} Account

As we saw in Section 4.1, in cases of embedding under unaware and exactly one, the supervaluationist approach generates presuppositions that are weaker than those of the presuppositional approach. This is an entirely general fact: the Basic Supervaluationist Account predicts inferences that are entailed - sometimes asymmetrically entailed - by those derived by the presuppositional approach. To put it informally, the key is that the presuppositional approach derives conditions on the Context Set $\mathrm{C}$ that are so strong that that they guarantee that, relative to $\mathrm{C}$, the sentence with the co-speech gesture is equivalent to the bare sentence without the co-speech gesture; as a result, if one of them is true, both are - and thus whenever the presuppositional condition is satisfied, so is the supervaluationist condition. This is explained in greater detail in (106).

(106) The presuppositional account predicts stronger inferences than the Basic Supervaluationist Account

a. Suppose that a sentence ... Ge $\ldots$ with a gesture $G$ modifying an expression $e$ is true and felicitous according to the presuppositional approach. Then it is true and felicitous according to the Basic Supervaluationist Account.

Proof: If ... Ge ... is felicitous in a Context Set $\mathrm{C}$, then relative to the local context of $\mathrm{e}, \mathrm{e}=>\mathrm{g}$ (if $\mathrm{g}$ is an expression with the same content as $\mathrm{G})$. This guarantees that

$\mathrm{C} \vDash \ldots \mathrm{e} \ldots<\Rightarrow \quad \ldots(\mathrm{e} \& \mathrm{~g}) \ldots$

If ...Ge ... is felicitous and true, then both $\ldots e \ldots$ and $\ldots(e \& g) \ldots$ are felicitous and true, which shows that ...Ge ... is felicitous and true on the Basic Supervaluationist Account.

b. There are cases in which the presuppositional account predicts stronger inferences than the Basic Supervaluationist Account.

A case in point, pertaining to gestures embedded under exactly one, is given in (51) and (71)

An additional remark will be useful below. In our Basic Supervaluationist Account, we only required that two versions of the sentence be true, one with and one without the gestural enrichment. But one could investigate a supervaluationist approach that makes stronger predictions, and requires that a sentence ...Ge ... with a predicate $e$ enriched by a gesture $G$ with content $g$ should be true on all the possible pointwise resolutions of the uncertainty about the presence of the enrichment $g$ (henceforth, 'Pointwise Supervaluationist Account'). In other words, we consider all the values of the predicate $e$ obtained by requiring that arbitrary objects satisfying $e$ also satisfy the gestural enrichment $g$. Technically, this amounts to a requirement that the original sentence ... Ge ... should be true just in case ...e ... is true on all interpretation on which $e$ takes values within the set $\mathrm{R}(\mathrm{e}, \mathrm{g})$ defined as in (107):

$(107) \mathrm{R}(\mathrm{e}, \mathrm{g})=\{[\lambda \mathrm{w} \lambda \mathrm{x} . \mathbf{e}(\mathrm{w})(\mathrm{x})=1 \&(<\mathrm{x}, \mathrm{w}>\in \mathrm{F}=>\mathbf{g}(\mathrm{w})(\mathrm{x})=1)]: \mathrm{F} \subseteq \mathrm{D} \times \mathrm{W}\}$

This yields a stronger requirement than our 'official' supervaluationist approach, since on the latter we only require that ...e ... should be true when $e$ takes the two values $\{\lambda \mathrm{w} \lambda \mathrm{x} . \mathbf{e}(\mathrm{w})(\mathrm{x})=1, \lambda \mathrm{w} \lambda \mathrm{x}$. $\mathbf{e}(\mathrm{w})(\mathrm{x})=1 \& \mathbf{g}(\mathrm{w})(\mathrm{x})=1\}$; by contrast, the pointwise definition using (107) requires that the sentence should be true for many other values of the predicate. 


\section{- The problem of downward-monotonic environments}

At this point, it might seem that the supervaluationist analysis has an advantage over the presuppositional one. But when we consider downward-monotonic environments, the situation changes. We saw that under the quantifier no one intuitively obtains a non-trivial conditional inference; thus for None of these 10 guys SLAP punished his son, we obtain the inference that for each of these 10 guys, if he had punished his son, he would have done so by slapping him. The presuppositional approach derives this result. But the supervaluationist approach derives nothing at all: the problem is that in downward-monotonic environments, the enriched version of the sentence is weaker than the original version, with the result that only the latter makes its truth-conditional effects felt.

(108)a. None of these 10 guys SLAP punished his son.

a'. [No g] Sp

b. (a') is true and felicitous according to the Basic Supervaluationist Account iff [No g] $p$ and [No g](p

and $e$ ) are both true and felicitous, iff [No g] $p$ is true and felicitous.

Importantly, the very same problem extends to the Pointwise Supervaluationist Account we considered at the end of the preceding section. In that approach, the sentence [No g] $S p$ is true just in case [No $g$ ] $p$ under al interpretations on which $p$ takes values within the set $\mathrm{R}(\mathrm{p}, \mathrm{s})=\{[\lambda \mathrm{w} \lambda \mathrm{x}$. $\mathbf{p}(\mathrm{w})(\mathrm{x})=1 \&<\mathrm{x}, \mathrm{w}>\in \mathrm{F}=>\mathbf{s}(\mathrm{w})(\mathrm{x})=1]: \mathrm{F} \subseteq \mathrm{D} \times \mathrm{W}\}$. But since each of these values is at least as restrictive as the original value $\mathbf{p}$, and the environment is downward-monotonic, the truth conditions of [No g] Sp end up being the same as those of the bare sentence [No g] p.

\section{- A mixed approach}

We could try to fix the problem by combining the advantages of the supervaluationist and of the presuppositional approach, along the following lines:

(109) Mixed Supervaliationist Account: supervaluations and presuppositions

(i) One first tries to interpret a co-speech gesture according to a supervaluationist analysis.

(ii) However, if the result makes the co-speech gesture vacuous, we interpret it according to the presuppositional approach.

While this approach is obviously complicated, it has the possible advantage of predicting conditional presuppositions under the quantifier no, but not under non-monotonic quantifiers such as exactly one. Still, as we will now see, it suffers from further deficiencies.

\section{- Remaining problems for the supervaluationist accounts}

Even the mixed solution envisaged in (109) ('first try a supervaluationist analysis; and if this still makes the gesture vacuous, go for a presuppositional treatment') encounters problems. Consider the sentences in (110):

(110)a. An odd number of guys SLAP punished their son.

$=>$ an odd number of guys punished their son, and they did so by slapping him

b. Three or five guys SLAP punished their son.

$=>$ three or five guys punished their son, and they did so by slapping him

I believe we get a fairly strong inference that all the guys who punished their son did so by slapping him. But this is not predicted by the supervaluationist account, even in its mixed version. The predictions of our Basic Supervaluationist Account are laid out in (111) and (112).

(111)Predictions of the Basic Supervaluationist Account: an odd number

a. An odd number of guys SLAP punished their son.

$\mathrm{a}^{\prime}$. [Odd g] Sp

b. (a') is true iff [Odd $g$ ] $p$ and [Odd $g$ ] ( $p$ and $s$ ) are both true.

Thus (a') is true in particular if exactly five guys punished their son, and exactly three guys punished their son by slapping him.

(112) Predictions of the Basic Supervaluationist Account: three or five a. Three or five guys SLAP punished their son. 
$\mathrm{a}^{\prime}$. [ $=3$ or $\left.=5 \mathrm{~g}\right] \mathrm{Sp}$

b. (a') is true iff $[=3$ or $=5 \mathrm{~g}] \mathrm{p}$ and $[=3$ or $=5 \mathrm{~g}]$ ( $\mathrm{p}$ and $\mathrm{s}$ ) are both true.

Thus ( $\left.\mathrm{a}^{\prime}\right)$ is true in particular if exactly five guys punished their son, and exactly three guys punished their son by slapping him.

In both cases, the Basic Supervaluationist Account predicts that the gesture is non-vacuous. To see this, notice that without the gesture, the sentences would end up meaning that an odd number of guys punished their son or that three or five guys punished their son. With the gesture, the Basic Supervaluationist Account imposes the additional requirement that an odd number of guys punished their son by slapping him, or that three or five guys punished their son by slapping him - a non-trivial condition that doesn't follow from the meaning of the bare sentence. So even the mixed theory predicts that we should stick to the supervaluationist analysis of these sentences. But the readings we obtain are too weak: we do not get the intuitively desirable inference that all the guys who punished their son did so by slapping him, as the supervaluationist truth conditions allow for the possibility that only a strict subset of the guys who punished their son did so by slapping him. In particular, as mentioned in (111) and (112), both sentences are predicted to be true if exactly five guys punished their son, and exactly three guys punished their son by slapping him - a dubious result. (We note for future reference that the same situation shows that a similar problem arises for the sentence Between three and five of these guys SLAP punished their son.)

\section{- Solution within the Pointwise Supervaluationist Account}

On our Pointwise Supervaluationist Account, the initial problem gets solved. Recall that on this approach [Odd $g$ ] $S p$ is true just in case [Odd $g$ ] $p$ is true on all interpretations on which $p$ takes values within the set: $\mathrm{R}(\mathrm{e}, \mathrm{g})=\{[\lambda \mathrm{w} \lambda \mathrm{x} . \mathrm{e}(\mathrm{w})(\mathrm{x})=1 \& \leq \mathrm{x}, \mathrm{w}>\in \mathrm{F} \Rightarrow \mathbf{g}(\mathrm{w})(\mathrm{x})=1]: \mathrm{F} \subseteq \mathrm{D} \times \mathrm{W}\}$. Clearly, this interpretation is stronger than the bare sentence without a co-speech gesture, and thus it entails that an odd number of guys punished their son. Furthermore, relative to the Context Set it is equivalent to: An odd number of guys punished their son, and all these guys did so by slapping him.

The argument is in two steps.

(i) Clearly, if an odd number of guys punished their son, and all did so by slapping him, the sentence will be true on the relevant supervaluationist analysis, because relative to the Context Set the underlined condition will be vacuous for all $\mathrm{w}, \mathrm{x}$ for which $\mathbf{p}(\mathrm{w})(\mathrm{x})=1$.

(ii) To establish the converse, we show that if an odd number of guys punished their son in a world $\mathrm{w}^{*}$ of the Context Set, and if at least one guy g* didn't do so by slapping him, then the target sentence will not be true on the relevant supervaluationist interpretation. To see this, take $W^{\prime}=\left\{w^{*}\right\}$ and $D^{\prime}=$ $\left\{\mathrm{g}^{*}\right\}$. It is clear that if for $\mathrm{w}=\mathrm{w}^{*}$ an odd number of guys punished their son in $\mathrm{w}$, then in $\mathrm{w}$ an even number of guys $x$ satisfy the condition $\mathbf{p}(\mathrm{w})(\mathrm{x})=1 \& \leq \mathrm{x}, \mathrm{w}>\in \mathrm{D}^{\prime} \times \mathrm{W}^{\prime} \Rightarrow \mathbf{s}(\mathrm{w})(\mathrm{x})=1$ - since the underlined condition is vacuously satisfied by all guys except $\mathrm{g}^{*}$, and $\mathrm{g}^{*}$ falsifies it.

Furthermore, on the Pointwise Supervaluationist Account, we still preserve the positive features of our analysis of embedding under exactly one, as shown in (113).

(113)a. Exactly one of these guys SLAP punished his son.

$\mathrm{a}^{\prime} .[=1 \mathrm{~g}] \mathrm{Sp}$

b. Predictions of the Basic Supervaluationist Account

$\left(\mathrm{a}^{\prime}\right)$ is true and felicitous iff $[=1 \mathrm{~g}] p$ and $[=1 \mathrm{~g}](\mathrm{p} \& \mathrm{~s})$ are both true and felicitous. It follows that exactly one guy punished his son, and furthermore he did so by slapping him.

b'. Predictions of the Pointwise Supervaluationist Account

$\left(\mathrm{a}^{\prime}\right)$ is true and felicitous in a world $\mathrm{w}^{*}$ iff $[=1 \mathrm{~g}] p$ is true at $\mathrm{w}^{*}$ on all interpretations on which $p$ takes values within the set: $R(p, s)=\{[\lambda w \lambda x \cdot \mathbf{p}(w)(x)=1 \&<x, w>\in F=>s(w)(x)=1]: F \subseteq D \times W\}$.

As in $\mathrm{b}$., in a world $\mathrm{w}^{*}$ this requires that exactlyl one guy $\mathrm{g}^{*}$ punished his son, and $\mathrm{g}^{*}$ did so by slapping him (if $\mathrm{g}^{*}$ didn't punish his son by slapping him, by taking $\mathrm{F}=\left\{\mathrm{w}^{*}\right\} \times\left\{\mathrm{g}^{*}\right\}$, we could find an interpretation on which zero guy satisfies $p$ ).

Still, in some cases the Pointwise Supervaluationist Account yields potentially counterintuitive results - although judgments are somewhat subtle. In particular, in the case of the quantifier between three and five of these guys, we fail to derive the inference that all the guys who 
punished their son did to by slapping him (this problem does not arise for the sentence Three or five of these guys SLAP punished their son ${ }^{56}$ ). This is shown for both versions of the supervaluationist account in (114), symbolizing the relevant quantifier as $[3 \leq \bullet \leq 5 \mathrm{~g}]$.

(114)a. Between 3 and 5 guys SLAP punished their son.

$\mathrm{a}^{\prime} .[3 \leq \bullet \leq 5 \mathrm{~g}] \mathrm{Sp}$

b. Predictions of the Basic Supervaluationist Account

$\left(\mathrm{a}^{\prime}\right)$ is true iff $[3 \leq \bullet \leq 5 \mathrm{~g}] p$ and $[3 \leq \bullet \leq 5 \mathrm{~g}](\mathrm{p}$ and $s$ ) are both true.

Thus (a') is true in particular if exactly 5 guys punished their son, and exactly 3 guys punished their son by slapping him.

b'. Predictions of the Pointwise Supervaluationist Accountt

(a') is true iff $[3 \leq \bullet \leq 5 \mathrm{~g}] p$ is true at a certain world $\mathrm{w}^{*}$ on all interpretation on which $p$ takes values within the set: $\mathrm{R}(\mathrm{p}, \mathrm{s})=\{[\lambda \mathrm{w} \lambda \mathrm{x} \cdot \mathbf{p}(\mathrm{w})(\mathrm{x})=1 \&<\mathrm{x}, \mathrm{w}>\in \mathrm{F}=>\mathbf{s}(\mathrm{w})(\mathrm{x})=1]: \mathrm{F} \subseteq \mathrm{D} \times \mathrm{W}\}$.

We still have the result that (a') is true in particular if exactly 5 guys punished their son, and exactly 3 guys punished their son by slapping him.

\section{- Tentative conclusions}

Our current conclusions are as follows.

(i) In upward-monotonic and some non-monotonic environment (e.g. embedding under be unaware, exactly one), supervaluationist accounts make potentially good predictions.

(ii) In downward-monotonic environments, the supervaluationist accounts we have discussed make the incorrect prediction that the gestural enrichment doesn't affect the meaning of the sentence. They could be supplemented with a presuppositional treatment for such cases, but at the cost of making the analysis quite a bit more complicated.

(iii) On the most intuitive supervaluationist treatment (the Basic Supervaluationist Account, which takes the presence of the gesture to be somehow vague), incorrect predictions are made even with the modification in (ii), especially for the case of embedding under an odd number and between 3 and 5. The less natural Pointwise Supervaluationist Account makes better predictions for the first case, but still makes somewhat unintuitive predictions for the second - although these would need to be tested.

(iv) As mentioned at the end of Section 4.1 (= Anvari's remark), one can derive stronger inferences if we assume that our vagueness-inspired supervaluationist accounts come with a presupposition that the utterance is clearly true or clearly false; we leave an exploration of this direction for future research.

\section{- A cautionary note: supervaluationist accounts of gestures vs. supervaluationist accounts of presuppositions}

In the foregoing, our use of supervaluations was motivated by the idea that the presence of a gestural enrichment makes it 'vague' whether it should be taken into account or not. In our Basic Account, we thus provided truth conditions on which a sentence with a co-speech gesture is true just in case it is true both in its bare form and in its enriched version. In our Pointwise Account, we extended this approach pointwise to predicates. These vagueness-inspired approaches should be compared to

\footnotetext{
${ }^{56}$ Specifically, in this case the Pointwise Supervaluationist Account derives an inference that all the guys who punished their son did so by slapping him. To see this, assume that three or five of the relevant guys punished their son in a world $\mathrm{w}^{*}$ of the Context Set, but that one of them, $\mathrm{g}^{*}$, didn't do so by slapping his son. Take $\mathrm{W}^{\prime}=$ $\left\{\mathrm{w}^{*}\right\}$ and $\mathrm{D}^{\prime}=\left\{\mathrm{g}^{*}\right\}$. Assume that for $\mathrm{w}=\mathrm{w}^{*}$ three or five guys punished their son in $\mathrm{w}$.

Case 1. In $\mathrm{w}=\mathrm{w}^{*}$, exactly three guys (including $\mathrm{g}^{*}$ ) punished their son. But due to $\mathrm{g}^{*}$, exactly two guys satisfy the condition $\mathbf{p}(\mathrm{w})(\mathrm{x})=1 \& \leq \mathrm{x}, \mathrm{w}>\in \mathrm{D}^{\prime} \times \mathrm{W}^{\prime} \Rightarrow \mathbf{s}(\mathrm{w})(\mathrm{x})=1$ - since the underlined condition is vacuously satisfied by all guys except $\mathrm{g}^{*}$, and $\mathrm{g}^{*}$ falsifies it.

Case 2. In $w=w^{*}$, exactly five guys (including $g^{*}$ ) punished their son. But due to $g^{*}$, exactly four guys satisfy the condition $\mathbf{p}(\mathrm{w})(\mathrm{x})=1 \& \leq \mathrm{x}, \mathrm{w}>\in \mathrm{D}^{\prime} \times \mathrm{W}^{\prime} \Rightarrow \mathbf{s}(\mathrm{w})(\mathrm{x})=1$ - since the underlined condition is vacuously satisfied by all guys except $\mathrm{g}^{*}$, and $\mathrm{g}^{*}$ falsifies it.

The upshot is that Three or five guys SLAP punished their son couldn't be true on the Pointwise Supervaluationist account if at least one of the guys who punished their son did so without slapping him. (It is immediate that if all did slap, the sentence is true.)
} 
supervaluation-based analyses of presuppositions, which were discussed (and sometimes advocated) in George 2008, Fox 2008, and Schlenker 2008b, among others (see also Beaver and Krahmer 2001 for related approaches using modified versions of Strong Kleene logic). These analyses proceed in two steps.

(i) They start from the idea that an expression $\underline{d} d$ ' whose presupposition $d$ is not satisfied by objects or parameters $o_{1}, \ldots, o_{n}$ is neither true nor false of these objects - hence a value \# when evaluated with respect to them.

(ii) However, if no matter how the value \# is resolved the entire sentence has one and the same value, it can 'recover' from the failure and be evaluated as true or false, as the case may be.

There are some similarities and some differences between the supervaluationist approach to presuppositions and that based on local contexts.

(a) In upward-monotonic environments, the supervaluationist approach often predicts weaker and possibly more adequate inferences than the approach based on local contexts. For instance, for At least one of these 10 students knows that he is incompetent, the supervaluationist approach just predicts an inference that at least one of these 10 students is incompetent (and knows it), whereas approaches based on local contexts typically predict an inference that each of these ten students is incompetent.

(b) For None of these 10 students knows that he is incompetent, the supervaluationist approach to presuppositions yields an entailment that each of these 10 students is incompetent (because if at least one isn't, the value of the predicate evaluated at that student would yield the value \#, and if this value is resolved as 'true', this would falsify the statement). In this simple case, the inference is comparable (though not quite of the same nature) as the one we derive from an approach based on local contexts, which yields a presupposition that each of these 10 students is incompetent.

(c) For Exactly 1 of these 10 students knows that he is incompetent, the supervaluationist approach to presuppositions also predicts a universal entailment that each of these 10 students is incompetent. This is again because if any one of them isn't, the predicate evaluated at that student would yield the value \#; and resolving this value as 'true' or as 'false' would affect the number of students that satisfy the predicate, hence the impossibility of getting a true 'exactly one' statement no matter how the value is resolved.

In two of these three cases, we would get different results from our vagueness-inspired account if we treated gestures as simple presupposition triggers within a supervaluationist treatment of presuppositions - with the assumption that $x$ SLAP punished his son triggers a presupposition that $\mathrm{x}$ slapped his son.

(a') For At least one of these 10 guys SLAP punished his son, we get the same result, namely an inference that at least one of these 10 guys punished his son by slapping him.

(b') For None of these 10 guys SLAP punished his son, the two accounts make entirely different predictions, since we saw that vagueness-inspired accounts predict that the co-speech gesture should be vacuous (which in turn argues for an enrichment of the theory), whereas the presuppositional supervaluationist analysis will yield an inference that each of these 10 guys slapped his son. This is of course an inference which is far too strong.

(c') For Exactly one of these 10 guys SLAP punished his son, the two accounts make different predictions again. Vagueness-inspired accounts predict that exactly one of these 10 guys punished his son, and he did so by slapping him. By contrast, if we treat SLAP as a simple presupposition resolved by supervaluationist means, we obtain an inference that each of these 10 guys slapped his son - which is again far too strong.

Interestingly, our (vagueness-inspired) Pointwise Supervaluationist Account appears to converge with the supervaluationist account of presuppositions if within the latter the gestural contribution is treated as a cosupposition rather than as a simple presupposition (this is what we call the Supervaluationist Account of Cosuppositions). Informally, this can be seen by considering the bivalent extensions of a unary predicate $G e$ that are accessed in each case, where $e$ is an expression modified by a co-speech gesture $G$ with content $\mathrm{g}$. We write as $w$ the world argument of the predicate and as $x$ its individual argument.

(i) Pointwise Supervaluationist Account: a predicate Ge gives rise to binary extensions with values 
1 if $\mathbf{e}(\mathrm{w})(\mathrm{x})=\mathbf{g}(\mathrm{w})(\mathrm{x})=1$ (both the expression and the gesture are true at $\mathrm{w}, \mathrm{x}$, and thus the predicate is clearly true at that point);

0 if $\mathbf{e}(\mathrm{w})(\mathrm{x})=0$ (the expression is false at $\mathrm{w}, \mathrm{x}$, and thus the predicate is clearly false at that point); 0 and 1 if $\mathbf{e}(\mathrm{w})(\mathrm{x})=1$ and $\mathbf{g}(\mathrm{w})(\mathrm{x})=0$ (it is 'vague' whether the contribution $\mathrm{g}$ of the gesture $G$ should be taken into account, and thus the predicate has different values at $\mathrm{w}, \mathrm{x}$ depending on whether the gesture is taken into account or not).

(ii) Supervaluationist Account of Cosuppositions: a predicate Ge gives rise to binary extensions with values

1 if the at-issue component is true, $\mathbf{e}(\mathrm{w})(\mathrm{x})=1$, and the cosupposition is true as well, $[\mathbf{e}(\mathrm{w})(\mathrm{x})=>$ $\mathbf{g}(\mathrm{w})(\mathrm{x})]=1$, i.e. in $\operatorname{sum}$ if $\mathbf{e}(\mathrm{w})(\mathrm{x})=\mathbf{g}(\mathrm{w})(\mathrm{x})=1$;

0 if the at-issue component is false, $\mathbf{e}(\mathrm{w})(\mathrm{x})=0$;

0 and 1 if the at-issue component is true, $\mathbf{e}(\mathrm{w})(\mathrm{x})=1$, and the cosupposition is false, $[\mathbf{e}(\mathrm{w})(\mathrm{x})=>$ $\mathbf{g}(\mathrm{w})(\mathrm{x})]=0$, i.e. if $\mathbf{e}(\mathrm{w})(\mathrm{x})=1$ and $\mathbf{g}(\mathrm{w})(\mathrm{x})=0$.

It is clear that (i) and (ii) give rise to the same bivalent extensions. 


\section{References}

Beaver, David: 2001, Presupposition and Assertion in Dynamic Semantics. CSLI, Stanford.

Beaver, David and Krahmer, Emiel: 2001, A partial account of presupposition projection. Journal of Logic, Language and Information 10.147-182. DOI 10.1023/A:1008371413822

Beaver, David: 2010, Have you noticed that your belly button lint colour is related to the colour of your clothing? In R. Bauerle, U. Reyle, and T. E. Zimmerman (Eds.), Presupposition: Papers in Honor of Hans Kamp. Bingley, UK: Emerald.

Beaver, David and Geurts, Bar: 2011, Presupposition. In: Stanford Encyclopedia of Philosophy, http://plato.stanford.edu/entries/presupposition/

Beckman, Mary E. and Pierrehumbert, Janet B.: 1986, Intonational structure in English and Japanese. Phonology Yearbook, 3, 255-310.

Breheny, Richard: 2003b, On Bindability. In Proceedings of the 14th Amsterdam Colloquium, ILLC, University of Amsterdam.

Chemla, Emmanuel: 2009, Presuppositions of quantified sentences: experimental data. Natural Language Semantics,17(4):299-340.

Davidson, Kathryn: 2015, Quotation, Demonstration, and Iconicity. Linguistics \& Philosophy 38(6), 477-520.

Del Gobbo, Francesca. 2003. Appositives at the Interface. $\mathrm{PhD}$ dissertation, University of California.

Ebert, Cornelia and Ebert, Christian: 2014, Gestures, Demonstratives, and the Attributive/Referential Distinction. Handout of a talk given at Semantics and Philosophy in Europe (SPE 7), Berlin, June 28, 2014.

Ebert, C., S. Evert and K. Wilmes: 2011, Focus Marking via Gestures. In Reich, Ingo et al. (eds.), Proceedings of Sinn \& Bedeutung 15. Saarland Unversity Press: Saarbrücken, Germany.

Esipova, Maria: 2016a, Alternatives matter: Contrastive focus and presupposition projection in standard triggers and co-speech gestures. Poster, MACSIM conference, CUNY, October 1, 2016.

Esipova, Maria: 2016b, Presuppositions under Contrastive Focus: Standard Triggers and Co-speech Gestures. Manuscript, New York University.

Fintel, Kai von 2008. What is presupposition accommodation, again? Philosophical Perspectives 22 (1): 137-170.

Fox, Danny, 2008.Two short notes on Schlenker's theory of presupposition projection. Theoretical Linguistics, vol. 34, no. 3, pp. 237-252, 2008

George, Benjamin: 2008, A new predictive theory of presupposition projection. In: Proceedings of SALT 18, pp. 358-375.

Geurts, Bart: 1994, Presupposing, PhD dissertation, Universität Osnabrück.

Geurts, Bart: 1999, Presuppositions and Pronouns. Elsevier.

Giorgolo, Gianluca: 2010, Space and Time in Our Hands. PhD Dissertation, Utrecht University.

Goldin-Meadow, Susan and Brentari, Diane: 2015, Gesture, sign and language: The coming of age of sign language and gesture studies. Forthcoming

Heim, Irene: 1983, On the Projection Problem for Presuppositions. In D. Flickinger et al. (eds), Proceedings of the Second West Coast Conference on Formal Linguistics, 114-125. Reprinted in Davis 1991.

Heim, Irene: 1992, Presupposition projection and the semantics of attitude verbs. Journal of Semantics, 9(3), 183-221. DOI 10.1093/jos/9.3.183

Heim, Irene and Kratzer, Angelika: 1998, Semantics in Generative Grammar. Blackwell.

Katzir, Roni: 2007, Structurally-defined alternatives. Linguistics \& Philosophy 30, 669-690

Keefe, Rosanna: 2008, Vagueness: Supervaluationism. Philosophy Compass 3/2 (2008): 315-324,

Kendon, Adam: 1972, Some relationships between body motion and speech: An analysis of an example. In A. Siegman and B. Pope (Eds.), Studies in dyadic communication. New York: Pergamon Press.

Kendon, Adam: 1980, Gesticulation and speech: Two aspects of the process of utterance. In Mary Ritchie Key (Ed.), The Relationship of Verbal and Nonverbal Communication (207-227). The Hague: Mouton.

Kendon, Adam: 2004, Gesture: visible action as utterance. Cambridge. 
Koev, Todor: 2012, On the Information Status of Appositive Relative Clauses. Logic, Language and Meaning Lecture Notes in Computer Science 7218: 401-410.

Križ, Manuel, 2015. Aspects of homogeneity in the semantics of natural language (Doctoral dissertation, $\mathrm{PhD}$ thesis, University of Vienna).

Križ, Manuel: 2016. Homogeneity, Non-maximality, and all. Journal of Semantics 33/3.

Lascarides, Alex and Stone, Matthew: 2009, A Formal Semantic Analysis of Gesture. Journal of Semantics, 26(3): 393-449.

Leffel, Timothy: 2014. The semantics of modification: Adjectives, nouns, and order. $\mathrm{Ph} . \mathrm{D}$ dissertation, New York University.

Loehr, D. P.: 2004, Gesture and intonation. Doctoral dissertation, Georgetown University, Washington, DC

McGee, Vann, 1991, Truth, Vagueness, and Paradox, Indianapolis: Hackett.

McNeill, David: 2005, Gesture and Thought. University of Chicago Press.

Potts, Christopher: 2005, The Logic of Conventional Implicatures. Oxford University Press.

Rooth, Mats and Partee, Barbara: 1982, Conjunction, type ambiguity and wide scope «or». In Flickenger, D., Macken, M., and Wiegand, N., editors, Proceedings of the First West Coast Conference on Formal Linguistics, pp. 1-10. Linguistics Dept, Stanford University.

Rothstein, Susan, 2004: Structuring Events: A Study in the Semantics of Lexical Aspect. Blackwell: Oxford.

Saebø, Kjell Johan: 2013, Reports of Specific Indefinites. Journal of Semantics, 30: 267-314.

Schlenker, Philippe: 2005, Minimize Restrictors! (Notes on Definite Descriptions, Condition C and Epithets), in Bary, Huitink and Maier (eds), Proceedings of Sinn und Bedeutung 2004, 385-416

Schlenker, Philippe: 2007a, Expressive Presuppositions. Invited commentary on C. Pott's 'Expressive Dimension'. Theoretical Linguistics 33 (2) : 237-246

Schlenker, Philippe: 2007b, Anti-Dynamics: Presupposition Projection Without Dynamic Semantics. Journal of Logic, Language and Information 16, 3: 325-256. DOI 10.1007/s10849-006-9034-x

Schlenker, Philippe: 2008a, Be Articulate: A Pragmatic Theory of Presupposition Projection. Target article in Theoretical Linguistics, 34, 3: 157-212

Schlenker, Philippe: 2008b, Presupposition Projection: The New Debate. In Friedman, T. and Ito, S. (eds.) Proceedings of SALT 18, pp. http://elanguage.net/journals/index.php/salt/issue/view/281

Schlenker, Philippe: 2009, Local Contexts. Semantics \& Pragmatics, Volume 2, Article 3: 1-78, doi: $10.3765 /$ sp. 2.3

Schlenker, Philippe: 2010a, Presuppositions and Local Contexts. Mind 119, Issue 474: 377-391

Schlenker, Philippe: 2010b, Supplements Within a Unidimensional Semantics I: Scope. In: Maria Aloni, Harald Bastiaanse, Tikitu de Jager, and Katrin Schulz (eds) Logic, Language and Meaning: 17th Amsterdam Colloquium, Amsterdam, The Netherlands, December 16-18, 2009, Revised Selected Papers, Springer, 74-83.

Schlenker, Philippe: 2010c, Local Contexts and Local Meanings. Philosophical Studies 151, 1, 115142 (special issue on Stalnaker's "Assertion")

Schlenker, Philippe: 2012, Maximize Presupposition and Gricean reasoning. Natural Language Semantics 20, 4: 391-429

Schlenker, Philippe: 2013, Supplements within a unidimensional semantics II: Epistemic status and projection. In S. Kan, C. Moore-Cantwell \&R. Staubs (eds.), Proceedings of the $40^{\text {th }}$ Annual Meeting of the North East Linguistic Society, Vol. 2. GLSA. Amherst, MA. 167-182.

Schlenker, Philippe: 2015a, Gestural Presuppositions (squib). Snippets (Issue 30) doi: 10.7358/snip2015-030-schl

Schlenker, Philippe: 2015b, The Semantics and Pragmatics of Appositives. Manuscript, Institut JeanNicod and New York University.

Schlenker, Philippe: 2015c, Gestural Cosuppositions within the Transparency Theory [Squib]. Manuscript, Institut Jean-Nicod and New York University.

Schlenker, Philippe: 2016, Iconic Pragmatics. Manuscript, Institut Jean-Nicod and New York University.

Schlenker, Philippe: to appear a, The Semantics/Pragmatics Interface. To appear in the Cambridge Handbook of Formal Semantics, eds. Aloni and Dekker. 
Schlenker, Philippe: to appear b. Iconic Enrichments: Signs vs. Gestures [Short Commentary]. To appear in Behavioral and Brain Sciences.

Schlenker, Philippe: to appear c, Visible Meaning: Sign Language and the Foundations of Semantics. Target article in Theoretical Linguistics.

Schlenker, Philippe, Lamberton, Jonathan and Santoro, Mirko: 2013, Iconic Variables. Linguistics \& Philosophy 36, 2, 91-149.

Simons, Mandy: 2001, On the conversational basis of some presuppositions. In R. Hastings, B. Jackson, and Z. Zvolenszky (Eds.), Semantics and Linguistic Theory, 11. Ithaca, NY: CLC Publications.

Simons, Mandy; Beaver, David; Roberts, Craige; Tonhauser, Judith: to appear, The Best Question: Explaining the Projection Behavior of Factives. To appear in a special issue of Discourse Processes, edited by Anton Benz and Katja Jasinskaja.

Spector, Benjamin: 2013, Homogeneity and plurals: From the Strongest Meaning Hypothesis to Supervaluations. Presented at Sinn und Bedeutung 18.

Spector, Benjamin and Sudo, Yasutada: to appear, Presupposed Ignorance and Exhaustication: How Scalar Implicatures and Presuppositions Interact. Linguistics \& Philosophy.

Stalnaker, Robert: 1974, Pragmatic presuppositions. In Munitz, M. and Unger, P. (eds.),Semantics and Philosophy, New York University Press, 197-214.

Stalnaker, R. 2002. Common ground. Linguistics and Philosophy 25 (5-6): 701-721.

Sudo, Yasutada: 2012, On the Semantics of Phi Features on Pronouns. Ph.D. dissertation, MIT.

Sudo, Yasutada: 2014, Presupposition Projection in Quantified Sentences and Cross-Dimensional Anaphora. Manuscript, UCL

Tieu, Lyn; Pasternak Rob; Schlenker, Philippe; Chemla, Emmanuel: to appear, Co-speech gesture projection: Evidence from truth value judgments and picture selection. Glossa.

Tieu, Lyn; Pasternak Rob; Schlenker, Philippe; Chemla, Emmanuel: 2017, Co-speech gesture projection: Evidence from inferential judgments. Manuscript.

Tonhauser, Judith; Beaver, David; Roberts, Craige; Simons, Mandy: 2013, Toward a taxonomy of projective content. Language 89(1): 66-109.

van Fraassen, Bas: 1969, Presuppositions, Supervaluations, and Free Logic. In K. Lambert (ed.), The Logical Way of Doing Things, New Haven, Yale University Press, pp.67-91. 